\title{
Cost-effective policy instruments for greenhouse gas emission re- duction and fossil fuel substitution through bioenergy production
} in Austria

Johannes Schmidt $^{1^{*}}$; Sylvain Leduc ${ }^{2}$; Erik Dotzauer ${ }^{3}$; Erwin Schmid ${ }^{1}$;

\author{
Affiliations \\ ${ }^{1}$ Institute for Sustainable Economic Development, University of Natural Resources and \\ Life Sciences, Peter Jordan Straße 82, A-1190 Vienna, Austria. \\ ${ }^{2}$ International Institute for Applied Systems Analysis, Schlossplatz 1, A-2361 Laxen- \\ burg, Austria. \\ ${ }^{3}$ Mälardalen University, P.O. Box 883, SE-72123 Västerås, Sweden.
}

\begin{abstract}
Climate change mitigation and security of energy supply are important targets of Austrian energy policy. Bioenergy production based on resources from agriculture and forestry is an important option to attain these targets. In order to increase the share of bioenergy, supporting policy instruments are necessary. The cost-effectiveness of these instruments in attaining policy targets depends on the availability of bioenergy technologies. Advanced technologies such as second generation biofuels, biomass gasification for power

* Correspondence to: Johannes Schmidt, Institute for Sustainable Economic Development, University of Natural Ressources and Life Sciences, Feistmantelstraße 4, A-1180 Vienna, Austria. E-Mail: johannes.schmidt@boku.ac.at
\end{abstract}


production and bioenergy with carbon capture and storage (BECCS) will likely change the performance of policy instruments. This article assesses the cost-effectiveness of energy policy instruments with respect to greenhouse gas emission (GHG) reduction and fossil fuel substitution under consideration of new bioenergy technologies for the year 2030. Instruments that directly subsidize bioenergy are compared with instruments that aim at reducing GHG emissions. A spatially explicit modeling approach is used to account for biomass supply and energy distribution costs in Austria. Results indicate that a carbon tax performs cost effective with respect to both policy targets if BECCS is not available. However, the availability of BECCS creates a tradeoff between GHG emission reduction and fossil fuel substitution. Biofuel blending obligations are costly in attaining the policy targets.

Keywords: Bioenergy Policy, Bioenergy with Carbon Capture and Storage, Spatially Explicit Modeling 


\section{Nomenclature}

\begin{tabular}{|c|c|c|}
\hline Variables & Unit & Description \\
\hline$A$ & $€$ & Biomass supply costs \\
\hline $\mathrm{a}_{i, s c, p l}^{a g r a r}$ & - & Decision variable for separable programming for agricultural biomass \\
\hline $\mathrm{b}_{i, o, u}$ & - & Decision variable for separable programming for forestry biomass \\
\hline $\mathrm{b}_{i, k, b}^{\text {direct }}$ & $\mathrm{MWh}_{\text {biomass }}$ & Biomass transported directly to consumers (e.g. fuel wood) \\
\hline $\mathrm{b}_{i, j, b, l, t}^{\text {plant }}$ & $\mathrm{MWh}_{\text {biomass }}$ & Biomass transported to plants \\
\hline emtaxed & $\mathrm{tCO}_{2}$ & $\begin{array}{l}\mathrm{CO}_{2} \text { emissions that may be taxed by policy (all emissions without } \\
\text { agriculture) }\end{array}$ \\
\hline $\mathrm{p}$ & $€ \mathrm{MWh}^{-1}$ & Price of wood supply \\
\hline $\mathrm{q}$ & MWh & Quantity of wood supply \\
\hline $\mathrm{q}_{j, t}^{b i o}$ & MWh & Heat production in the plant \\
\hline $\mathrm{q}_{j, h, n s, t}^{\mathrm{dh}}$ & MWh & Heat transportation from plant to district heating network \\
\hline $\mathrm{q}_{h, n s, t}^{\operatorname{dhf}}$ & MWh & Fossil district heat production \\
\hline $\mathbf{q}_{h, n s}^{\text {gas }}$ & MWh & Amount of gas used for heating \\
\hline totem & $\mathrm{tCO}_{2} \mathrm{e}$ & Total GHG emissions in $\mathrm{tCO}_{2}$ equivalents \\
\hline $\mathrm{u}_{h, n s}^{\text {gnet }}$ & - & Binary variable for investment in gas network \\
\hline $\mathrm{u}_{h, n s}^{\text {dnet }}$ & - & Binary variable for investment in district heating network \\
\hline $\mathrm{u}_{j, h, n s}^{\text {pipe }}$ & - & Binary variable for investment in transportation pipeline \\
\hline $\mathrm{u}_{j, l}^{\text {plant }}$ & - & Binary variable for plant investment \\
\hline $\mathrm{z}_{j, c}^{b i o}$ & MWh & Amount of energy commodity produced in a plant \\
\hline $\mathrm{z}_{j, k, c, t}^{b i o}$ & MWh & Amount of energy commodity transported to consumers in each period \\
\hline $\mathrm{Z}_{k, f}^{\text {fossil }}$ & MWh & Amount of fossil fuel used to satisfy demand \\
\hline \multicolumn{3}{|c|}{ Parameters } \\
\hline$\varepsilon, \varepsilon_{o}$ & - & Elasticity of biomass supply \\
\hline$\eta_{c, d}^{b i o}$ & - & Efficiency of converting a bioenergy commodity to useful energy \\
\hline$\eta_{b, d}^{b i o d}$ & - & $\begin{array}{l}\text { Efficiency of converting biomass directly to useful energy (e.g. fuel } \\
\text { wood) }\end{array}$ \\
\hline$\eta_{j, l, c}^{c o n v}$ & - & Conversion efficiency in bioenergy plants \\
\hline$\eta_{h, t}^{d h}$ & - & Efficiency of distributing heat in district heating network \\
\hline$\eta_{h, t}^{\text {dhf }}$ & - & Efficiency of fossil district heating boiler \\
\hline$\eta_{f, d}^{\text {fossil }}$ & - & Efficiency of converting fossil fuel to useful energy \\
\hline$\eta^{g a s}$ & - & Efficiency of converting natural gas to heat \\
\hline$\eta_{j, l}^{\text {heat }}$ & - & Heat efficiency in bioenergy plants \\
\hline$\eta_{j, h, n s, t}^{\text {trans }}$ & - & Transportation efficiency of heat pipeline \\
\hline $\bar{b}_{i, o}$ & MWh y ${ }^{-1}$ & Maximum sustainable yield (MSY) in supply cell \\
\hline $\bar{b}_{j, l, t}$ & MWh & Production capacity of plant \\
\hline
\end{tabular}




\begin{tabular}{|c|c|c|}
\hline $\bar{b}_{f s, o}$ & MWh y ${ }^{-1}$ & MSY in federal state \\
\hline C & - & Constant in wood supply function \\
\hline$c^{c c s}$ & $€ \mathrm{tCO}_{2}^{-1}$ & Costs of carbon capture and storage \\
\hline$c_{t}^{d h f}$ & $€ M W h_{\text {fuel }}^{-1}$ & Costs of fossil districting heat fuel \\
\hline$c_{h, n s}^{\text {dnet }}$ & $€ \mathrm{y}^{-1}$ & Annualized costs of investment in district heating network \\
\hline$c^{e m}$ & $€ \mathrm{tCO}_{2}^{-1}$ & $\mathrm{CO}_{2}$ price \\
\hline$c_{f}^{\text {fossil }}$ & $€ \mathrm{MWh}_{\text {fuel }}{ }^{-1}$ & Price of fossil fuel \\
\hline$c_{f}^{\text {fossilinv }}$ & $€ \mathrm{MWh}_{\text {fuel }}{ }^{-1}$ & Investment costs necessary at consumer for fossil technology \\
\hline$c_{t}^{\text {gas }}$ & $€ \mathrm{MWh}_{\mathrm{gas}}{ }^{-1}$ & Costs of natural gas \\
\hline$C_{h, n s}^{g n e t}$ & $€ \mathrm{MWh}_{\mathrm{gas}}{ }^{-1}$ & Costs of natural gas \\
\hline$c_{c}^{i n v}$ & $€ \mathrm{MWh}_{\text {biomass }}{ }^{-1}$ & Investment cost necessary at consumer for bioenergy technology \\
\hline$c_{k, b}^{i n v d}$ & $€ \mathrm{MWh}_{\text {biomass }}{ }^{-1}$ & $\begin{array}{l}\text { Investment cost necessary at consumer for direct biomass consump- } \\
\text { tion (e.g. fuel wood) }\end{array}$ \\
\hline$c_{j, h, n s}^{p i p e}$ & $€ \mathrm{y}^{-1}$ & Annualized costs of investment in transportation pipeline \\
\hline$C_{j, l}^{\text {plant }}$ & $€ \mathrm{y}^{-1}$ & Annualized costs of plant investment \\
\hline$C_{j, l}^{\text {prod }}$ & $€ \mathrm{MWh}_{\text {biomass }}{ }^{-1}$ & Variable costs of bioenergy production \\
\hline$C_{i}^{\text {sup }}$ & $€ \mathrm{MWh}_{\text {biomass }}{ }^{-1}$ & Costs of biomass supply \\
\hline$C_{i, j, b}^{\text {transb }}$ & $€ \mathrm{MWh}_{\text {biomass }}^{-1}$ & Costs of biomass transportation from $i$ to $j$ \\
\hline$C_{j, k, c}^{\text {transc }}$ & $€ \mathrm{MWh}^{-1}$ & Costs of transporting commodity from $j$ to $k$ \\
\hline$C_{i, k, b}^{\text {transd }}$ & $€ \mathrm{MWh}_{\text {biomass }}{ }^{-1}$ & Costs of biomass transportation from $i$ to $k$ \\
\hline$d_{k, d}$ & MWh y ${ }^{-1}$ & Energy demand \\
\hline$e_{s c, b, p l}^{a g r a r}$ & $\mathrm{tCO}_{2} \mathrm{e} \mathrm{MWh}_{\text {biomass }}^{-1}$ & $\begin{array}{l}\text { GHG Emissions in } \mathrm{tCO}_{2} \text { equivalents from fertilizer application in } \\
\text { agricultural production }\end{array}$ \\
\hline$e_{l, b}^{c c s}$ & $\mathrm{tCO}_{2} \mathrm{MWh}_{\text {biomass }}{ }^{-1}$ & Carbon capture rate in plant \\
\hline$e^{d h f}$ & $\mathrm{tCO}_{2} \mathrm{MWh}_{\text {fuel }}^{-1}$ & $\mathrm{CO}_{2}$ emission factor of fossil district heating fuel \\
\hline$e^{g a s}$ & $\mathrm{tCO}_{2} \mathrm{MWh}_{\mathrm{gas}}{ }^{-1}$ & $\mathrm{CO}_{2}$ emission factor of natural gas \\
\hline$e_{f}^{\text {fossil }}$ & $\mathrm{tCO}_{2} \mathrm{MWh}^{-1}$ & $\mathrm{CO}_{2}$ emission factor of fossil fuels \\
\hline$e_{i, j, b}^{\text {trans }}$ & $\mathrm{tCO}_{2} \mathrm{MWh}_{\text {biomass }}^{-1}$ & $\mathrm{CO}_{2}$ emission factor of biomass transportation from $i$ to $j$ \\
\hline$e_{i, k, b}^{\text {trans }}$ & $\mathrm{tCO}_{2} \mathrm{MWh}_{\text {biomass }}{ }^{-1}$ & $\mathrm{CO}_{2}$ emission factor of commodity transportation from $i$ to $k$ \\
\hline$e_{j, k, c}^{\text {trans }}$ & $\mathrm{tCO}_{2} \mathrm{MWh}_{\text {commodity }}^{-}$ & $\mathrm{CO}_{2}$ emission factor of commodity transportation \\
\hline$f_{c, d}^{b l e n d}$ & - & Mandatory share of bioenergy commodity in final energy demand \\
\hline$\hat{p}$ & $€ \mathrm{MWh}^{-1}$ & Price of forest wood \\
\hline$p_{i, s c, b, p l}^{a g r a r}$ & $€ \mathrm{MWh}^{-1}$ & Price of agricultural products \\
\hline$q_{i, s c, b, p l}^{a g r a r}$ & MWh & Amount of agricultural products \\
\hline$q^{*}$ & MWh & Supply of wood harvests \\
\hline$q_{u}^{*}$ & - & Quantities for separable programming \\
\hline$\widehat{q}, \hat{q}_{i, o}, \hat{q}_{f s, o}$ & MWh y ${ }^{-1}$ & $\begin{array}{l}\text { Observed quantities of wood harvests total, in supply cell, in federal } \\
\text { state }\end{array}$ \\
\hline
\end{tabular}




$\begin{array}{lll}q_{h, t}^{D} & \text { MWh season }^{-1} & \text { Heat demand in settlement } \\ q_{h, n s, t}^{D} & \text { MWh season }^{-1} & \text { Heat demand in district heating network } \\ \overline{-}_{n s, t}^{p i p e} & \text { MWh season }^{-1} & \text { Capacity of heat transportation pipeline } \\ t x^{s}, t x_{f}^{f} & - & \text { Binary parameters controlling which fossil fuels are priced }\end{array}$

\section{Subscripts}

b

c

$d$

Feedstock

Energy commodity

Energy demand for useful energy

Fossil fuels

Federal state

Settlements supplied by heat networks

Biomass supply site

Plant location

Demand region

Technology and size of bioenergy plant

District heating network size

Forest ownership

Price level of agricultural biomass

Price scenario for agricultural biomass

Season

Index for separable programming 


\section{Introduction}

Climate change mitigation and security of energy supply are among the main drivers of current European energy policies (COM, 2010). Austria committed to a 13\% reduction of greenhouse gas (GHG) emissions with respect to the reference year 1990 in the Kyoto commitment period of 2008-2012 (Council, 2002) and to an increase of renewable energy production by 11 percentage points until 2020 according to EU directive 2009/28/EC. Currently, Austria is far from reaching the Kyoto target (Umweltbundesamt Austria, 2010) and significant efforts are necessary to meet the 2020 energy targets (Nakicenovic et al., 2008). More forestry biomass utilization (Schadauer, 2009) and agricultural biomass production are still possible and necessary to reach the ambitious climate change mitigation and renewable energy targets in Austria. Particularly after 2020, the global GHG emission reductions will need to be considerably higher than the Kyoto targets to limit the maximum warming of the global mean temperature to $2^{\circ} \mathrm{C}$ (Roeckner et al., 2010).

\subsection{Policy Instruments}

Several policy instruments are in place or under discussion to facilitate the achievement of these policy targets in Austria. This article focuses on bioenergy as climate change mitigation option and discusses policies that directly or indirectly support bioenergy production. Policies that are introduced to reduce GHG emissions and thus indirectly promote bioenergy, including a $\mathrm{CO}_{2}$ tax and the EU Emission Trading Scheme (ETS) are compared to policies that directly support bioenergy production including biofuel blending obligations, feed-in tariffs for biomass power production and subsidies to biomass furnaces. 
Policy instruments that are designed to directly reduce GHG emissions are expected to be cost-effective in reducing GHG emissions if they allow an efficient allocation of reduction efforts among market participants and technologies. Even in that case costeffectiveness with respect to fossil fuel substitution may be low because GHG emission reduction does not necessarily correspond with fossil fuel substitution (Schmidt et al., 2010a). Also, long-term technological development may not be triggered by these policies because technologies that are close to being competitive on the market are chosen mainly (Sandén and Azar, 2005). The following GHG emission reduction policies are considered in our analysis:

- $\quad \mathrm{A} \mathrm{CO}_{2}$ tax is currently under discussion in the European Union and is proposed as one measure of financing the Union's budget. It is applied on all fossil fuels before combustion according to the carbon content of the respective fuel. Denmark, Finland, Italy, Ireland and Sweden are EU members that have already implemented a $\mathrm{CO}_{2}$ tax. However, none of these countries apply a uniform tax on all fossil fuel consumers but exempt some sectors from the tax. Tax rates vary from $10 € \mathrm{tCO}_{2}^{-1}$ to up to $150 € \mathrm{tCO}_{2}^{-1}$ (Pope and Owen, 2009). As marginal abatement costs are not known with certainty, the total amount of GHG emission abatement cannot be determined a-priori when introducing a tax. A $\mathrm{CO}_{2}$ tax on fossil fuels only would not encourage CCS. If Carbon Capture and Storage (CCS) should be supported, bioenergy producers would have to receive tax exemptions. In Norway, this approach has been taken to make a commercial CCS project profitable (International Energy Agency, 2010). 
- The EU ETS was introduced in 2005. About 250 facilities which emit around one third of total GHG emissions were affected in Austria. $\mathrm{CO}_{2}$ emission permits were allocated for free in the start-up phase by applying a grandfathering principle. The $\mathrm{CO}_{2}$ emission allowances can be traded on a market to attain efficient allocations. The second phase of the EU ETS is from 2008 to 2012. In Austria, the main differences to the first phase (from 2005 to 2008) are a slightly lower cap (reduction from $33.19 \mathrm{MtCO}_{2}$ to $32.8 \mathrm{MtCO}_{2}$ ) and the auctioning of $1.2 \%$ of the allowances in the initial phase of the scheme (Federal Ministry of Agriculture, Forestry, Environment and Water Management, 2007; Paoletta and Taschini, 2006). GHG emissions from biomass are assumed to be carbon neutral and therefore no ETS allowances have to be acquired for biomass combustion.

Direct promotion of specific bioenergy technologies is expected to have low costeffectiveness because only a subset of available technologies is usually subsidized. However, technological development may be triggered for these technologies which will make them in the long-term competitive (Sandén and Azar, 2005). We include the following policies in our analysis:

- Feed-in tariffs for different forms of renewable electricity production such as bioenergy power plants, small water power plants and photovoltaic power are defined in the Austrian renewable energy law. Facilities that are included in the support scheme receive feed-in tariffs for 12 years. Feed-in tariffs are chosen to be close to production costs of specific technologies and therefore depend on the respective technology. 
- The EU directive 2003/30/EC sets an indicative target for all member states to blend a share of $5.75 \%$ of biofuels with gasoline until $31^{\text {st }}$ December 2010 . Austria ratified this law in 2003. In 2009, the EU decided on directive 2009/28/EC, which demands among other targets a share of $10 \%$ of renewable energies in the transportation sector. In contrast to directive 2003/30/EC, this regulation does not dictate the utilization of biofuels. Electric cars or public transportation relying on renewably produced electricity are measures that can also be applied to. However, biofuels are one major technological option to attain the targets in the short term (Sandy Thomas, 2009).

- Subsidies are granted for wood heating systems by all federal states in Austria. These subsidies are granted if a heating system is installed in a new building or if an old heating system is replaced. Technological development is not the main aim of this policy, because heating furnaces are technically mature and significant technological improvements cannot be expected. However, subsidies may be politically more accepted in promoting renewable energy than new taxes, e.g. a $\mathrm{CO}_{2}$ tax.

While the presented policy instruments work differently, their overall targets are the same: they are implemented to reduce GHG emissions and shift energy production from fossil fuels to renewable energies. The cost-effectiveness, i.e. the costs of attaining the policy targets, is likely to vary between the policy instruments and strongly depends on the availability of bioenergy technologies in energy consuming sectors. Highly efficient power production with Biomass Integrated Combined Cycle Plants (BIGCC) in the power sector and second generation biofuel production based on woody biomass in the 
transportation sector are technologies that are expected to increase bioenergy productivity significantly (Havlík et al., 2010; Lange, 2007; Marbe et al., 2004; Steenhof and McInnis, 2008). In addition, BioEnergy with Carbon Capture and Storage (BECCS), i.e. the application of CCS to bioenergy plants, is considered a possible major contributor to future climate mitigation efforts (Azar et al., 2010; Luckow et al., 2010). However, it is not clear by now, how much these technologies can contribute to carbon mitigation and renewable energy targets and how the respective policy instruments will perform in attaining these policy targets at least costs, if these technologies become available.

\subsection{Challenges in Bioenergy Modeling}

The relative performance of the discussed policy instruments not only relies on technological development but also on the spatial variation of demand and supply. We have identified the following important factors. (i) Energy distribution costs, particularly for district heating, depend on heat demand densities and on the distance from plant to demand (Grohnheit and Mortensen, 2003; Ivezic et al., 2008; Konstantin, 2007). (ii) Bio-

energy technologies rely on different types of feedstock - e.g. starchy energy crops for first generation biofuels versus short rotation lignocellulose or forest wood for second generation biofuels. The availability and the costs of different types of biomass depend on biophysical characteristics of land and on current agricultural production systems. (iii) Transportation costs have significant impact on the final cost of the bioenergy supply chain and vary with the technology, plant size, and the distance from plant to production sites (Eriksson and Björheden, 1989; Luckow et al., 2010; Richard, 2010). Spatial variation of biomass supply and heat demand is high in Austria (Schmidt et al., 2010b). The location of plants in relation to feedstock supply and energy demand is 
therefore relevant. Modeling efforts that spatially explicitly integrate biophysical and logistic constraints in the bioenergy supply chains as well as facility and infrastructure constraints in energy demand may increase the reliability of modeling results. Additionally, feedstock production on agricultural land competes with food and feed production. The trade-offs between food and energy crop production should therefore be made explicit in bioenergy models (Bryan et al., 2010).

Previous research on this topic comparatively assessed bioenergy policies. Global, continental and regional studies have been conducted using different methodologies. They produce different results and come to different conclusions on optimal application of technologies and policies (see Table 1). However, a regional spatially explicit bioenergy model that includes feedstock production, considers competition for land use, models

Table 1: Studies on costs of bioenergy technologies and policy instruments.

\begin{tabular}{|c|c|c|c|c|}
\hline Article & $\begin{array}{l}\text { Modeling } \\
\text { approach }\end{array}$ & Biomass supply modeling & $\begin{array}{l}\text { Demand } \\
\text { modeling }\end{array}$ & \begin{tabular}{lr}
\multicolumn{2}{l}{ Technologies / } \\
selected for & cost- \\
effective GHG emis- \\
sion reduction
\end{tabular} \\
\hline \multicolumn{5}{|c|}{ Global and continental models } \\
\hline $\begin{array}{lll}\text { Azar } & \text { et } & \text { al. } \\
\text { (2003) } & & \end{array}$ & Optimization Model & $\begin{array}{l}\text { Fixed assumptions on total } \\
\text { availability of biomass }\end{array}$ & Scenarios & $\begin{array}{l}\text { Biomass based heat and } \\
\text { power production, } \\
\text { biofuels play minor role }\end{array}$ \\
\hline $\begin{array}{l}\text { Berndes et al. } \\
\text { (2007) }\end{array}$ & Optimization Model & $\begin{array}{l}\text { Fixed assumptions on total } \\
\text { availability of biomass }\end{array}$ & Scenarios & $\begin{array}{l}\text { Biofuel policy costly, } \\
\text { carbon tax prefers heat } \\
\text { and power production }\end{array}$ \\
\hline $\begin{array}{l}\text { Gielen et al. } \\
\text { (2003) }\end{array}$ & Optimization Model & $\begin{array}{l}\text { Fixed assumptions on total } \\
\text { availability of biomass }\end{array}$ & Scenarios & $\begin{array}{l}\text { Mainly heat and fuel } \\
\text { production selected, no } \\
\text { power production }\end{array}$ \\
\hline $\begin{array}{l}\text { Luckow et al. } \\
\text { (2010) }\end{array}$ & $\begin{array}{l}\text { Partial Equilibrium } \\
\text { Model }\end{array}$ & $\begin{array}{l}\text { Supply Curves, shows } \\
\text { trade-off between energy } \\
\text { and food production }\end{array}$ & Demand Curves & $\begin{array}{l}\text { Without CCS: fuel, } \\
\text { power and heat produc- } \\
\text { tion, with CCS: mainly } \\
\text { power production }\end{array}$ \\
\hline $\begin{array}{l}\text { Magné et al. } \\
\text { (2010) }\end{array}$ & $\begin{array}{l}\text { Combined bottom } \\
\text { up and top down } \\
\text { model }\end{array}$ & $\begin{array}{l}\text { Supply Curves but does not } \\
\text { show decline in food pro- } \\
\text { duction }\end{array}$ & Demand Curves & $\begin{array}{l}\text { No detailed assessment } \\
\text { of bioenergy technolo- } \\
\text { gies }\end{array}$ \\
\hline \multicolumn{5}{|l|}{ Regional Models } \\
\hline $\begin{array}{l}\text { Alfonso et al. } \\
(\mathbf{2 0 0 9 )}\end{array}$ & Optimization Model & $\begin{array}{l}\text { Modeling of technical } \\
\text { biomass potential }\end{array}$ & $\begin{array}{l}\text { Bottom - Up } \\
\text { Model }\end{array}$ & Power \\
\hline $\begin{array}{l}\text { Bryan et al. } \\
(\mathbf{2 0 1 0 )}\end{array}$ & Cost calculations & $\begin{array}{l}\text { Modeling of land productiv- } \\
\text { ity, shows trade-off between } \\
\text { energy and food production }\end{array}$ & $\begin{array}{l}\text { Demand not } \\
\text { considered }\end{array}$ & Only biofuels assessed \\
\hline König (2011) & Optimization Model & $\begin{array}{l}\text { Fixed assumptions on costs } \\
\text { and availability of biomass }\end{array}$ & $\begin{array}{l}\text { Scenarios } \\
\text { Bottom Up }\end{array}$ & $\begin{array}{l}\text { Heat and Power, } \\
\text { Biofuel Policy costly }\end{array}$ \\
\hline
\end{tabular}


energy production technologies and distribution systems in detail and is applied to analyze the cost-effectiveness of policy instruments has not been published in the scientific literature yet. This article presents such a model to analyze the cost-effectiveness of two classes of energy policy instruments with respect to GHG emission reduction and fossil fuel substitution: instruments that are designed to reduce $\mathrm{CO}_{2}$ emissions, including a $\mathrm{CO}_{2}$ tax and the ETS, and technology specific instruments for the promotion of bioenergy, including feed-in tariffs for biomass power plants, biofuel policies and pellets subsidies. The trade-offs between the two policy goals, assuming the availability of new bioenergy technologies, are analyzed as well.

The article is structured as follows: section 2 introduces the model and data as well as the bioenergy technologies included in the assessment and describes the policy scenarios. Section 3 presents the results including costs, GHG emission reductions, and fossil fuel substitution of the policy scenarios. Section 4 discusses the article with respect to the results and derives major conclusions. Model details can be found in the Appendix.

\section{Data and Methodology}

\subsection{A techno-economic spatially explicit model}

A spatially explicit, techno-economic mixed integer program (MIP) is developed and applied to assess the cost-effectiveness of different policy instruments in attaining the policy targets of reducing GHG emissions and substituting fossil fuels in Austria. The model minimizes the costs of supplying Austria with transportation fuels, heat and electricity from either bioenergy or fossil fuels. It is static and simulates one year of operation. The year is split into two heating seasons to consider the differences in heat demand between winter and summer. The current model version considers domestic bio- 
mass supply and energy demand and does not allow imports and exports of biomass or bioenergy commodities. The model determines which bioenergy plants (i.e. pellets, first generation ethanol or biodiesel, second generation methanol, BIGCC or BECCS, heating) of a specific size and specific location shall be built and which demand regions are supplied with bioenergy and/or with fossil fuels. Direct delivery of fuel wood from forest production sites to demand regions is possible. Each plant produces various energy commodities (Figure 1). They replace fossil fuels in heating, power generation, and transportation. By assumption, pellets and fuel wood are burnt in boilers of households or community heating networks, power is transmitted to the national grid, surplus heat is

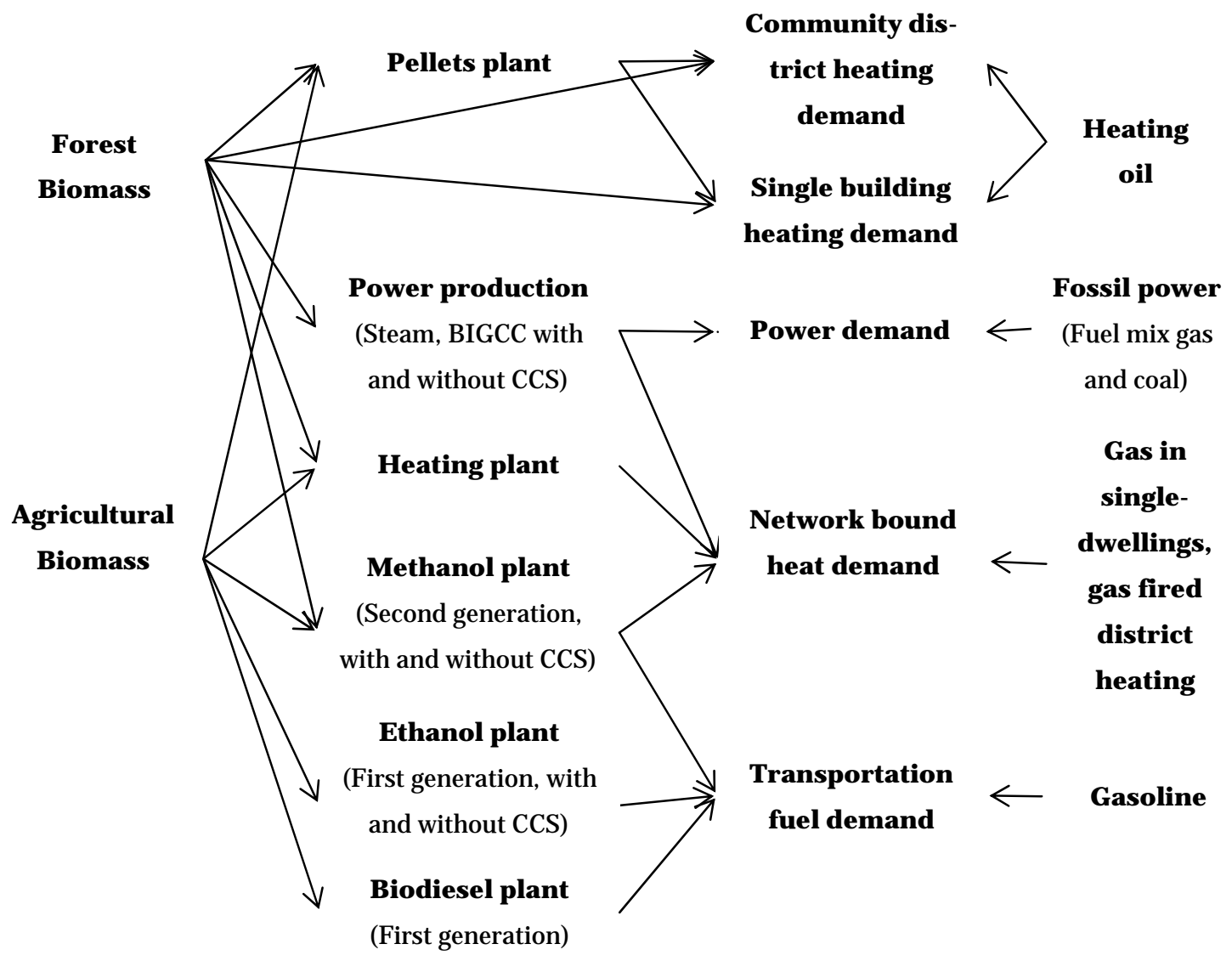

Figure 1: Diagram of the mixed integer programming model. 
delivered to district heating networks and biofuels replace gasoline for transportation purposes. The objective function is minimized and consists of the costs of biomass supply from forestry and agriculture, biomass transportation (i.e. transportation of energy crops and forest biomass from biomass supply sites to plants and of fuel-wood from biomass supply sites to consumers), plant investment annuities, district heating infrastructure annuities, investment annuities of heating furnaces, CCS costs, commodity transportation (i.e. transportation of pellets and transportation fuels from plants to consumers) and the costs of the fossil reference technologies. Biomass supply curves endogenously determine the price of feedstock from forestry and agriculture, while prices of fossil fuels are given exogenously. Energy demand is defined exogenously by scenario assumptions. The modeling approach focuses on bioenergy technologies and does not explicitly consider other low-carbon or renewable technologies. Instead, their development is implicitly considered in the demand scenarios (see section 2.4.). Energy efficiency measures, particularly in the heating sector, as well as an expansion of non-bioenergy renewable power production is modeled by reducing the demand for final energy. The model is able to assess the relative cost-effectiveness of policy instruments with respect to attaining two policy objectives i.e. reducing GHG emissions and substituting fossil fuels under consideration of bioenergy technologies. We assess energy supply system costs associated with a shift from fossil fuels to bioenergy while transaction costs induced by the policy instruments are not considered in the analysis. Taxes currently applied to both fossil and bioenergy fuels are not included in the model. A detailed description of the mixed integer program can be found in the appendix. 


\subsection{Biomass Resources}

We consider biomass from forestry and agriculture as possible feedstock for bioenergy production. Biomass supply curves are used to model the amount of biomass that can be provided at different prices. However, data is separately available for forestry and agriculture. The sectors are therefore implemented with different approaches in the MIP.

\section{Forestry Biomass}

An inverse biomass supply curve using a constant elasticity function is applied

$$
p=C q^{\frac{1}{\varepsilon}}
$$

where $p$ is the price, $q$ is the quantity, $C$ is a constant and $\varepsilon$ is the supply elasticity. The integral

$$
A=\int_{0}^{q^{*}} \hat{p}\left(\frac{q^{*}}{\hat{q}}\right)^{\frac{1}{\varepsilon}} d q=\left(\frac{q^{*}}{\hat{q}}\right)^{\frac{1}{\varepsilon}} q^{*} \hat{p} \frac{\varepsilon}{1+\varepsilon}
$$

yields the area $A$ under the supply curve and thus the biomass supply costs when biomass amount $q^{*}$ is produced. Parameters $\hat{p}$ and $\hat{q}$ represent an observed price and quantity.

Schwarzbauer (1997) estimates different supply elasticities $\varepsilon_{0}$ for different types of forest ownership (index $o$ ). Supply elasticities of private owners of small forests are estimated to be lower (around 0.4) than of large forests (around 0.5). The supply elasticities of state managed forests are even higher (around 0.7). Data on observed quantities $\hat{q}_{f s, o}$ by ownership are available on the level of federal states (index $f s$ ), while price $\hat{p}$ is a single national value because local price variations are not reported (Federal Ministry of 
Agriculture, Forestry, Environment and Water Management, 2009). We expect them to be of minor magnitude and account for transportation costs explicitly in the model. To further refine the spatial resolution of the biomass supply, we use spatially explicit estimates on the maximum sustainable yield (MSY). Details on the modeling of MSY can be found in Schmidt et al. (2010b). Denoting the MSY of an ownership (index $o$ ) in one supply cell (index $i$ ) with $\bar{b}_{i, o}$, the observed quantity $\hat{q}_{i, o}$ for that cell is determined by

$$
\hat{q}_{i, o}=\hat{q}_{f s, o} \frac{\bar{b}_{i, o}}{\bar{b}_{f s, o}}
$$

The total observed value $\hat{q}_{s, o}$ is multiplied by the proportion of estimated MSY $\bar{b}_{i, o}$ and total MSY of that state and ownership $\bar{b}_{f s, o}$. The aggregated forest wood supply curve, with indications of the MSY and observed prices and quantities in the year 2009 can be found in Figure 2.

Equation (4) shows a transformation of Equation (2) where supply by ownership and grid cell are included. The function is convex and can therefore be linearized by separable programming (Jensen and Bard, 2002) which is also shown in the following equation:

$$
\left(\frac{q_{i, o}^{*}}{\hat{q}_{i, o}}\right)^{\frac{1}{\varepsilon_{o}}} q_{i, o}^{*} \hat{p} \frac{\varepsilon_{o}}{1+\varepsilon_{o}} \approx \frac{\varepsilon_{o}}{1+\varepsilon_{o}} \hat{q}_{i, o} \hat{p} \sum_{u}\left(q_{u}^{*}\right)^{\frac{1}{\varepsilon_{o}}} q_{u}^{*} b_{i, o, u}
$$

where parameter $q_{u}^{*}$ denotes the share of the observed amount of biomass that is produced, e.g. a value of 0.1 means that $10 \%$ of the amount of biomass observed in the reference period is supplied. Variable $b_{i, o, u}$ is a decision variable involved in the separable programming and $u$ is the index of the separable steps. The amount of forestry biomass 
in a supply cell available for bioenergy production (see model details in the Appendix) is limited by

$$
\sum_{j, b, l} \mathrm{~b}_{i, j, b, l, t}^{\text {plant }}+\sum_{i, k, b} \mathrm{~b}_{i, k, b}^{\text {direct }} \leq \sum_{o, u} \hat{q}_{i, o}\left(q_{u}^{*}\right)^{\frac{1}{\varepsilon_{o}}} q_{u}^{*} b_{i, o, u}
$$

The term $\sum_{j, b, l} \mathrm{~b}_{i, j, b, l, t}^{\text {plant }}+\sum_{i, k, b} \mathrm{~b}_{i, k, b}^{\text {direct }}$ represents biomass transported from supply regions (i) to bioenergy plants $(j)$ of different types $(l)$ and to consumers $(k)$ in season $(t)$. Index $b$ indicates the type of biomass, in this case forest wood. The following convexity condition is necessary in separable programming:

$$
\sum_{u} b_{i, o, u}=1
$$

\section{Agricultural Biomass}

Biomass growth on agricultural land for different crops under different management options and crop rotations is simulated with the biophysical process model EPIC (Environmental Policy Integrated Climate) (Izaurralde et al., 2006; J. R. Williams, 1995). Outputs of EPIC are part of gross margin calculations, which are input in the spatially explicit land use optimization model PASMA (Positive Agricultural Sector Model Austria) (Schmid and Sinabell, 2007) to find optimal land use management choices by maximizing total gross margin subject to resource endowments at municipal level. Prices of crops are taken from the year 2006 (Statistik Austria, 2010) and linearly extrapolated to 2030, based on the OECD agricultural outlook (OECD, 2009). About 40 agricultural crops with three intensification levels are represented in PASMA. They have been grouped into seven categories for the MIP including grains, oil seeds, forage crops, ethanol crops, oil crops, short rotation cellulose, and others. Ethanol crops are starchy 

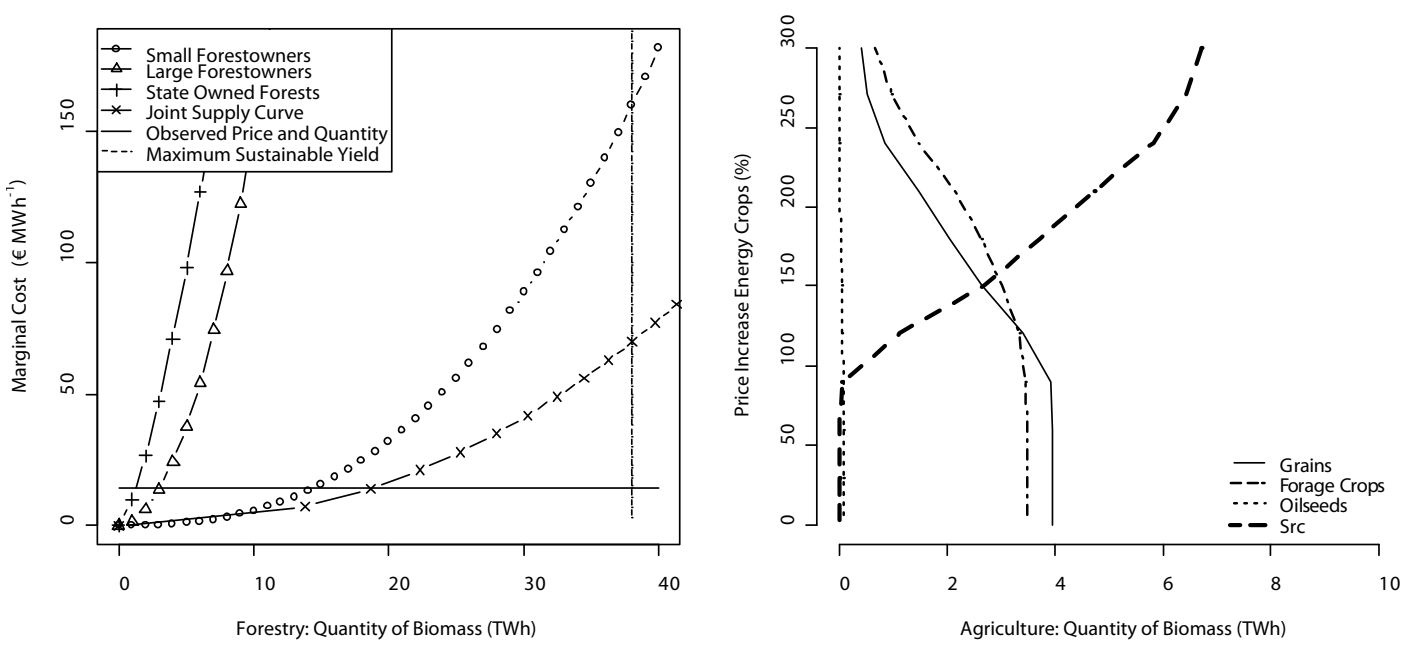

Figure 2: Forest wood supply curve (left) and agricultural supply curve (right).

Note: The right picture shows the increase in short rotation cellulose (src) production and the respective decrease in the production of the most important food and feed crops if prices for short rotation lignocellulose are increased. Both supply curves are an agreggate for Austria.

and sugar crops that can be used for first generation ethanol production while oil crops (e.g. sunflower and rapeseed) are used for biodiesel production. Heat, power and second generation biofuels may be produced from short rotation cellulose (e.g. short rotation poplar). Spatially explicit biomass supply curves are generated with PASMA by steadily increasing prices for energy crops from $0 \%$ to $300 \%$ while leaving the prices of all other crops constant. Thus, points on the supply curve are generated accounting for intensification and land use changes, i.e. bioenergy crops substitute food and feed. Combinations of single crop price changes (e.g. ethanol crops only) and multi-crop price changes (e.g. ethanol and oil crops) shall depict a wide set of supply responses. An aggregated supply curve for short rotation lignocellulose can be found in Figure 2. The figure shows that price increases of $100 \%$ are necessary to trigger substantial amounts of short rotation cellulose production in Austria. The increases in production cause significant decreases in food and feed production. Parameters $p_{i, s c, b, p l}^{\text {agra }}$ (price of crops) and $q_{i, s c, b, p l}^{\text {agrar }}$ (quantity of crop) represent points on the supply curve. Index $i$ denotes the supply region, index $s c$ 
indicates the price scenario, $b$ is the index for the crop type and $p l$ is the price level of the energy crop. Costs of agricultural production are determined by

$\sum_{i, s c, f, p l} p_{i, s c, b, p l}^{\text {agrar }} q_{i, s c, b, p l}^{a g r a r} a_{i, s c, p l}^{a g r a r}$

where $\mathrm{a}_{i, s c, p l}^{\text {agrar }}$ is the decision variable for separable programming as outlined in the previous section. Transportation of energy crops to plants $\sum_{j, b, l} \mathrm{~b}_{i, j, b, l}^{\text {plant }}$ is limited by

$\sum_{j, b, l} \mathrm{~b}_{i, j, b, l, t}^{\text {plant }} \leq \sum_{c r, p l} q_{i, s c, b, p l}^{\text {agrar }} a_{i, s c, p l}^{a g r a r}$

where $b$ is any type of biomass except of forest wood. There are two dimensions (price scenario $s c$ and price level $p l$ ) over which the convexity of the curve has to be guaranteed in each supply cell:

$\sum_{s c, p l} a_{i, s c, p l}^{a g r a r}=1$.

\subsection{Biomass conversion technologies}

There are numerous bioenergy conversion technologies, either commercially developed or under research. We select a subset of these technologies based on the current deployment and availability of the technologies as well as on a literature review for technologies that are still under research. Input costs for the technologies are based on Kalt et al. (2010) who estimated the costs of bioenergy technologies up to 2030, applying a learning curve approach to model decreases in costs of technologies. BECCS is not modeled by Kalt et al. (2010). Several other sources are taken into account to estimate these costs. Costs and technological data for bioenergy production are listed in Table 2. Solid biomass technologies are available for heating of individual buildings or small settlements 
Table 2: Investment costs, conversion efficiencies and carbon capture and storage characteristics of bioenergy technologies.

\begin{tabular}{|c|c|c|c|c|}
\hline \multicolumn{2}{|c|}{ Parameter name } & Unit & Value & References \\
\hline \multicolumn{5}{|c|}{ 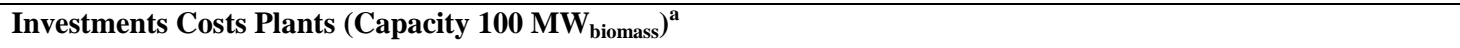 } \\
\hline \multicolumn{2}{|l|}{ Steam Power } & Million $€$ & 48 & d \\
\hline \multicolumn{2}{|c|}{ Steam Power with CCS } & Million $€$ & 50 & e \\
\hline \multicolumn{2}{|l|}{ BIGCC } & Million $€$ & 78 & $\mathrm{t}$ \\
\hline \multicolumn{2}{|c|}{ BIGCC with CCS } & Million $€$ & 79.5 & e \\
\hline \multicolumn{2}{|c|}{ Ethanol First Generation } & Million $€$ & 35 & d \\
\hline \multicolumn{2}{|c|}{ Ethanol First Generation with CCS } & Million $€$ & 40 & g \\
\hline \multicolumn{2}{|c|}{ Biodiesel First Generation } & Million $€$ & 9 & $\mathrm{~d}$ \\
\hline \multicolumn{2}{|c|}{ Methanol Second Generation } & Million $€$ & 87 & h \\
\hline \multicolumn{2}{|c|}{ Methanol Second Generation with CCS } & Million $€$ & 89 & $\mathrm{i}$ \\
\hline \multicolumn{2}{|l|}{ Pellets } & Million $€$ & 5 & $\mathrm{~d}, \mathrm{k}$ \\
\hline \multicolumn{2}{|l|}{ Heating Plant } & Million $€$ & 17 & d \\
\hline \multicolumn{4}{|c|}{ Conversion Efficiency } & Commodity $\quad$ Plant Type \\
\hline \multirow[t]{4}{*}{ Power } & Steam & $\%$ & 29 & d \\
\hline & Steam with CCS & $\%$ & 20 & e \\
\hline & BIGCC & $\%$ & 42 & f \\
\hline & BIGCC with CCS & $\%$ & 30 & e \\
\hline \multirow[t]{6}{*}{ Heat } & Steam & $\%$ & 52 & d \\
\hline & Steam with CCS & $\%$ & 52 & e \\
\hline & BIGCC & $\%$ & 43 & $\mathrm{f}$ \\
\hline & BIGCC with CCS & $\%$ & 43 & e \\
\hline & Methanol Second Generation & $\%$ & 8 & $\mathrm{j}$ \\
\hline & Methanol Second Generation with CCS & $\%$ & 8 & $\mathrm{i}$ \\
\hline \multirow[t]{4}{*}{ Fuels } & Ethanol First Generation (without and with CCS) & $\%$ & 47 & d \\
\hline & Biodiesel First Generation & $\%$ & 62 & d \\
\hline & Methanol Second Generation & $\%$ & 59 & h \\
\hline & Methanol Second Generation with CCS & $\%$ & 57 & $\mathrm{i}$ \\
\hline Pellets Plant ${ }^{b}$ & Pellets & $\%$ & 100 & $\mathrm{~d}, \mathrm{k}$ \\
\hline \multicolumn{5}{|c|}{ CCS: $\mathrm{CO}_{2}$ emissions captured in production } \\
\hline \multicolumn{2}{|c|}{ BIGCC with CCS } & $t C \mathrm{O}_{2} \mathrm{MWh}_{\text {biomass }}^{-1}$ & 0.36 & e \\
\hline \multicolumn{2}{|c|}{ Ethanol First Generation with CCS } & $t C \mathrm{O}_{2} \mathrm{MWh}_{\text {biomass }}^{-1}$ & 0.05 & $\mathrm{~g}$ \\
\hline \multicolumn{2}{|c|}{ Methanol Second Generation with CCS } & $\mathrm{tCO}_{2} M W h_{\text {biomass }}^{-1}$ & 0.22 & $\mathrm{i}$ \\
\hline \multicolumn{5}{|c|}{ Investment Costs at Consumers $^{c}$} \\
\hline \multicolumn{2}{|c|}{ Fuel Wood Boiler 15 kW } & $€ \mathrm{MWh}_{\text {biomass }}{ }^{-1}$ & 76 & d \\
\hline \multicolumn{2}{|c|}{ Fuel Wood Boiler 100 kW } & $€ \mathrm{MWh}_{\text {biomass }}{ }^{-1}$ & 19 & d \\
\hline \multicolumn{2}{|c|}{ Pellets Boiler 15 kW } & $€ \mathrm{MWh}_{\text {biomass }}{ }^{-1}$ & 82 & d \\
\hline Pellets Boiler 1 & $0 \mathrm{~kW}$ & $€ \mathrm{MWh}_{\text {biomass }}^{-1}$ & 24 & d \\
\hline Conversion Ef & ciencies at Consumers & & & \\
\hline Fuel Wood Boi & er $15 \mathrm{~kW}$ and $100 \mathrm{~kW}$ & $\%$ & 80 & d \\
\hline Pellets Boiler 1 & $\mathrm{~kW}$ and $100 \mathrm{~kW}$ & $\%$ & 89 & d \\
\hline
\end{tabular}


${ }^{a}$ Costs are given in the biomass capacity of the plants. Cost differences between plants with and without CCS are relatively low because the electric capacity of CCS plants is significantly smaller (see efficiencies).

${ }^{\mathrm{b}}$ Electricity consumption of pellets plants induces costs and $\mathrm{CO}_{2}$ emissions which are considered in the variable costs and in the emissions of the plant.

${ }^{\mathrm{c}}$ Investment costs per MWh are calculated by determining the annuity of total investment costs and assuming 1800 load hours per year.

${ }^{\mathrm{d}}$ Kalt et al. (2010); ${ }^{\mathrm{e}}$ Azar et al. (2006); Rhodes \& Ketih (2005); Uddin \& Barreto (2007); ${ }^{\mathrm{f}}$ Dornburg \& Faaij (2001); Marbet et al. (2004); Uddin \& Barreto (2007); ${ }^{g}$ Bonijoly et al. (2009); Lindfeldt \& Westermark; ${ }^{\mathrm{h}}$ Azar et al. (2003);

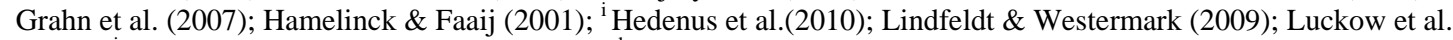
(2010); ${ }^{j}$ Leduc et al. (2008); Leduc et al. (2009); ${ }^{k}$ Polagye et al.(2007); Thek \& Obernberger (2004);

(i.e. community heating networks). Fuelwood is a cheap option with respect to investment and fuel costs (Kalt et al., 2010) and is broadly used in Austria. Pellets systems are more efficient, comfortable to handle and need less labor from the users (Ammann et al., 2009; Gustavsson et al., 2005). A large increase in installed capacity has been observed in the last years (Statistik Austria, 2009). The model considers both technologies. However, opportunity costs of fuel wood users caused by additional time requirements for handling fuelwood boilers are not considered. This may create a bias towards fuel wood boilers. This affects the competition between the two bioenergy technologies but does not change overall model results.

Power is currently produced from biomass mainly with steam engines combined heat and power (CHP) plants (Marbe et al., 2004). BIGCC plants produce power more efficiently (Dornburg and Faaij, 2001; Marbe et al., 2004), but they are more costly. Currently no commercial facilities are installed worldwide. We include both power producing technologies to explicitly address the trade-offs between them. Power production from biogas based on agricultural products is not considered. High feedstock and transportation costs make biogas power production more costly than power production in BIGCC or steam engine plants based on woody biomass feedstock (König, 2011). Both, steam engines and BIGCC can be integrated with CCS (Azar et al., 2006; Uddin and Barreto, 2007). 
A wide range of technologies is available and under development for the use of biomass in the transportation sector. They are commonly differentiated in first and second generation production technologies. While first generation fuels rely on starchy, sugar and oil crops as feedstock, second generation biofuels allow converting lignocellulosic feedstock, including forest products and short rotation lignocellulose from agriculture, into fuels. First generation biofuels are commercially available and ethanol and biodiesel facilities are operating around the world. Second generation biofuels are currently only produced in very few commercial facilities worldwide (Bacovsky et al., 2010). The most important first generation biofuel production technologies in Austria are ethanol and biodiesel production (Kranzl and Haas, 2008), which are both included in this analysis. Due to the early development state of second generation biofuels, various production technologies are still under research. Hydrolysis and subsequent fermentation competes with gasification of biomass. From what is known today, gasification, which allows the production of various fuels such as Fischer Tropsch (FT) diesel, DME or methanol (Demirbas, 2006) is estimated to be more competitive than hydrolysis (Bram et al., 2009; Lange, 2007). Uncertainties in production costs and GHG emission reduction potentials of DME and methanol are high. Comparative studies can be found in Wahlund et al. (2004) and Semelsberger et al. (2006). Due to the uncertainties, a modeling of both methodologies will not produce significant advantages of one technology over the other. We therefore chose gasification of biomass and subsequent methanol production as representative second generation production technology. Due to lower conversion efficiencies, FT diesel production costs are higher and GHG emission reductions are lower than those of DME and methanol fuels (Sues et al., 2010). FT diesel is therefore not considered in the model. Carbon capture and storage can be applied to first generation ethanol 
and to second generation methanol production (Azar et al., 2010; Faaij, 2006; Hedenus et al., 2010; Lindfeldt and Westermark, 2009). Relatively clean $\mathrm{CO}_{2}$ streams are generated in the production process that can be compressed, transported and stored directly without the need of cleaning processes as in power plants. However, only a limited part of the carbon stored in the biomass can be captured as most of the $\mathrm{CO}_{2}$ is released when the biofuels are combusted in the vehicles (Hedenus et al., 2010).

Bioenergy with carbon capture and storage (BECCS) is an emerging technology and one of the few options that allows achieving negative $\mathrm{CO}_{2}$ emissions (Kraxner et al., 2003), which may be necessary to manage climate risks effectively (Obersteiner et al., 2001). The carbon that is captured at the bioenergy production sites is transported by pipelines or ships to the final deposits which may be oil, gas or coal fields, deep saline aquifers or oceans. Costs for CCS after capture at the plant arise mainly from transportation and injection of the $\mathrm{CO}_{2}$ into the reservoir. According to Hendriks et al. (2004) costs for transportation over distances from 500 to $2000 \mathrm{~km}$ are estimated to be at $10 € \mathrm{tCO}_{2}^{-1}$. Major oil and gas fields as well as saline aquifers can be found within this distance from Austria (Hendriks and Grais, 2004). The total storage capacity in Europe is estimated to be $86.8 \mathrm{GtCO}_{2}$, which amounts to 18 years of total GHG emissions in the European Union in 2008. Injection costs range from 1.1 to $11.4 € \mathrm{tCO}_{2}{ }^{-1}$, depending on the type and depth of storage. Others estimate transportation and injection costs to be in the range of 13 to $42 € \mathrm{tCO}_{2}^{-1}$ (Azar et al., 2006; Rhodes and Ketih, 2005; Uddin and Barreto, 2007). We assume those costs to be at $25 € \mathrm{tCO}_{2}^{-1}$. However, the technological development, storage capacities, storage security, and the ecological effects of carbon storage remain uncertain (Holloway, 1997; Thistle et al., 2006; van der Zwaan and Gerlagh, 2009). We 
therefore run all scenarios with and without the option for CCS to account for these uncertainties. For all plants, a scaling factor of 0.7 (Marbe et al., 2004; Hamelinck and Faaij, 2001) with respect to investment costs is assumed, i.e. increasing plant sizes decreases the specific investment costs.

Better integration of bioenergy and CCS in industrial processes may create significant $\mathrm{CO}_{2}$ emission reductions (Möllersten et al., 2006; Möllersten et al., 2004; Möllersten et al., 2003) . However, a detailed modeling of the technologies in the relevant industries would be necessary for assessing the GHG emission reduction potentials. This is out of the context of this analysis. A rough calculation shows that the introduction of carbon capture and storage to the pulp and paper industry could currently save around $4 \mathrm{MtCO}_{2}$ if the technology is applied to all Austrian pulp and paper industries assuming a carbon recovery rate of $90 \%$. The costs are estimated to be between 30 and $40 €$ (Möllersten et al., 2006). The industry had a capacity of around 6.63 Mt of biomass in 2005 (Schwarzbauer and Stern, 2010).

\subsection{Energy demand}

Heating demand is estimated spatially explicitly with a bottom up model that combines average consumption values with private dwelling areas by age cohort and with the

Table 3: Assumptions for demand scenario in 2030

\begin{tabular}{lcc}
\hline Sector & $\begin{array}{c}\text { Demand 2030 } \\
\left(\text { TWh y }{ }^{-1}\right)\end{array}$ & $\begin{array}{c}\text { Change from 2008 }^{\mathbf{a}} \\
(\%)\end{array}$ \\
\hline Transportation & 89 & 12 \\
Thermal power & 24 & 25 \\
Single building boiler heat and & 31 & -37 \\
community district heat demand & 30 & 5 \\
Network bound heat & & \\
\hline${ }^{a}$ The demand in 2008 is taken from Statistik Austria (2009b) and E-Control (2009)
\end{tabular}


number of employees for commercial buildings and industrial low temperature applications. High temperature heat (industrial heat) is not considered in the model. The bottom up model is validated with national consumption values for heating fuels (Statistik Austria, 2009b). Heating demand is estimated in cells of $1 \mathrm{~km}^{2}$ size for Austria. Demand is split in three demand classes depending on the heating demand density. The first class (network bound heat) includes all cells that have a heating demand density of above 10,000 MWh $\mathrm{km}^{-2} \mathrm{a}^{-1}$. Gas and district heating networks compete in these cells. Between 5,000 MWh km $\mathrm{a}^{-1}$ and 10,000 MWh km $\mathrm{a}^{-1}$, supply is based on community heating networks with a maximum boiler capacity of $100 \mathrm{~kW}$ (community district heat). Demand of up to 5,000 MWh $\mathrm{km}^{-2} \mathrm{a}^{-1}$ is exclusively supplied by boilers in single buildings with a capacity of up to $15 \mathrm{~kW}$ (single building heat). The demand classes are chosen so that district heating and gas supply is reproduced for the base year 2008. A detailed description of the heating demand model can be found in (Schmidt et al., 2010b). Future heat demand is assumed to change drastically because of demoliton of old buildings, construction of new buildings and retrofitting of existing buildings (Kalt et al., 2010). Heating demand in the year 2030 is therefore estimated by assuming demolition and retrofitting rates for the various age cohorts based on linear trends from 1990 to 2009 (Statistik Austria, 2009a). The spatially explicit distribution of demolished and newly constructed buildings is based on spatially explicit population growth estimates (ÖROK, 2009). Also, a growth in square meter of housing area per person is assumed, following a linear trend from 1991-2009 (Statistik Austria, 2009a). Combining these factors, a $27 \%$ reduction of heating demand of private dwellings (from $65 \mathrm{TWh} \mathrm{a}^{-1}$ to $48 \mathrm{TWh} \mathrm{a}^{-1}$ ) from the base year level 2008 is estimated, which is in line with other scenarios (Kranzl and Haas, 2008). However, demand is shifted from low density regions to higher density 
regions as cities are expected to grow significantly while population in rural areas is expected to decline (ÖROK, 2009). Demand for commercial and low temperature process heat is assumed to stay constant as efficiency gains and production increases are assumed to level out. Transportation fuel demand is assumed to grow by $12 \%$ (Kranzl and Haas, 2008) from the 2008 level of $82 \mathrm{TWh} \mathrm{a}^{-1}$ (Statistik Austria, 2009b). Spatially explicit data on the distribution of the population is used to distribute fuel demand. Power demand is expected to grow by $25 \%$ (Kranzl and Haas, 2008). We assume that the share of thermal power production remains unchanged, i.e. that renewable energy production and fossil power production have equal growth rates which leads to an increase of thermal power production from $19 \mathrm{TWh}_{\text {power }} \mathrm{a}^{-1}$ in 2008 (E-Control, 2009) to 24 $\mathrm{TWh}_{\text {power }} \mathrm{a}^{-1}$ in 2030. Table 4 shows the resulting demand for power, heat and transportation.

\subsection{GHG emissions and reference technologies}

We account for GHG emissions which are produced within the modeled region. Leakage effects caused by national carbon policies are not considered. With respect to bioenergy, the most important leakage effect concerns GHG emissions which are caused by direct and indirect land use change in other world regions (Havlík et al., 2010; Lapola et al., 2010; Searchinger et al., 2008). Although possible GHG emissions from indirect land use changes are not quantitatively assessed, the applied methodology allows showing the decline in domestic production of food and feed crops caused by additional production of energy crops. The following direct GHG emissions are considered: $\mathrm{N}_{2} \mathrm{O}$ emissions from fertilizer application in agriculture, $\mathrm{CO}_{2}$ emissions from biomass and commodity transportation, $\mathrm{CO}_{2}$ emissions in the bioenergy production process (e.g. from power con 
Table 4: $\mathrm{CO}_{2}$ Emissions and costs of fossil fuel reference technologies in the baseline scenario

\begin{tabular}{|c|c|c|c|}
\hline $\begin{array}{l}\text { Bioenergy } \\
\text { technology }\end{array}$ & $\begin{array}{l}\text { Fossil } \\
\text { reference } \\
\text { technology }\end{array}$ & $\begin{array}{l}\mathrm{CO}_{2} \text { emissions of } \\
\text { reference technology }\end{array}$ & Costs of reference technology ${ }^{\mathbf{b}}$ \\
\hline $\begin{array}{l}\text { Pellets / Fuelwood } \\
\text { boilers }\end{array}$ & $\begin{array}{l}\text { Heating oil } \\
\text { boilers }\end{array}$ & $0.28 \mathrm{tCO}_{2} \mathrm{MWh}_{\mathrm{oil}}^{-1}$ & $\begin{array}{l}\text { Investment costs for oil boilers: } 47 € \mathrm{MWh}_{\text {fuel }}{ }^{-} \\
{ }^{1} \text { for boilers of } 15 \mathrm{~kW} \text { and } 32 € \mathrm{MWh}_{\text {fuel }}{ }^{-1} \text { for } \\
\text { boilers of } 100 \mathrm{~kW} \text { (Kalt et al., 2010). } \\
\text { Heating oil price: } 65 € \mathrm{MWh}_{\text {fuel }}\end{array}$ \\
\hline Power - no CCS & $\begin{array}{l}\text { Fuel mix } 80 \% \\
\text { gas, } 20 \% \text { coal }\end{array}$ & $0.39 \mathrm{tCO}_{2} \mathrm{MWh}_{\text {power }}{ }^{-1}$ & $\begin{array}{l}75 € \mathrm{MWh}_{\text {power }}^{-1} \\
\text { Investment costs and efficiencies of fossil } \\
\text { power production from Tzimas et al. (2010). }\end{array}$ \\
\hline Power - with CCS & $\begin{array}{l}\text { Fuel mix of } \\
80 \% \text { gas and } \\
20 \% \text { coal }\end{array}$ & $0.05 \mathrm{tCO}_{2} \mathrm{MWh}_{\text {power }}^{-1}$ & $\begin{array}{l}100 € \mathrm{MWh}^{-1} \\
\text { Investment costs and efficiencies of fossil } \\
\text { power production with CCS from Tzimas et } \\
\text { al. (2010). }\end{array}$ \\
\hline District Heating & $\begin{array}{l}\text { Gas fired heat- } \\
\text { ing in single } \\
\text { building boilers, } \\
\text { gas fired district } \\
\text { heating }\end{array}$ & $0.2 \mathrm{tCO}_{2} \mathrm{MWh}_{\mathrm{gas}}{ }^{-1}$ & $\begin{array}{l}\text { Investment costs for gas boilers } 32 € \mathrm{MWh}^{-1} \\
\text { (Kalt et al., 2010). } \\
\text { Gas Price: } 42 € \mathrm{MWh}_{\text {fuel }}\end{array}$ \\
\hline $\begin{array}{l}\text { Ethanol, Methanol, } \\
\text { Biodiesel }\end{array}$ & Gasoline & $0.26 \mathrm{tCO}_{2} \mathrm{MWh}_{\text {gasoline }}{ }^{-1}$ & Gasoline price: $65 € \mathrm{MWh}_{\text {fuel }}$ \\
\hline
\end{tabular}

${ }^{\mathrm{a}}$ Emissions are based on Emission Factors in the Austrian Emissions Inventory (Umweltbundesamt Austria, 2010)

sumption), $\mathrm{CO}_{2}$ emissions of fossil fuel combustion and negative $\mathrm{CO}_{2}$ emissions from BECCS. Changes in carbon sequestration of forests due to increased fuel wood consumption are not included. The carbon released in bioenergy production and consumption is assumed to be neutralized by the plant growth. This assumption is consistent with the current version of the UNFCCC reporting guidelines for the Kyoto Protocol that assumes that woody biomass use in energy applications is GHG emission neutral (UNFCCC, 2006). GHG emission reductions achieved by bioenergy technologies as well as the economic competitiveness depend on the chosen reference technologies. Wood pellet and fuelwood boilers most likely replace heating oil boilers in single buildings and community district heating. They are similar in operation and also need fuel storage space (Gustavsson et al., 2005). We assume that surplus heat of bioenergy plants competes with gas fired district heating and gas fired single-building boilers in the network bound heating cells. The costs of the district heating infrastructure are determined by 
applying an exponential cost function that depends on heat demand density (Konstantin, 2007). Costs of competing gas networks are assumed to be half the costs of district heating networks (Torekov et al., 2007). BIGCC and BIGCC with CCS are thermal power plants and are therefore able to produce constant base load power unlike other renewable energy technologies. In the model, power production therefore competes with thermal fossil power production. A mix of fossil fuels consisting of gas (80\%) and coal (20\%) is modeled, assuming that coal is slowly faded out from the current production share of $40 \%$ and that oil with a current share of $8 \%$ further looses relevance in power production (E-Control, 2009). A sensitivity analysis is used to determine effects of different power generation fuels. In the CCS scenario, fossil power production applies CCS which leads to decreased GHG emission factors and increased power prices. Methanol is blended with gasoline for utilization in the transportation sector (Leduc et al., 2008) and is therefore regarded as direct substitute of gasoline. Surplus heat from bioenergy plants replaces gas which is either used locally in boilers or as fuel in district heating networks. $\mathrm{CO}_{2}$ emissions of the different bioenergy technologies with regard to the reference technologies and costs of reference technologies can be found in Table 3.

\subsection{Policy Scenarios}

We assess the effect of energy policies in a scenario for the year 2030 with focus on GHG emission reductions and fossil fuel substitution in energy production and transportation. GHG emissions in these sectors currently account for around 49\% of total Austrian GHG emissions in 2008 (Umweltbundesamt Austria, 2010). The base scenario (BA) does not contain any policy intervention. The scenario for the oil price is based on the IEA world energy outlook (International Energy Agency, 2009). It is assumed that 
Table 5: Energy prices and $\mathrm{CO}_{2}$ emissions of fossil reference technologies used in the scenarios and the sensitivity analysis.

\begin{tabular}{|c|c|c|c|c|}
\hline Scenario & $\begin{array}{l}\text { Power costs } \\
\left(€ \mathrm{MWh}_{\text {power }}{ }^{-1}\right)\end{array}$ & $\begin{array}{l}\mathrm{CO}_{2} \text { emissions of } \\
\text { power production } \\
\left(\mathrm{tCO}_{2} \mathrm{MWh}_{\left.\text {power }^{-1}\right)}\right.\end{array}$ & $\begin{array}{l}\text { Costs of heating tech- } \\
\text { nology (single build- } \\
\text { ings) including fuel } \\
\left(€ \mathrm{MWh}_{\text {heat }}{ }^{-1}\right)\end{array}$ & $\begin{array}{l}\mathrm{CO}_{2} \text { emissions of } \\
\text { heating technology } \\
\left(\mathrm{tCO}_{2} \mathrm{MWh}_{\text {heat }^{-1}}\right)\end{array}$ \\
\hline \multicolumn{5}{|l|}{ Without CCS } \\
\hline Base scenario & 75 & 0.38 & 124 & 0.27 \\
\hline Coal Scenario & 60 & 0.67 & 124 & 0.27 \\
\hline Gas Scenario & 80 & 0.32 & 124 & 0.27 \\
\hline Heat Pump Scenario & 75 & 0.38 & 119 & 0.13 \\
\hline \multicolumn{5}{|l|}{ With CCS } \\
\hline Base Scenario & 100 & 0.05 & 124 & 0.27 \\
\hline Coal Scenario & 75 & 0.08 & 124 & 0.27 \\
\hline Gas Scenario & 106 & 0.04 & 124 & 0.27 \\
\hline Heat Pump Scenario & 100 & 0.05 & 119 & 0.13 \\
\hline
\end{tabular}

the spread between gas and oil remains comparable to today and that no significant

spread between heating oil and gasoline develops. The power price is modeled by regarding fossil fuel prices and investment costs of thermal power plants. The power price and $\mathrm{CO}_{2}$ emissions of fossil power production are varied in a sensitivity analysis. The assumptions for the sensitivity analysis are stated in Table 5. We assess the costeffectiveness of five energy policy instruments with respect to reducing GHG emissions and substituting fossil fuels. The cost-effectiveness of policies is defined such that the attainment of energy policy targets, i.e. GHG emission reduction and fossil fuel substitution is cost minimal in the energy supply system. We model policies that focus on reducing GHG emissions and policies that directly promote bioenergy technologies. The first class includes the following two scenarios:

- The TX policy scenario taxes $\mathrm{CO}_{2}$ emissions of all fossil fuels, including private heating and transportation fuels. It is assumed that BECCS gains tax returns for negative $\mathrm{CO}_{2}$ emissions.

- The EU ETS is modeled in the TS scenario where the application of a carbon price is limited to power and district heat production only. Fossil fuel consumption in single building boilers, community district heating and transportation is 
not included in the trading scheme. Trading of allowances in the EU ETS is not modeled explicitly. Constant allowance prices are assumed instead.

The second class includes the following three scenarios:

- Feed-in tariffs that guarantee fixed levels of power prices are modeled in the FI scenario.

- In the BF scenario, fixed shares of biofuel in transportation fuel consumption are imposed.

- Investment subsidies are guaranteed to pellets and fuel wood furnaces in the PE scenario.

Table 6 reports the levels of the policy instruments considered in the analysis. All scenarios are assessed with and without BECCS due to the uncertainty of technological development. In the BECCS scenarios it is assumed that fossil fuel based power production also relies on CCS which decreases emissions but increases production costs. Costs, GHG emission reductions, and fossil fuel substitutions in the scenarios are compared to

Table 6: Levels of policy instruments considered in the scenario analysis.

\begin{tabular}{llll}
\hline Policy instrument & Description & Range & Increment \\
\hline TX & Tax on $\mathrm{CO}_{2}$ emissions of all fossil fuels & $2 € \mathrm{tCO}_{2}^{-1}$ to $150 € \mathrm{tCO}_{2}^{-1}$ & $5 € \mathrm{tCO}_{2}^{-1}$ \\
TS & $\mathrm{CO}_{2}$ emission trading scheme & $2 € \mathrm{tCO}_{2}^{-1}$ to $150 € \mathrm{tCO}_{2}^{-1}$ & $5 € \mathrm{tCO}_{2}^{-1}$ \\
FI & Feed-in tariffs for biomass power produc- & $80 € \mathrm{MWh}^{-1}$ to $120 € \mathrm{MWh}^{-1}$ & $5 € \mathrm{MWh}^{-1}$ \\
& tion & & \\
$\mathrm{BF}$ & Biofuel shares imposed & $0.20 \%$ to $12.00 \%$ & $0.40 \%$ \\
$\mathrm{PE}$ & Subsidies to pellet and fuel wood boilers & $50 € \mathrm{~kW}^{-1}$ to $1000 € \mathrm{~kW}^{-1}$ & $45 € \mathrm{~kW}^{-1}$ \\
\hline
\end{tabular}


the base scenario, i.e. relative changes in GHG emissions, fossil fuel substitution and costs in relation to the base scenario are used to measure the effect of the policy instruments.

\section{Results}

\subsection{GHG emission reduction, fossil fuel substitution, costs and technolo-} gies

\subsubsection{Without CCS}

In the base scenario without any policy intervention, GHG emissions are slightly higher than in 2008 (see Table 7). The decrease in heating demand and lower $\mathrm{CO}_{2}$ emissions

Table 7: Model results of the base scenario with and without CCS.

\begin{tabular}{|c|c|c|c|c|}
\hline & \multicolumn{2}{|c|}{ Base 2030 without CCS } & \multicolumn{2}{|c|}{ Base 2030 with CCS } \\
\hline & $\begin{array}{l}\text { Amount in } \\
\text { scenario }\end{array}$ & $\begin{array}{l}\text { Change from } \\
2008^{\mathrm{a}}\end{array}$ & $\begin{array}{l}\text { Amount in } \\
\text { scenario }\end{array}$ & $\begin{array}{l}\text { Change from } \\
2008^{\mathrm{a}}\end{array}$ \\
\hline GHG emissions $\left(\mathrm{MtCO}_{2} \mathrm{e}\right)$ & 44 & +2 & 39 & -3 \\
\hline \multicolumn{5}{|l|}{ Biomass heat production $\left(\mathrm{TWh}_{\text {heat }}\right)$} \\
\hline Single- and multi-dwelling buildings & 4 & -13 & 2 & -15 \\
\hline District heating ${ }^{\mathrm{b}}$ & 7 & +6 & 8 & +7 \\
\hline \multicolumn{5}{|l|}{ Fossil fuel heat production ( $\left.T W h_{\text {heat }}\right)$} \\
\hline $\begin{array}{l}\text { Heating oil, single- and multi-dwelling } \\
\text { buildings }^{\mathrm{c}}\end{array}$ & 30 & +7 & 32 & +9 \\
\hline Gas, district heating & 8 & +1 & 7 & 0 \\
\hline Gas, heat production in buildings & 18 & +4 & 18 & +4 \\
\hline Biomass power production $\left(\mathrm{TWh}_{\text {power }}\right)$ & 5 & +3 & 12 & +10 \\
\hline Fossil fuel power production ( $\mathrm{TWh}_{\text {power }}$ ) & 19 & 0 & 12 & -7 \\
\hline Biofuel production $\left(\mathrm{TWh}_{\mathrm{fuel}}\right)$ & 4 & +0.3 & 0 & -3.7 \\
\hline Gasoline consumption $\left(\mathrm{TWh}_{\mathrm{fuel}}\right)$ & 85 & +3 & 89 & +7 \\
\hline $\begin{array}{l}\text { Total biomass consumption } \\
\text { (TWh } \\
\text { biomass) }\end{array}$ & 25 & +2 & 29 & +6 \\
\hline
\end{tabular}

a 2008 values taken from Statistik Austria (2009b), E-Control (2009) and Umweltbundesamt (2010), ${ }^{\mathrm{b}}$ Guesstimate for $2008,{ }^{\mathrm{C}} 2008$ values include coal and electricity 
from power generation are more than compensated by increases in power and transportation fuel demand. A shift from heat to power and transportation fuel production can be observed due to lower heat demand levels, higher power prices and more efficient BIGCC production. Biomass consumption increases slightly in comparison to 2008. Forestry provides the whole bioenergy feedstock. The results of the policy scenarios are shown in Figure 3. A carbon tax on all modeled sectors (TX) leads mainly to an increase of biomass utilization for heating. Up to a price of $50 € \mathrm{tCO}_{2}^{-1}$, forestry provides the entire biomass. For higher prices, agriculture produces additional short rotation lignocellulose. At a price of $75 € \mathrm{tCO}_{2}^{-1}$, some limited amount of first generation ethanol production is triggered because marginal prices of lignocellulose from agriculture are high in comparison to marginal prices of ethanol crops. However, the total amount of ethanol production remains small. About $2.5 \mathrm{TWh}$ of ethanol is produced at a $\mathrm{CO}_{2}$ price of $150 €$ $\mathrm{tCO}_{2}{ }^{-1}$. The scenarios TS and FI show similar results. Power production is the main mitigation option in TS, with minor amounts of reducing GHG emissions by district heating. FI solely subsidizes power production. GHG emission savings and fossil fuel substitution are low in comparison to TX because the private heat sector is not included in the mitigation efforts. In the BF scenario, second generation methanol is chosen as production technology for biofuels, relying mainly on woody biomass from forestry. GHG emissions are comparable to the baseline scenario while fossil fuel substitution is lower. The main feedstock is forest wood, if biomass heat is directly subsidized (PE). Only a small fraction of short rotation lignocellulose is used to produce pellets for heat production. The relative performance of the policies is shown in Figure 5. TX is superior in attaining both targets cost-effectively, i.e. GHG emission reduction and fossil fuel substitution. In TX, a mix of bioenergy technologies is chosen. No single technology can 
therefore be regarded as superior with respect to cost-effective GHG emission reduction and fossil fuel substitution. There is less cost-effectiveness in all other policy scenarios, because some technologies are excluded from the mitigation efforts. In these scenarios, biomass utilization in highly cost-effective applications (such as heating) may be
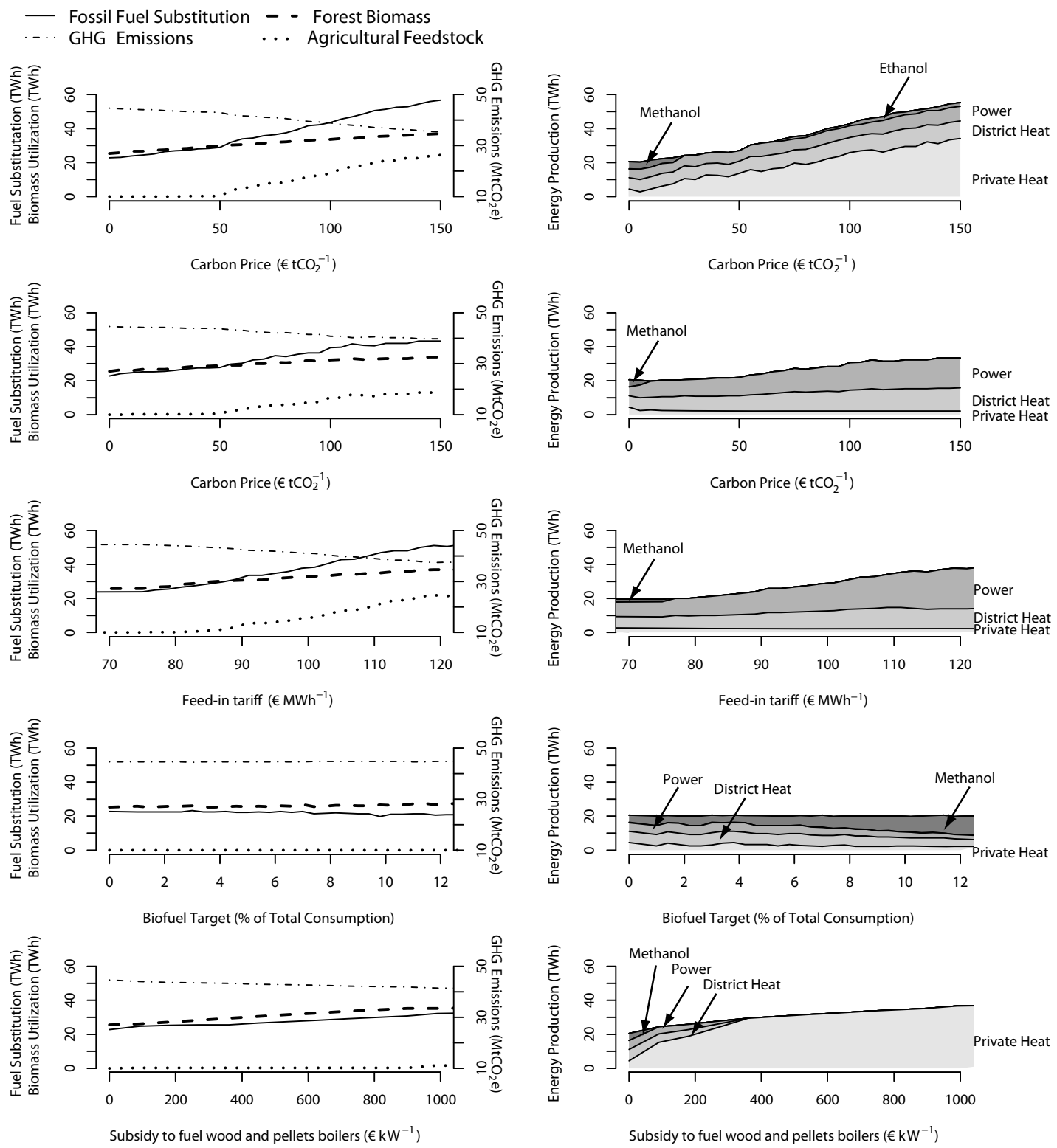

Figure 3: GHG emission savings, fossil fuel substitution and biomass utilization from forestry and agriculture (left) and technological mix (right) in scenarios without CCS. (1) TX, (2) TS, (3) FI, (4) BF, (5) PE 
reduced in comparison to the baseline scenario because increasing biomass prices make the application in non-subsidized sectors non-competitive. There are, however, differences in the performance of these instruments. TS and FI perform comparable while subsidies for heating (PE) are more costly in reducing GHG emissions and increasing fossil fuel substitution. The investment costs for fossil and biomass based heating boilers are significantly higher than for oil heating boilers which explain the high costs of PE. The biofuel policy (BF) performs worse than any other policy instrument. Fossil fuel substitution is actually negative in comparison to the base scenario.

\subsubsection{With CCS}

The existence of CCS in fossil power production leads to a significant decrease in GHG emissions in this sector in the base scenario (see Table 7). Overall, a decrease of $3 \mathrm{Mt}$ $\mathrm{CO}_{2} \mathrm{e}$ in comparison to 2008 is modeled. A big shift from heat to power production from biomass occurs because the utilization of CCS in the power production sector increases power prices substantially and therefore makes power production based on biomass more profitable. Short rotation cellulose from agriculture provides 1 TWh as bioenergy feedstock in the base scenario. Figure 4 shows detailed results of the policy scenarios. At low $\mathrm{CO}_{2}$ prices, biomass power production without CCS and, to less extent, heat production increases in the TX scenario. GHG emission reductions are larger for biomass heating than for biomass power production due to the low $\mathrm{CO}_{2}$ emissions of fossil CCS plants. At $\mathrm{CO}_{2}$ prices above $70 € \mathrm{tCO}_{2}^{-1}$, BECCS becomes competitive. Methanol and power production with CCS have a comparable share of total production while heat production declines. Methanol CCS is chosen although the $\mathrm{CO}_{2}$ capture rate is lower than for power production. However, the reference technology for methanol is fossil gasoline 
which has higher $\mathrm{CO}_{2}$ emissions in comparison to the reference technology for power, i.e. fossil power production with CCS. A large amount of short rotation lignocellulose comes from agriculture. Forestry production is also increased in Austria. GHG emission savings from the transportation sector and the power sector decrease significantly due to the negative $\mathrm{CO}_{2}$ emissions caused by BECCS. More than half of the GHG emissions of
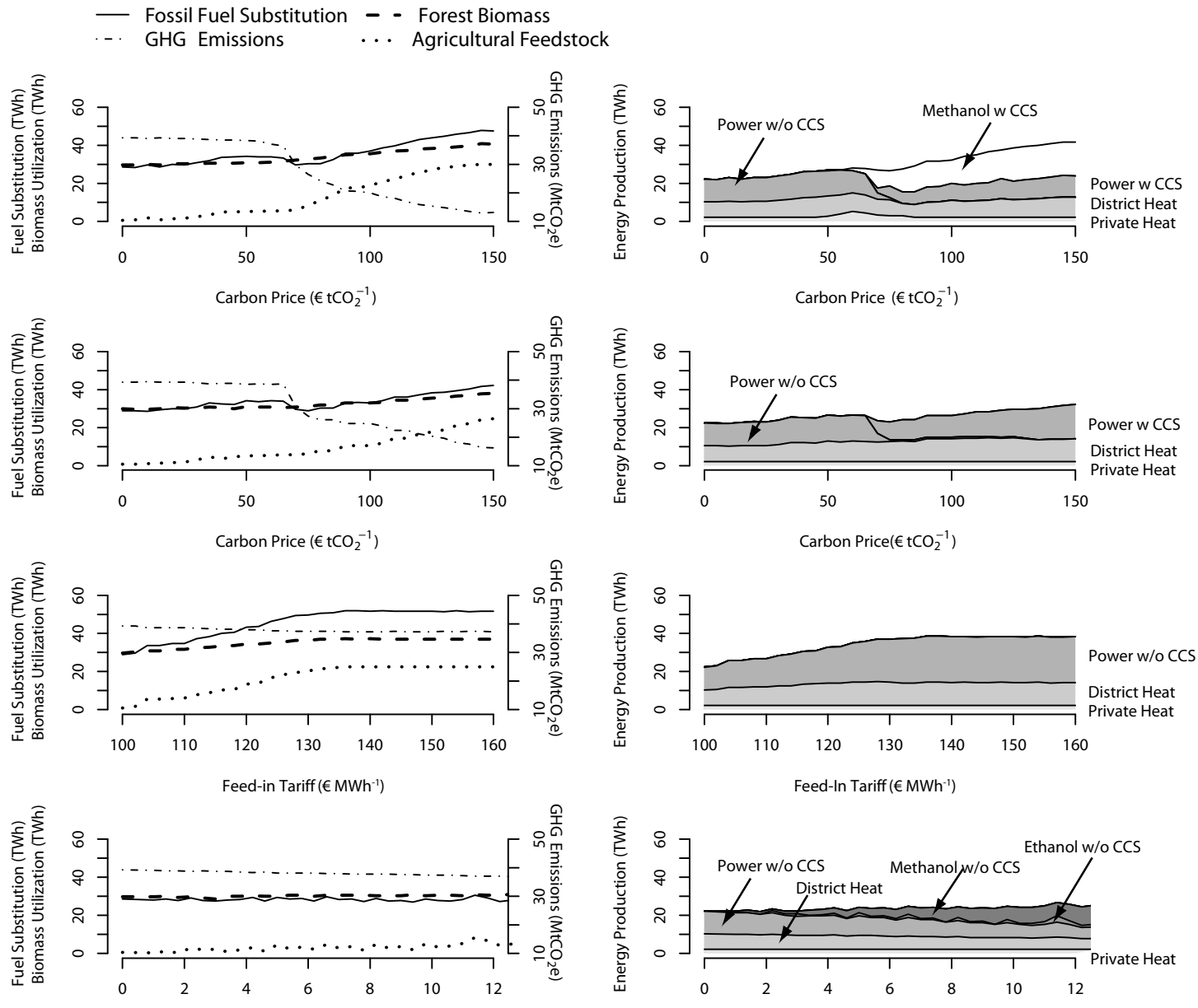

Biofuel Target (\% of Total Consumption)
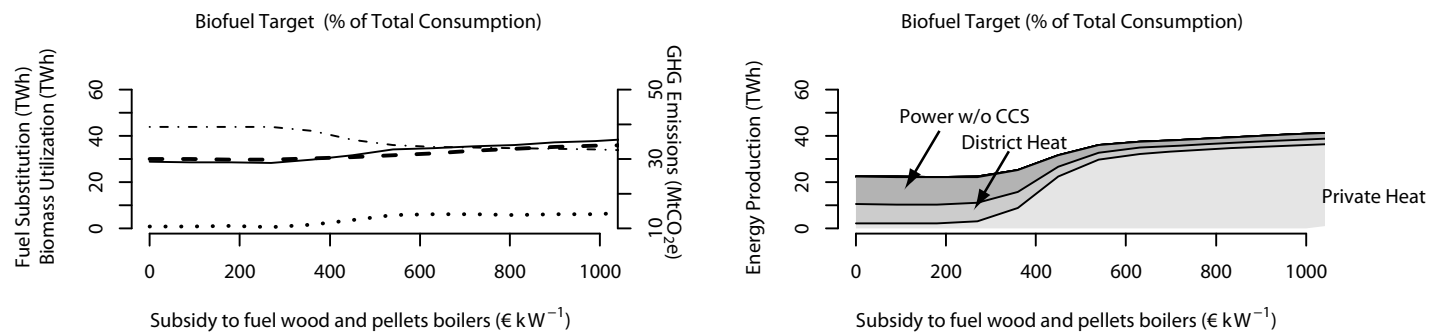

Figure 4: GHG emission savings, fossil fuel substitution and biomass utilization from forestry and agriculture (left) and technological mix (right) in scenarios with CCS. (1) TX, (2) TS, (3) FI, (4) BF, (5) PE 
the observed sectors can be reduced at a $\mathrm{CO}_{2}$ price of $150 € \mathrm{tCO}_{2}{ }^{-1}$. However, fossil fuel substitution is low because additional fossil power production has to be in place when biomass power with CCS substitutes biomass power without CCS. In the TS scenario, there is no relevant change in the supply structure up to a price of $70 € \mathrm{tCO}_{2}^{-1}$ when biomass based power production with CCS becomes competitive. Biomass power with CCS gradually replaces biomass power production without CCS. GHG emission savings are significant and reach $40 \%$ of total GHG emissions. Fossil fuel substitution is low.

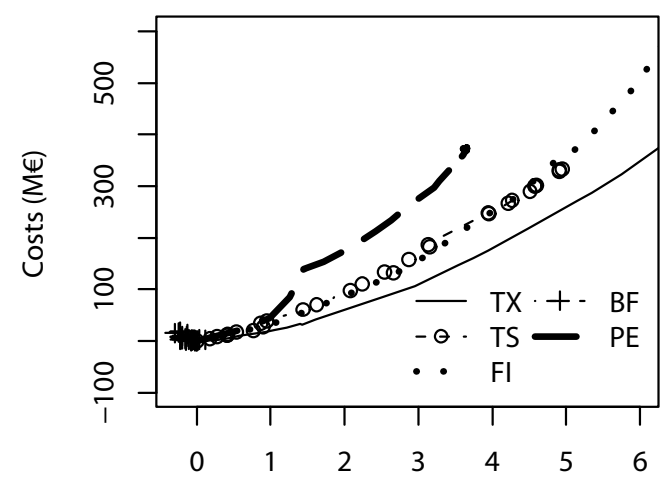

GHG Emission Reductions $\left(\mathrm{MtCO}_{2} \mathrm{e}^{-1}\right)$

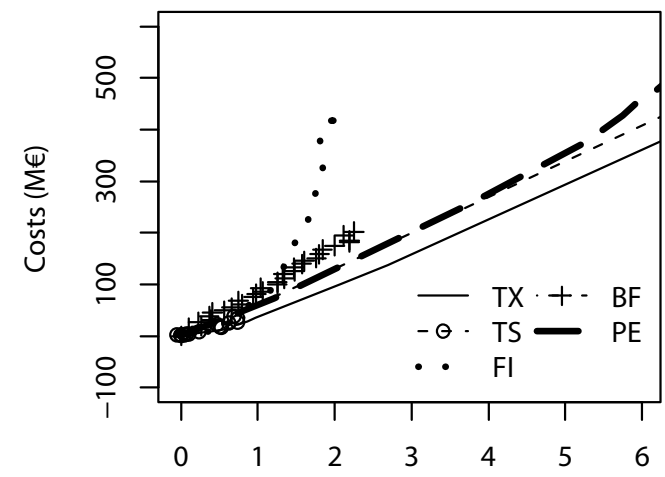

GHG Emission Reductions $\left(\mathrm{MtCO}_{2}\right.$ e $\left.\mathrm{a}^{-1}\right)$
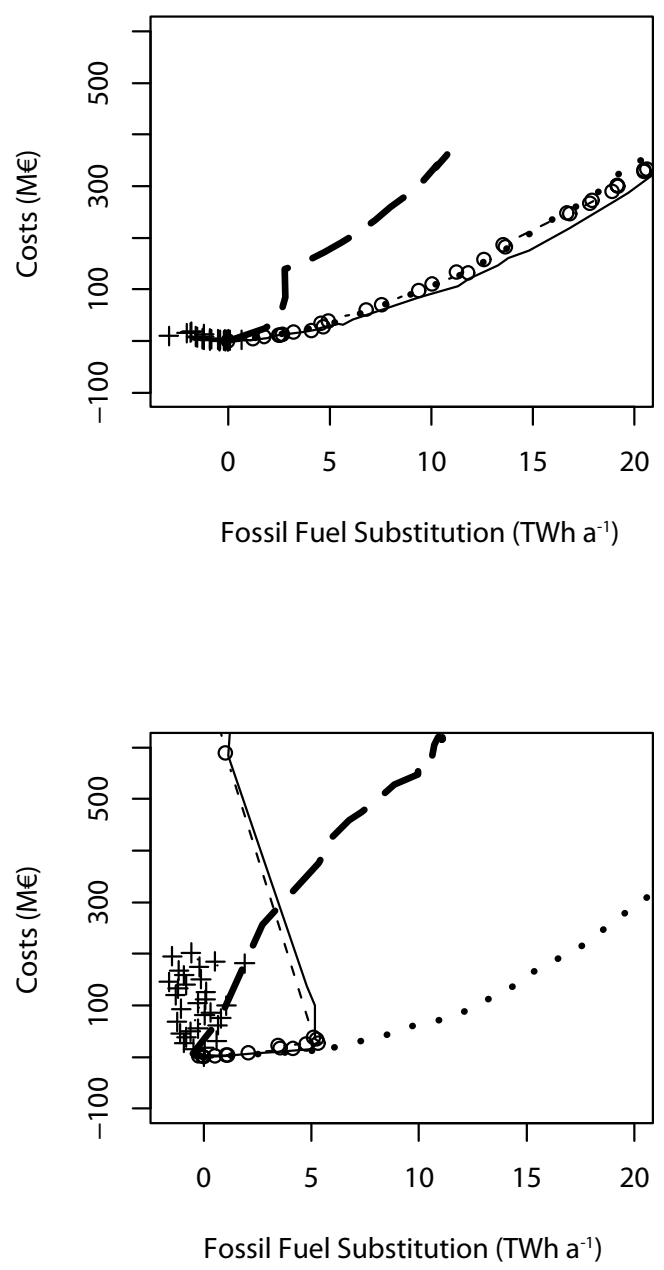

Figure 5: GHG emission reductions (left) and fossil fuels substituted (right) in relation to costs in the scenario without CCS (upper) and with CCS (lower). 
Agricultural production of lignocellulose increases significantly. The promotion of bioenergy by feed-in tariffs (FI) causes an increase in biomass power production without CCS. Fossil fuel substitution is therefore substantial while almost no GHG emission reduction effects can be observed. Biofuel production in the BF scenario mainly replaces existing power and heat production. GHG emission savings are low and fossil fuel substitution does not occur at all. Little amounts of agricultural feedstock are used for biofuel production. Heat production in PE gradually replaces other bioenergy applications. Short rotation lignocellulose is used for the production of pellets to supply the heating demand. GHG emission savings are not comparable to TX and TS because no BECCS is deployed.

There is a clear trade-off between fossil fuel substitution and GHG emission reduction when CCS is available, which is shown in Figure 5. The TX and TS scenarios allow a very significant reduction in GHG emissions, however, effects on fossil fuel substitution are low. FI performs very well with respect to this policy target, but GHG emission reductions are comparably expensive and limited. Subsidies on heating systems and the biofuel policy lead to reductions in GHG emissions but fossil fuel substitution is low.

\subsubsection{Technologies}

BIGCC dominates steam engines in TS and FI. When CCS is available, only BIGCC is deployed. Second generation methanol production is the main biofuel production technology deployed in the biofuel scenarios. In the TX scenario without CCS, ethanol is chosen because the feedstock availability for methanol is constrained due to the high utilization of short rotation lignocellulose by the other sectors. Biodiesel is only de- 
ployed at very small scale ( $<0.3$ TWh in all scenarios). If CCS is available, second generation methanol with CCS clearly dominates first generation ethanol with CCS.
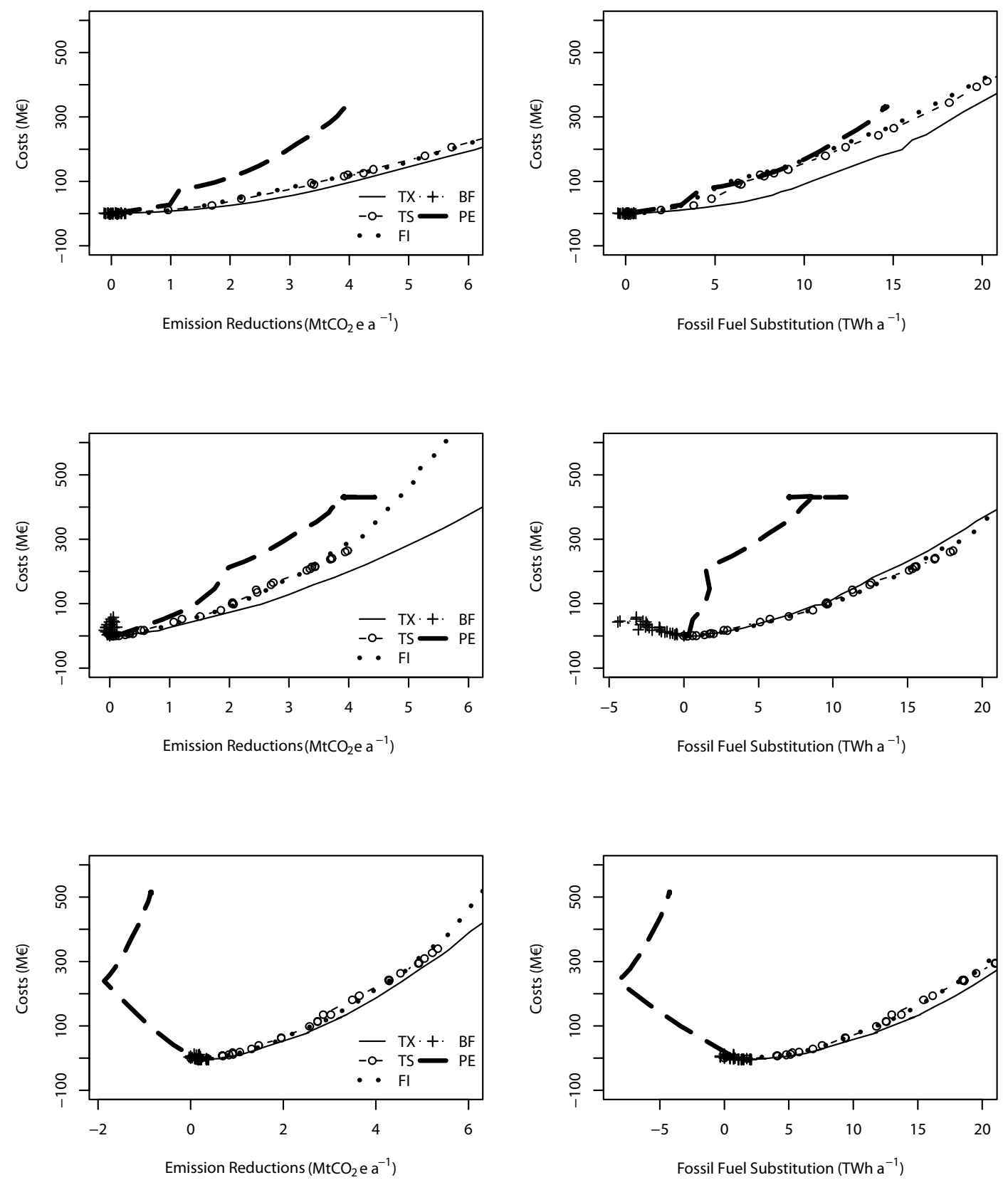

Figure 6: GHG emission reductions (left) and fossil fuel substitution (right) in relation to costs for alternative reference technologies without CCS. (upper) coal power, (middle) gas power, (lower) heat pumps 
With the exemption of pellets plants, plant sizes are always chosen at the maximum capacity, i.e. $300 \mathrm{MW}_{\text {biomass }}$ for all technologies. Although logistic costs are high for such plants, decreasing investment costs for the plants make up for this additional transportation costs.

\subsection{Alternative Reference Technologies}

Previous sensitivity analysis of the model (Schmidt et al., 2010a) have shown that fossil fuel prices and characteristics of fossil reference technologies have the most significant influence on model results. Uncertainties in the development of the costs and efficiencies of technologies are less important. Instead of conducting a full sensitivity analysis on all model parameters, we analyze the performance of policy instruments when costs and $\mathrm{CO}_{2}$ emissions of the fossil reference technologies are changed. We test for the sensitivity of results of the scenarios with and without CCS to changes in the fossil power production technology and the availability of an additional heating technology. There are two alternative fossil power production cases: in the first case, only gas is used as fuel while in the other one only coal. We consider heat pumps as alternative reference technology for the heating of single buildings. The parameters applied in the sensitivity analysis are reported in Table 5.

\section{Without CCS}

Figure 8 shows the relative performance of the policies in the three scenarios without CCS. Generally, the ordering of the policies with respect to cost-effectiveness is stable. The only change in this order occurs if a low carbon and low cost heating technology (i.e. heat pumps) is available. In that case, BF performs better than PE. However, quantitative differences between policy instruments do change. The performance of PE with 

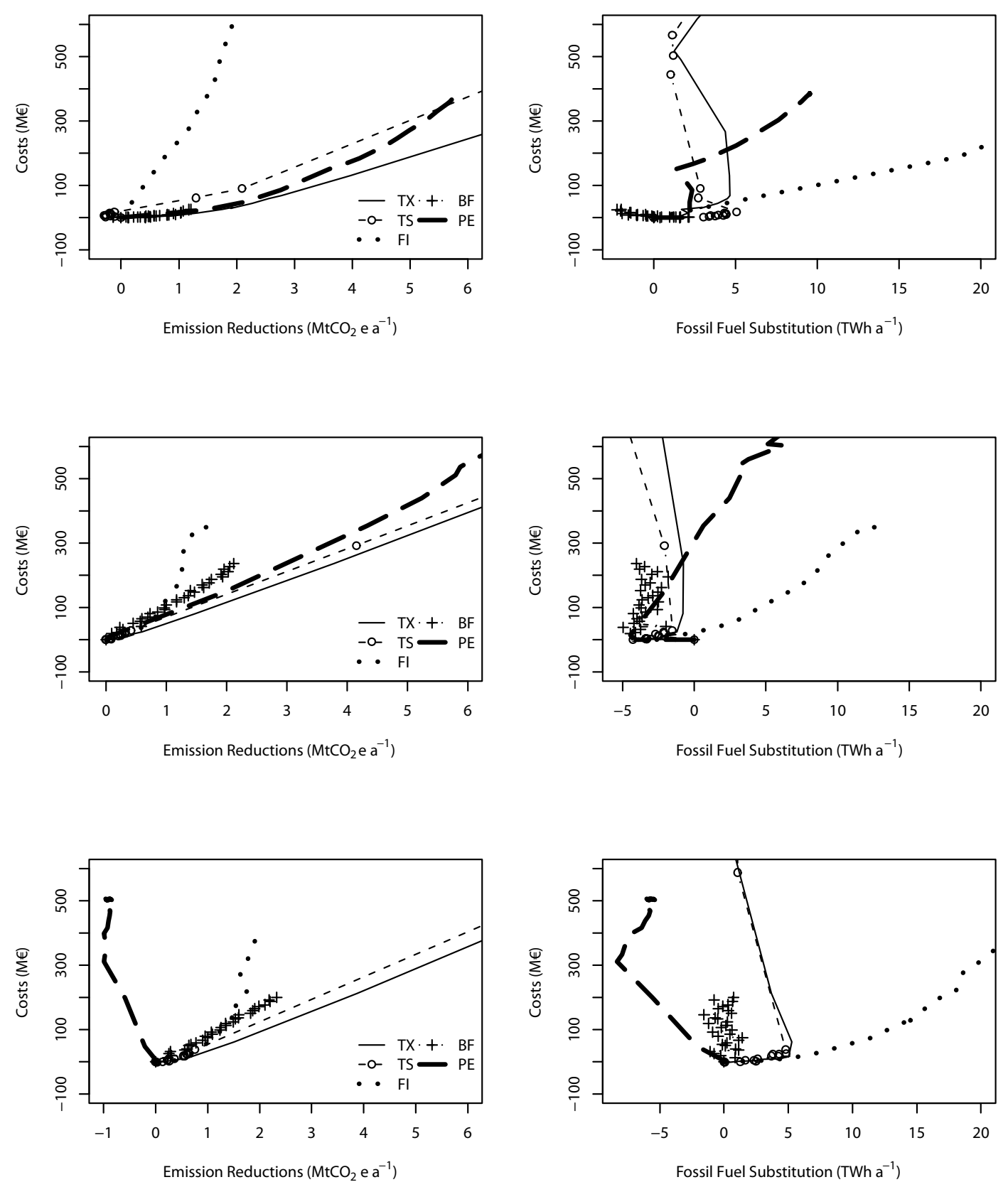

Figure 7: GHG emission reductions (left) and fossil fuels substituted (right) in relation to costs for alternative reference technologies with CCS. (upper) coal power, (middle) gas power, (lower) heat pumps

regard to fossil fuel substitution is close to the performance of TS and FI in the coal power scenario. Costs of fossil fuel substitution by biomass heating are similar to biomass power due to the low fossil power prices. In the gas power scenario, fossil fuel 

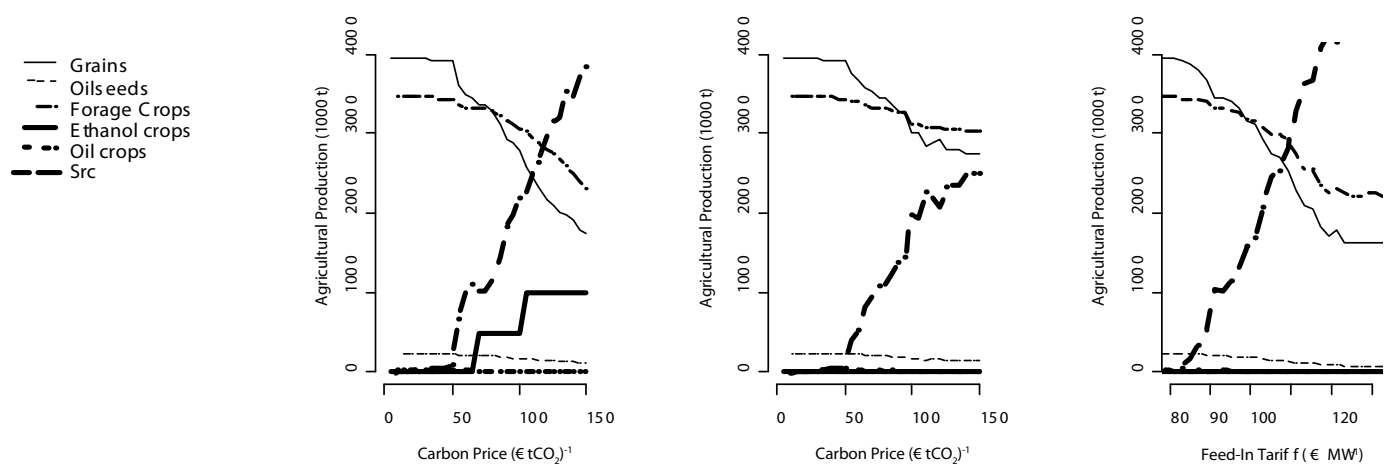

Figure 8: Food and energy crop production in the TX (left), TS (middle), and FI (right) scenario without CCS.

substitution by FI and TS is comparable to the TX scenario. Higher fossil power costs are the reason. GHG emissions reductions with TS and FI are costly because gas fueled power generation has lower $\mathrm{CO}_{2}$ emissions. When heat pumps are available, TX, TS and FI have similar performance because mitigation efforts are mainly concentrated in the power sector. The PE policy instrument performs worse than BF in that scenario.

\section{With CCS}

Figure 8 shows the relative performance of the policy instruments for alternative reference technologies with CCS. Again, the ordering of the policy instruments is stable with the exemption of the third scenario where the availability of heat pumps decreases the cost-effectiveness of PE in relation to BF and FI.

\subsection{Feedstock}

The TX, TS and FI policy scenarios lead to an increase of agricultural biomass, mainly short rotation lignocellulose. Figure 6 shows that in the TX, TS and FI scenarios without CCS (comparable to the ones with CCS) the production of grains, forage crops and oilseeds decreases significantly. Grain production is reduced to $50 \%$ of the production level of the baseline scenario, oilseeds to $60 \%$ and forage crops to $72 \%$ in the TX scenario of $150 € \mathrm{tCO}_{2}^{-1}$. Production of forest wood is increased from around $25 \mathrm{TWh}$ in the 
base scenario to 38 TWh in the TX scenario. TS and FI show comparable production increases.

\section{Discussion \& Conclusions}

\subsection{Discussion}

Results of our model analysis confirm to some degree results of other studies. Berndes et al. (2007) and König (2011) find that the European biofuel policy is costly in comparison to other measures while Azar et al. (2003) conclude that biofuels are not competitive to other mitigation options. Gielen et al. (2003) find that biofuels have to play a major role in a stringent GHG reduction scenario if no other mitigation options are available in the transportation sector. The potentials for additional supply of biomass to the transportation sector are however low in Austria if power and heat production are based on biomass. Luckow et al. (2010) conclude that mainly biomass based power production with CCS is a major mitigation option with very stringent GHG emission targets. We conclude in contrast that methanol CCS can also contribute to GHG emission reductions because very significant reductions in the transportation sector can be achieved that are otherwise not possible. All results with respect to CCS depend on the development of that technology which remains uncertain.

The large substitution of food crops for energy utilization, especially in the TX scenario (i.e. 50\% reduction of grain production), will increase agricultural imports to or decrease exports from Austria. Additional agricultural imports or less exports may trigger direct and indirect land use changes in other regions that likely offset GHG emission reductions from bioenergy production in Austria (Havlík et al., 2010; Lapola et al., 2010; Searchinger et al., 2008). An intensive utilization of domestic agricultural resources for 
bioenergy will likely have negative effects on the total carbon balance of the policy instruments therefore. Only BECCS allows very significant GHG emission reductions that may offset such indirect effects. Increasing the supply of domestic forest wood can partly deliver additional bioenergy resources without replacing existing crop production, however, the total potential from sustainable forest management is limited to around 38 $\mathrm{TWh}_{\text {biomass }} \mathrm{a}^{-1}$ (Schadauer, 2009). A strategy that relies on importing biofuels instead of producing them domestically could be more effective. For instance, production of Brazilian ethanol is significantly less expensive than European biofuels (Cerqueira Leite et al., 2009; Nass et al., 2007; de Vries et al., 2010). However, serious social and ecological concerns are connected with biofuel production in tropical countries (Delzeit and Holm-Müller, 2009; Martinelli and Filoso, 2008).

We have assumed exogenous development of different new bioenergy conversion technologies. These assumptions rely on a vast literature survey but cost estimates remain uncertain. The influence on model results is however limited as previous sensitivity studies have shown (Schmidt et al., 2010a). Influences of prices and GHG emissions of reference technologies mainly affect the competition between CHP and heat production in single building boilers and community district heating boilers.

Policy instruments that support the development of new technologies such as feed-in tariffs and biofuel policies may be less cost-effective than technology neutral instruments like carbon taxes. However, the former ones may be dynamically more efficient by promoting emerging technologies that allow substantial technological advances but still need $R \& D$ before being competitive to well established technologies. The applied 
methodology allows estimating the costs that have to be expected from these policy instruments and is able to identify a subset of technologies that may be worth to subsidize.

\subsection{Conclusions}

We presented a modeling approach to cost-effectively assess energy policy instruments and technologies as well as their impacts on the structure of bioenergy supply in Austria. The spatially explicit integration of the whole bioenergy supply chain, from biomass production to energy distribution, allows the integration of various important cost factors which are not covered by generalized energy system models. For instance, biophysical constraints are integrated in an economic biomass production optimization model to construct spatially explicit supply curves for different types of agricultural energy crops. The explicit assessment of the trade-off between food, feed and energy crop production is therefore possible and have been applied to the Austrian case. Spatially explicit estimation of energy demand allows to model energy distribution in detail, including the competition of district heating and natural gas networks.

The model results indicate that a carbon tax on all fossil fuels is cost-effective with regard to both policy targets, i.e. GHG emission reduction and fossil fuel substitution, if CCS is not available. A trade-off between the two targets exists if CCS is deployed on large scale. The missing of some sectors, particularly the private heating sector, in the ETS reduces its cost-effectiveness in comparison to a carbon tax on all fossil fuels. The cost-effectiveness of technology specific instruments can be ordered in the following way if CCS is not available: feed-in tariffs before subsidies to heating boilers before biofuel blending obligations. This ordering is robust to a change in fossil reference technologies with the exemption of the availability of a low cost heating technology, which 
makes the biofuel policy perform better than subsidies on heating boilers. The ordering of policy instruments with respect to fossil fuel substitution changes significantly if CCS is available. In this case, a carbon tax and ETS lead to large reductions in GHG emissions, but fossil fuel substitution is low. Feed-in tariffs show contrary results such that low GHG emission reductions and high amounts of fossil fuel substitution are achieved. Subsidies on heating boilers are in between the carbon policies and feed-in tariffs while the biofuel policy performs worse than all other policies with regard to both, $\mathrm{CO}_{2}$ emission reductions and fossil fuel substitution.

BECCS can deliver far higher GHG emission reductions than technologies without CCS. GHG emission reductions of $20 \%$ can be achieved in the case without CCS at the maximum $\mathrm{CO}_{2}$ emission price of $150 € \mathrm{tCO}_{2}^{-1}$ while $67 \%$ of $\mathrm{GHG}$ emissions are reduced in the case with CCS. Attaining very stringent GHG emission targets is therefore much easier when CCS is available. However, $20 \%$ of the fossil fuels are substituted at the maximum $\mathrm{CO}_{2}$ price without CCS while only $11 \%$ are substituted when CCS is available. Biofuel technologies do not play a significant role in policy scenarios without CCS, but methanol with CCS is a cost-effective mitigation option, because the fossil reference technology, i.e. fossil gasoline, does not allow CCS. The biofuel policy is costly and ineffective with regard to GHG emission reduction and fossil fuel substitution. Biofuel policies are often designed to attain not only energy policy targets but also foster rural economic development (Berndes and Hansson, 2007; Lehrer, 2009). Nevertheless, rural development goals can be more efficiently combined with energy policy goals if biomass resources are directed to other conversion chains than transportation fuel production, i.e. heat or power production. 
Forestry biomass is the preferred feedstock. In agriculture, mainly short rotation cellulose is chosen as feedstock while the use of other crops in ethanol and biodiesel production is limited. Results depend on the availability of BIGCC as power production technology. If BIGCC becomes commercially available, current feed-in tariffs should be directed specifically to large BIGCC projects instead of promoting CHP steam technology. Model results indicate that economics of scale of big production plants are higher than increasing transportation costs, i.e. big plant projects are less costly than small ones. This should be acknowledged in the design of future energy policies and our spatially explicit mixed integer program is able to account for it.

\section{Acknowledgements}

This article has been supported by the Austrian Climate Research Program project "Greenhouse Gas Reduction through Second Generation Biofuels in Austria (GHGSEBA)" as well as by the project "Energieversorgung aus Land- und Forstwirtschaft in Österreich unter Berücksichtigung des Klima- und Globalen Wandels in 2020 und 2040 (Energ.Clim)”. We are grateful to very valuable comments of two anonymous reviewers and want to thank the team of the Vienna Scientific Cluster (VSC) computer grid for the support when running the model scenarios on the VSC. 


\section{Appendix}

\section{Optimization model}

The MIP model builds on previous work (Leduc et al., 2010; Leduc et al., 2009; Schmidt et al., 2010b; Schmidt et al., 2010a) and minimizes the costs for supplying demand regions (index $k$ ) with different forms of energy products (index $d$ ) from either biomass plants or fossil fuels. Woody biomass and agricultural feedstock (index $b$ ) are transported from supply regions (index $i$ ) to possible plant locations (index $j$ ) where different conversion technologies (index $l$ ) may be employed to produce different commodities (index $c$ ). Plants of different size and type (index $l$ ) are allowed to assess the tradeoff between increasing costs due to increasing transportation distances and decreasing investment costs due to economies of scale with growing plant sizes. Biomass can also be transported to demand regions for direct use (e.g. burning of log wood in local furnaces).

Ethanol, methanol and pellets are transported to the demand regions by truck. Power is directly distributed to the power grid, while district heat is delivered to settlements (index $h$ ) using pipelines. District heating or gas networks of different sizes (index $n s$ ) have to be built in the settlements to allow heat or gas distribution. Bioenergy competes with fossil fuels (index $f$ ). The model is static and models one year of operation. All investment costs are annualized assuming an interest rate of $10 \%$ and 25 years of economical lifetime. Heating seasons (index $t$ ) are used to differentiate between seasonal heating demands. 
The total costs in the objective function $f(\mathrm{~b}, \mathrm{z}, \mathrm{q}, \mathrm{u})$ are minimized:

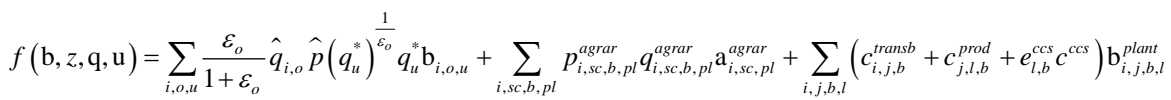

$$
\begin{aligned}
& +\sum_{i, k}\left(c_{i, k, b}^{\text {rransd }}+c_{k, b}^{\text {invd }}\right) \mathbf{b}_{i, k, b}^{\text {direct }}+\sum_{j, l} c_{j, l}^{\text {plant }} \mathbf{u}_{j, l}^{\text {plant }}+
\end{aligned}
$$

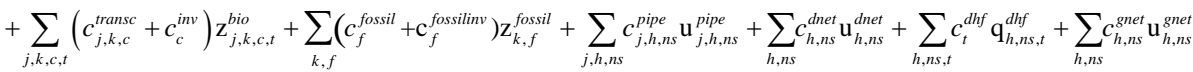

$$
\begin{aligned}
& +\sum_{h, n s, t} c_{t}^{g a s} q_{h, n s}^{g a s}+c^{e m} \text { emtaxed }
\end{aligned}
$$

where

$$
\begin{aligned}
& \operatorname{emtaxed}=t x^{s}\left(\sum_{i, j, b, l} e_{i, j, b}^{\text {trans }} \mathrm{b}_{i, j, b, l}^{\text {plant }}+\sum_{i, k, b} e_{i, k, b}^{\text {trans }} \mathrm{b}_{i, k, b}^{\text {direct }}+\sum_{j, k, c, t} e_{j, k, c}^{\text {rrans }} \mathrm{z}_{j, k, c, t}\right)+ \\
& \left(t x_{f}^{f} \sum_{k, f} e_{f}^{\text {fossil }} z_{k, f}^{\text {fossil }}+\sum_{h, n s, t} e^{g a s} \mathrm{q}_{h, n s, t}^{g a s}+\sum_{h, n s, t} e^{\text {dhf }} \mathrm{q}_{h, n s, t}^{\text {dhf }}-\sum_{i, j, b, l} e_{l}^{c c s} \mathrm{~b}_{i, j, b, l}^{\text {plant }}\right) \\
& \text { totem }=\text { emtaxed }+\sum_{i, s c, b, p l} e_{s c, b, p l}^{\text {agrar }} q_{i, s c, b, p l}^{\text {agrar }} a_{i, s c, p l}^{\text {agrar }}
\end{aligned}
$$

The different summands in the objective function represent:

1. Biomass supply costs from forests as described in section 2.2.

2. Agricultural supply costs as described in section 2.2.

3. biomass transportation costs (parameter $c_{i, j, b}^{\text {trans }}$ ) from supply to plant, variable bioenergy production costs (parameter $c_{j, l, b}^{\text {prod }}$ ) and carbon capture and storage costs (parameter $c^{c c s}$ times the amount of $\mathrm{CO}_{2}$ emissions captured by unit of biomass $e_{l, b}^{c c s}$ ) times the amount of feedstock (variable $\mathrm{b}_{i, j, b, l}^{\text {plant }}$ ).

4. Direct biomass transportation costs $\left(c_{i, k, b}^{\text {trans }}\right)$ from supply to demand (e.g. fuel wood), investment costs at demand ( $c_{k, b}^{\text {invd }}$, e.g. fuel wood boiler) times the amount of biomass transported directly to demand $\left(\mathrm{b}_{i, k, b}^{\text {direct }}\right)$. 
5. Annualized costs of plant investments (parameter $c_{j, l}^{\text {plant }}$ ) times the binary variable for plant selection $\left(\mathrm{u}_{j, l}^{\text {plant }}\right)$.

6. Costs for transporting energy commodities to demand regions (parameter $c_{j, k, c}^{\text {transc }}$ ) plus investment costs (parameter $c_{c}^{i n v}$ ) times the amount of commodities produced in each period (variable $\mathrm{z}_{j, k, c, t}^{b i o}$ ). Costs for power transportation and investment are zero as it is assumed that the power can be sold directly to the power grid. For ethanol, methanol and pellets, transportation costs from plants to demand regions by truck are considered. Investment costs $c_{c}^{\text {inv }}$ are zero for biofuels, because no additional investments are necessary to operate cars with ethanol or methanol. For pellets, the investment costs represent the investment costs for pellets boilers.

7. Costs for fossil fuels (parameter $c_{f}^{\text {fossil }}$ ) plus investment costs necessary at demand (parameter $c_{f}^{\text {fosilinv }}$ e.g. oil boiler) times the amount of fossil fuels used in a demand region (variable $\mathrm{z}_{k, f}^{\text {fossil }}$ ).

8. Annualized costs of building a pipeline from the plant to the settlement (parameter $\left.c_{j, h, p s}^{p p e}\right)$ times the binary variable for pipeline selection $\left(\mathrm{u}_{j, h, p s}^{\text {pipe }}\right)$.

9. Annualized costs for installing a district heating network in the settlement (parameter $c_{h, n s}^{\text {dnet }}$ ) times the binary variable for district heating network selection $\left(\mathrm{u}_{h, n s}^{\text {dnet }}\right)$.

10. Costs for producing fossil district heat (parameter $c_{t}^{\text {dhf }}$ ) times the amount of fossil district heat (variable $\mathrm{q}_{h, t}^{\text {dhf }}$ ) produced. 
11. Annualized costs for installing a gas network in the settlement (parameter $c_{h, n s}^{\text {gas }}$ ) times the binary variable for gas network selection $\left(\mathrm{u}_{h, n s}^{\text {gas }}\right)$.

12. Costs for natural gas ( $\left.c_{t}^{\text {gas }}\right)$ times the amount of natural gas consumed $\left(\mathrm{q}_{h, n s, t}^{\text {gas }}\right)$.

13. $\mathrm{CO}_{2}$ emissions (emtaxed) which consist of: (i) $\mathrm{CO}_{2}$ emissions of biomass transportation $\left(\mathrm{CO}_{2}\right.$ emission factor $\left.e_{i, j, b}^{\text {trans }}\right)$ from supply to plant, (ii) $\mathrm{CO}_{2}$ emissions of biomass transportation $\left(\mathrm{CO}_{2}\right.$ emission factor $\left.e_{i, j, b}^{\text {trans }}\right)$ from supply to demand, (iii) $\mathrm{CO}_{2}$ emissions of commodity transportation $\left(\mathrm{CO}_{2}\right.$ emission factor $\left.e_{j, k, c}^{\text {trans }}\right)$, (iv) $\mathrm{CO}_{2}$ emissions of fossil energy production $\left(\mathrm{CO}_{2}\right.$ emission factor $\left.e_{f}^{\text {fossil }}\right)$, (v) $\mathrm{CO}_{2}$ emissions of gas heat production $\left(\mathrm{CO}_{2}\right.$ emission factor $\left.e^{g a s}\right)$, (vi) $\mathrm{CO}_{2}$ emissions of fossil district heat production $\left(\mathrm{CO}_{2}\right.$ emission factor $\left.e^{\mathrm{dhf}}\right)$, and (vii) $\mathrm{CO}_{2}$ emission savings by BECCS in bioenergy production $\left(\mathrm{CO}_{2}\right.$ emission factor $e_{l}^{c c s}$ ). Those $\mathrm{CO}_{2}$ emissions ( empriced ) are multiplied by the $\mathrm{CO}_{2}$ price (parameter $\left.c^{e m}\right)$. Binary parameters $t x^{s}$ and $t x_{f}^{f}$ control if all fossil fuels or only part of the fossil fuels are taxed by a specific policy instrument.

14. Total greenhousegas emissions (empriced) are calculated as sum of $\mathrm{CO}_{2}$ emissions and as sum of $\mathrm{N}_{2} \mathrm{O}$ emissions from fertilizer application in agricultural production. The emission factor $e_{s c, b, p l}^{a g r a}$ describes the $\mathrm{CO}_{2}$ equivalent of $\mathrm{N}_{2} \mathrm{O}$ emissions.

The objective function in equation A1 is minimized subject to the following constraints. Forest biomass utilization is restricted by 
$\sum_{j, b, l, t} \mathrm{~b}_{i, j, b, l, t}^{\text {plant }}+\sum_{i, k, b} \mathrm{~b}_{i, k, b}^{\text {direct }} \leq \sum_{o, u} \hat{q}_{i, o}\left(q_{u}^{*}\right)^{\frac{1}{\varepsilon_{o}}} q_{u}^{*} b_{i, o, u}, b=$ forestwood

as described in section 2.2. The convexity condition necessary for the linearization of the supply curve is guaranteed by:

$\sum_{u} b_{i, o, u}=1$

Agricultural production is restricted by

$\sum_{j, b, l, t} \mathrm{~b}_{i, j, b, l, t}^{\text {plant }} \leq \sum_{c r, p l} q_{i, s c, b, p l}^{\text {agrar }} a_{i, s c, p l}^{\text {agrar }}, b \neq$ forestwood

as described in detail in section 2.2.

The convexity of the supply curves is guaranteed by

$\sum_{s c, p l} a_{i, s c, p l}^{a g r a r}=1$

The plant size constraints production by

$\sum_{i, b} \mathrm{~b}_{i, j, b, l, t}^{\text {plant }} \leq \bar{b}_{j, l, t} \mathbf{u}_{j, l}^{\text {plant }}$

where parameter $\bar{b}_{j, l, t}$ is the production capacity of plant $j$ in period $t$. Index $l$ indicates the size and technology of the plant (e.g. 50 MW steam CHP, 100 MW BIGCC). The commodity production in each period (variable $\mathrm{z}_{j, c, t}^{b i o}$ ) is determined by the biomass input and conversion efficiency (parameter $\eta_{j, b, l, c}^{\text {conv }}$ ) shown in the following equation:

$\sum_{i, l} \eta_{j, b, l, c}^{\text {conv }} \mathrm{b}_{i, j, b, l, t}^{\text {plant }}=\mathrm{z}_{j, c, t}^{\text {bio }}$. 
District heat production is modeled with variable $\mathrm{q}_{j}^{\text {bio }}$ because it is distributed differently than the other commodities:

$\sum_{i, b, l} \eta_{j, b, l}^{\text {heat }} \mathrm{b}_{i, j, b, l, t}^{\text {plant }}=\mathrm{q}_{j, t}^{\text {bio }}$,

where $\eta_{j, b, l}^{\text {heat }}$ is the conversion efficiency for heat. Distribution of commodities to demand regions $k$ is restricted by

$\sum_{k} \mathrm{z}_{j, k, c}^{b i o} \leq \sum_{t} \mathrm{z}_{j, c, t}^{b i o}$

where variable $\mathrm{z}_{j, k, c}^{b i c}$ denotes the amount of a commodity $c$ transported from plant location $j$ to demand region $k$.

Energy demands (parameter $d_{k, d}$ ) are satisfied by direct biomass utilization, different commodities from bioenergy production (variable $z_{j, k, c}^{b i o}$ ) and by fossil fuels (variable $\left.\mathbf{z}_{k, f}^{\text {fossil }}\right)$ :

$\sum_{i, b} \eta_{b, d}^{\text {biod }} \mathbf{b}_{i, k, b}^{\text {direct }}+\sum_{j, c} \eta_{c, d}^{\text {bio }} \mathbf{z}_{j, k, c}^{\text {bio }}+\sum_{f} \eta_{f, d}^{\text {fossil }} \mathbf{z}_{k, f}^{\text {fossil }}=d_{k, d}$.

In the equation, parameters $\eta_{b, d}^{\text {biod }}, \eta_{c, d}^{\text {bio }}$ and $\eta_{f, d}^{\text {fossil }}$ describe the efficiency of converting biomass, bioenergy commodities and fossil fuels to forms of useful energy.

Heat production limits the amount of heat available for district heating. Seasonal supply of heat in the plants is restricted by

$$
\sum_{h, p s} \mathrm{q}_{j, h, p s, t}^{d h} \leq \mathrm{q}_{j, t}^{b i o} .
$$


The production of heat by bioenergy plants $q_{j, h, n s, t}^{d h}$ plus the production of fossil district heating $\mathrm{q}_{h, n s, t}^{\mathrm{dhf}}$ and the production of heat in single-household gas fired boilers $\mathrm{q}_{h, n s, t}^{\text {gas }}$ has to meet the demand (parameter $q_{h, t}^{D}$ ) in each period, which is guaranteed by

$\eta_{h, t}^{\text {dh }}\left(\left(\sum_{j, p s} \eta_{j, h, n s, t}^{\text {trans }} \underset{j, h, n, t, t}{\text { dh }}\right)+\sum_{n s} \eta^{\text {dhf }} \mathrm{q}_{h, n s, t}^{\text {dhf }}\right)+\eta^{g a s} \mathrm{q}_{h, n s, t}^{g a s}=q_{h, t}^{D}$

where parameter $\eta_{j, h, h s, t}^{\text {trans }}$ denotes the heat losses in the pipe system from the plant to the settlement. Losses in the heat distribution network within the settlement are modeled by parameter $\eta_{h, t}^{d h}$. Parameters $\eta^{\text {dhf }}$ and $\eta^{\text {gas }}$ are introduced to describe conversion efficiencies of fossil district heating and gas fired boilers.

The sum of heat produced by the bioenergy plant and by the fossil district heating boiler has to match the district heating demand (parameter $q_{h, n s, t}^{D}$ ) in settlement $h$. This is modeled by

$\eta_{h, t}^{d h}\left(\left(\sum_{j, p s} \eta_{j, h, p s, t}^{\text {trans }} q_{j, h, p s, t}^{d h}\right)+\sum_{n s} \eta^{d h f} q_{h, s s, t}^{d h f}\right)=\sum_{n s} q_{h, n s, t}^{D} u_{h, n s}^{\text {dnet }}$.

The same is the case for gas-supplied settlements:

$\eta^{g a s} q_{h, n s, t}^{g a s}=q_{h, n s, t}^{D} u_{h, n s}^{g a s}$.

The existence of a transportation pipeline, in case a settlement is supplied by a bioenergy plant, is ensured by 
$\mathrm{q}_{j, h, n s, t}^{\mathrm{dh}} \leq \bar{q}_{n s, t}^{\text {pipe }} \mathrm{u}_{j, h, n s}^{\text {pipe }}$,

where parameter $\bar{q}_{p s, t}^{\text {pipe }}$ denotes the capacity of the pipeline.

The policy instruments are implemented in the following way: the price of carbon emissions is controlled by the value of $c^{e m}$. The binary parameters $t x^{s}$ and $t x_{f}^{f}$ control which $\mathrm{CO}_{2}$ emissions are taxed by the particular policy instrument. Feed-in tariffs are modeled by setting the fossil power price $c_{f}^{\text {fossil }}$ to the level of the tariff. The investment costs for pellet furnaces $c_{c}^{i n v}$ are decreased in the pellet subsidy scenario. The compliance with biofuel blending obligations is guaranteed by

$\sum_{j} z_{j, c}^{b i o} \geq f_{c, d}^{b l e n d} \sum_{k} d_{k, d}$

where $f_{c, d}^{b l e n d}$ is the mandatory share of a bioenergy commodity in total useful energy demand.

The MIP is finally defined as:

$\min [f(\mathrm{~b}, \mathrm{z}, \mathrm{q}, \mathrm{u})]$

s.t.

$(A 4)-(A 18)$

$0 \leq \mathrm{a}_{i, s c, p l}^{\text {agrar }}, \mathrm{b}_{i, o, u}, \mathrm{~b}_{i, k, b}^{\text {direct }}, \mathrm{b}_{i, j, b, l}^{\text {plant }}$, emtaxed, $\mathrm{q}_{j}^{\text {bio }}, \mathrm{q}_{j, h, p s, t}^{\text {dh }}, \mathrm{q}_{h, n s, t}^{\text {dhf }}, \mathrm{q}_{h, n s}^{\text {gas }}$, totem, $\mathbf{z}_{j, c}^{\text {bio }}, \mathrm{z}_{j, k, c, t}^{\text {bio }}, \mathrm{z}_{k, f}^{\text {fossil }}$,

$\mathrm{u}_{h, n s}^{\text {gnet }}, \mathrm{u}_{h, n s}^{\text {dnet }}, \mathrm{u}_{j, h, n s}^{\text {pipe }}, \mathrm{u}_{j, l}^{\text {plant }}, \in\{0,1\}$. 


\section{References}

Alfonso, D., Perpiñá, C., Pérez-Navarro, A., Peñalvo, E., Vargas, C. and Cárdenas, R., 2009. Methodology for optimization of distributed biomass resources evaluation, management and final energy use. Biomass and Bioenergy 33, 1070-1079.

Ammann, H., I, B. and Albisser Vögeli, G., 2009. Comparison of wood-fired heating systems. Agrarforschung 16, 64-69.

Azar, C., Lindgren, K. and Andersson, B.A., 2003. Global energy scenarios meeting stringent CO2 constraints - cost-effective fuel choices in the transportation sector. Energy Policy 31, 961-976.

Azar, C., Lindgren, K., Larson, E. and Möllersten, K., 2006. Carbon capture and storage from fossil fuels and biomass - costs and potential role in stabilizing the atmosphere. Climate Change 74, 47-79.

Azar, C., Lindgren, K., Obersteiner, M., Riahi, K., van Vuuren, D., den Elzen, K., Möllersten, K. and Larson, E., 2010. The feasibility of low CO2 concentration targets and the role of bio-energy with carbon capture and storage (BECCS). Climatic Change 100, 195-202.

Bacovsky, D., Dallos, M. and Wörgetter, M., 2010. Status of 2nd Generation Biofuels Demonstration Facilities in June 2010 - A Report to IEA Bioenergy Task 39.

Berndes, G. and Hansson, J., 2007. Bioenergy expansion in the EU: Cost-effective climate change mitigation, employment creation and reduced dependency on imported fuels. Energy Policy 35, 5965-5979.

Bonijoly, D., Fabbri, A., Chapuis, F., Laude, A., Ricci, O., Bauer, H., Grataloup, S. and Galiègue, X., 2009. Technical and economic feasibility of the capture and geological storage of $\mathrm{CO} 2$ from a bio-fuel distillery: CPER Artenay project. Energy Procedia 1, 3927-3934.

Bram, S., De Ruyck, J. and Lavric, D., 2009. Using biomass: A system perturbation analysis. Applied Energy 86, 194-201.

Bryan, B.A., King, D. and Wang, E., 2010. Biofuels agriculture: landscape-scale tradeoffs between fuel, economics, carbon, energy, food, and fiber. GCB Bioenergy 2, 330-345.

Cerqueira Leite, R.C.D., Verde Leal, M.R.L., Barbosa Cortez, L.A., Griffin, W.M. and Gaya Scandiffio, M.I., 2009. Can Brazil replace 5\% of the 2025 gasoline world demand with ethanol? Energy 34, 655-661.

COM, 2010. Energy 2020. A strategy for competitive, sustainable and secure energy, European Commission. 
Council, E., 2002. Council Decision of 25 April 2002 concerning the approval, on behalf of the European Community, of the Kyoto Protocol to the United Nations Framework Convention on Climate Change and the joint fulfilment of commitments thereunder, Official Journal.

Delzeit, R. and Holm-Müller, K., 2009. Steps to discern sustainability criteria for a certification scheme of bioethanol in Brazil: Approach and difficulties. Energy 34, 662-668.

Demirbas, A., 2006. Present and Future Transportation Fuels. Energy sources, Part A: Recovery, Utilization, and Enviornmental Effects 30, 1473-1483.

Dornburg, V. and Faaij, A., 2001. Efficiency and economy of wood-fired biomass energy systems in relation to scale regarding heat and power generation using combustion and gasification technologies. Biomass and Bioenergy 21, 91-108.

E-Control, 2009. Time Series of Power Production (Jahresreihen: Gesamte Elektrizitätsversorgung Aufbringung), E-Control.

Eriksson, L.O. and Björheden, R.W., 1989. Optimal storing, transport and processing for a forest-fuel supplier. European Journal of Operational Research 43, 26-33.

Faaij, A., 2006. Modern Biomass Conversion Technologies. Mitigation and Adaptation Strategies for Global Change 11, 335-367.

Federal Ministry of Agriculture, Forestry, Environment and Water Management, 2009. Logging Report 2008 (Holzeinschlagsmeldung 2008), Federal Ministry of Agriculture, Forestry, Environment and Water Management.

Federal Ministry of Agriculture, Forestry, Environment and Water Management, 2007. National Allocation Plan for Austria for the period 2008-2012 (Nationaler Zuteilungsplan für Österreich gemäß \& 11 Emissionszertifikategesetz für die Periode 2008-2012), Federal Ministry of Agriculture, Forestry, Environment and Water Management.

Gielen, D.J., Fujino, J., Hasimoto, S. and Moriguchi, Y., 2003. Modeling of global biomass policies. Biomass and Bioenergy 25, 177-195.

Grahn, M., Azar, C., Lindgren, K., Berndes, G. and Gielen, D., 2007. Biomass for heat or as transportation fuel? A comparison between two model-based studies. Biomass and Bioenergy 31, 747-758.

Grohnheit, P.E. and Mortensen, B.O.G., 2003. Competition in the market for space heating. District heating as the infrastructure for competition among fuels and technologies. Energy Policy 31, 817-826. 
Gustavsson, L., Mahapatra, K. and Madlener, R., 2005. Energy systems in transition: perspectives for the diffusion of small-scale wood pellet heating technology. International Journal of Technology Management 29, 327-347.

Hamelinck, C.N. and Faaij, A., 2001. Future prospects for production of methanol and hydrogen from biomass. Journal of Power sources 111, 1-22.

Havlík, P., Schneider, U.A., Schmid, E., Böttcher, H., Fritz, S., Skalský, R., Aoki, K., Cara, S.D., Kindermann, G., Kraxner, F., Leduc, S., McCallum, I., Mosnier, A., Sauer, T. and Obersteiner, M., 2010. Global land-use implications of first and second generation biofuel targets. Energy Policy, doi:10.1016/j.enpol.2010.03.030.

Hedenus, F., Karlsson, S., Azar, C. and Sprei, F., 2010. Cost-effective energy carriers for transport - The role of the energy supply system in a carbon-constrained world. International Journal of Hydrogen Energy 35, 4638-4651.

Hendriks, C. and Grais, W., 2004. Global Carbon Dixide Storage Potential and Costs, Ecofys.

Holloway, S., 1997. Safety of the Underground Disposal of Carbon dioxide. Energy conversion and Management 38, 241-245.

International Energy Agency, 2010. Carbon Capture and Storage - Progress and Next Steps, International Energy Agency.

International Energy Agency, 2009. World Energy Outlook, International Energy Agency.

Ivezic, D., Zivkovic, M., Tanskovic, T. and Dajic, N., 2008. An economic model for the appraisal and selection of energy supply system. Applied Thermal Engineering 29, 1440-1446.

Izaurralde, R., Williams, J., McGill, W., Rosenberg, N. and Jakas, M.Q., 2006. Simulating soil $\mathrm{C}$ dynamics with EPIC: Model description and testing against long-term data. Ecological Modelling 192, 362-384.

Jensen, P.A. and Bard, J.F., 2002. Operations Research Models and Methods, Wiley.

Kalt, G., Kranzl, L. and Haas, R., 2010. Long-term strategies for an efficient use of domestic biomass resources in Austria. Biomass and Bioenergy 34, 449-466.

König, A., 2011. Cost efficient utilisation of biomass in the German energy system in the context of energy and environmental policies. Energy Policy 39, 628-636.

Konstantin, P., 2007. Handbook energy industry (Praxisbuch Energiewirtschaft), Berlin: Springer Berlin Heidelberg. 
Kranzl, L. and Haas, R., 2008. Strategies for the optimal development of biomass potentials in Austria until the year 2050 aiming at a maximal reduction of green house gas emissions (Strategien zur optimalen Erschließung der Biomassepotenziale in Österreich bis zum Jahr 2050 mit dem Ziel einer maximalen Reduktion an Treibhausgasemissionen), Energy Economics Group, University of Technology Vienna.

Kraxner, F., Nilsson, S. and Obersteiner, M., 2003. Negative emissions from BioEnergy use, carbon capture and sequestration (BECS) - the case of biomass production by sustainable forest management from semi-natural temperate forests. Biomass and Bioenergy 24, 285-296.

Lange, J., 2007. Lignocellulose conversion: an introduction to chemistry, process and economics. Biofuels, Bioproducts and Biorefining 1, 39-48.

Lapola, D.M., Schaldach, R., Alcamo, J., Bondeau, A., Koch, J., Koelking, C. and Priess, J.A., 2010. Indirect land-use changes can overcome carbon savings from biofuels in Brazil. Proceedings of the National Academy of Sciences 107, 33883393.

Leduc, S., Schmid, E., Obersteiner, M. and Riahi, K., 2009. Methanol production by gasification using a geographically explicit model. Biomass and Bioenergy 33, 745-751.

Leduc, S., Schwab, D., Dotzauer, E., Schmid, E. and Obersteiner, M., 2008. Optimal location of wood gasification plants for methanol production with heat recovery. International Journal of Energy Research 32, 1080-1091.

Leduc, S., Starfelt, F., Dotzauer, E., Kindermann, G., McCallum, I., Obersteiner, M. and Lundgren, J., 2010. Optimal location of lignocellulosic ethanol refineries with polygeneration in Sweden. Energy 35, 2709-2716.

Lehrer, N., 2009. (Bio)fueling farm policy: the biofuels boom and the 2008 farm bill. Agriculture and Human Values 27, 427-444.

Lindfeldt, E.G. and Westermark, M.O., 2009. Biofuel production with CCS as a strategy for creating a CO2 -neutral road transport sector. Energy Procedia 1, 4111-4118.

Luckow, P., Wise, M., Dooley, J. and Kim, S., 2010. Large-scale utilization of biomass energy and carbon dioxide capture and storage in the transport and electricity sectors under stringent $\mathrm{CO} 2$ concentration limit scenarios. International Journal of Greenhouse Gas Control 4, 865-877.

Magné, B., Kypreos, S. and Turton, H., 2010. Technology Options for Low Stabilization Pathways with MERGE. The Energy Journal 31, 83-108.

Marbe, G., Harvey, S. and Berntsson, T., 2004. Biofuel gasification combined heat and 
power-new implementation opportunities resulting from combined supply of process steam and district heating. Energy 29, 1117-1137.

Martinelli, L.A. and Filoso, S., 2008. Expansion of sugarcane ethanol production in Brazil: environmental and social challenges. Ecological Applications 18, 885-898.

Möllersten, K., Gao, L. and Yan, J., 2006. CO2 Capture in Pulp and Paper Mills: CO2 Balances and Preliminary Cost Assessment. Mitigation and Adaptation Strategies for Global Change 11, 1129-1150.

Möllersten, K., Gao, L., Yan, J. and Obersteiner, M., 2004. Efficient energy systems with CO2 capture and storage from renewable biomass in pulp and paper mills. Renewable Energy 29, 1583-1598.

Möllersten, K., Yan, J. and R. Moreira, J., 2003. Potential market niches for biomass energy with $\mathrm{CO} 2$ capture and storage--Opportunities for energy supply with negative CO2 emissions. Biomass and Bioenergy 25, 273-285.

Nakicenovic, N., Haas, R., Schleicher, S.P., Klettner, C., Kletzan, D., Köppl, A. and Türk, A., 2008. Assessment of Austrian contribution toward EU 2020 Target Sharing, Austrian Institute of Economic Research WIFO.

Nass, L.L., Pereira, P.A.A. and Ellis, D., 2007. Biofuels in Brazil: An Overview. Crop Sci 47, 2228-2237.

Obersteiner, M., Azar, C., Kauppi, P., Möllersten, K., Moreira, J., Nilsson, S., Read, P., Raiahi, K., Schlamadinger, B. and Yamagata, Y., 2001. Managing climate risk. Science 294, 786-787.

OECD, 2009. OECD-FAO Agricultural Outlook 2009, OECD Publishing.

ÖROK, 2009. Scenarios for the spatial and regional development of Austria in the European context (Szenarien der Raumentwicklung Österreichs 2030. Regionale Herausforderungen und Handlungsstrategien, Wien 2009 ), Österreichische Raumordnungskonferenz (ÖROK).

Paoletta, M.S. and Taschini, L., 2006. An Econometric analysis of Emission Trading Allowances, Swiss Finance Institute.

Polagye, B.L., Hodgson, K.T. and Malte, P.C., 2007. An economic analysis of bioenergy options using thinnings from overstocked forests. Biomass \& Bioenergy 31, 105-125.

Pope, J. and Owen, A.D., 2009. Emission trading schemes: potential revenue effects, compliance costs and overall tax policy issues. Energy Policy 37, 4595-4603.

Rhodes, J.S. and Ketih, D.W., 2005. Engineering economic analysis of biomass IGCC 
with carbon capture and storage. Biomass \& Bioenergy 29, 440-450.

Richard, T.L., 2010. Challenges in Scaling Up Biofuels Infrastructure. Science 329, 793796.

Roeckner, E., Giorgetta, M., Crueger, T., Esch, M. and Pongratz, J., 2010. Historical and future anthropogenic emission pathways derived from coupled climate-carbon cycle simulations. Climatic Change, 1-18.

Sandén, B.A. and Azar, C., 2005. Near-term technology policies for long-term climate targets-economy wide versus technology specific approaches. Energy Policy 33, 1557-1576.

Sandy Thomas, C., 2009. Transportation options in a carbon-constrained world: Hybrids, plug-in hybrids, biofuels, fuel cell electric vehicles, and battery electric vehicles. International Journal of Hydrogen Energy 34, 9279-9296.

Schadauer, K., 2009. Wood and Biomass Study (Holz- und Biomassenstudie). BFW Praxis Information 18.

Schmid, E. and Sinabell, F., 2007. On the choice of farm management practices after the reform of the Common Agricultural Policy in 2003. Journal of Environmental Management 82, 332-340.

Schmidt, J., Leduc, S., Dotzauer, E., Kindermann, G. and Schmid, E., 2010a. Costeffective $\mathrm{CO} 2$ emission reduction through heat, power and biofuel production from woody biomass: A spatially explicit comparison of conversion technologies. Applied Energy 87, 2128-2141.

Schmidt, J., Leduc, S., Dotzauer, E., Kindermann, G. and Schmid, E., 2010b. Potential of biomass-fired combined heat and power plants considering the spatial distribution of biomass supply and heat demand. International Journal of Energy Research 34, 970-985.

Schwarzbauer, P., 1997. Austria. In B. Solberg, ed. Demand and supply analyses of roundwood and forest products markets in Europe. Helsinki: Proceedings of the 1st Workshop of the Concerted Action Project AIR3 - CT942288.

Schwarzbauer, P. and Stern, T., 2010. Energy vs. material: Economic impacts of a "wood-for-energy scenario" on the forest-based sector in Austria -- A simulation approach. Forest Policy and Economics 12, 31-38.

Searchinger, T., Heimlich, R., Houghton, R.A., Dong, F., Elobeid, A., Fabiosa, J., Tokgoz, S., Hayes, D. and Yu, T., 2008. Use of U.S. croplands for Biofuels Increases Greenhouse Gases Through Emissions from Land Use Change. Science 319, 1238-1240. 
Semelsberger, T.A., Borup, R.L. and Greene, H.L., 2006. Dimethyl ether (DME) as an alternative fuel. Journal of Power Sources 156, 497-511.

Statistik Austria, 2009a. Dwellings 2009, Results of the dwellings survey in the microcensus, yearly mean 2009 (Wohnen 2009, Ergebnisse der Wohnungserhebung im Mikrozensus Jahresdurchschnitt 2009).

Statistik Austria, 2009b. Energy bilances 1970-2008 (Energiebilanzen 1970-2008), Statistik Austria.

Statistik Austria, 2010. Price of products in agriculture and forestry 2003-2009 (Land und forstwirtschaftliche Erzeugerpreise 2003-2009), Statistik Austria.

Statistik Austria, 2009. Total use of energy sources (Gesamteinsatz aller Energieträger 2003/2004-2007/2008), Statistik Austria.

Steenhof, P.A. and McInnis, B.C., 2008. A comparison of alternative technologies to decarbonize Canada's passenger transportation sector. Technological Forecasting and Social Change 75, 1260-1278.

Sues, A., Jurascík, M. and Ptasinski, K., 2010. Exergetic evaluation of 5 biowastes-tobiofuels routes via gasification. Energy 35, 996-1007.

Thek, G. and Obernberger, I., 2004. Wood pellet production costs under Austrian and in comparison to Swedish framework conditions. Biomass \& Bioenergy 27, 671693.

Thistle, D., Sedlacek, L., Carman, K.R., Fleeger, J.W., Bewer, P.G. and Barry, J.P., 2006. Simulated sequestration of industrial carbon dioxide at a deep-sea site: Effects on species of harpacticoid copepods. Journal of Experimental Marine Biology and Ecology 330, 151-158.

Torekov, M.S., Bahnsen, N. and Qvale, B., 2007. The relative competitive positions of the alternative means for domestic heating. Energy 32, 627-633.

Tzimas, E. and Georgakaki, A., 2010. A long-term view of fossil-fuelled power generation in Europe. Energy Policy 38, 4252-4264.

Uddin, N.S. and Barreto, L., 2007. Biomass-fired cogeneration systems with CO2 capture and storage. Biomass \& Bioenergy 32, 1006-1019.

Umweltbundesamt Austria, 2010. Austria's National Inventory Report 2010, Umweltbundesamt Austria.

UNFCCC, 2006. Updated UNFCCC reporting guidelines on annual inventories following incorporation of the provisions of decision 14/CP.11, United Nations. 
de Vries, S.C., van de Ven, G.W., van Ittersum, M.K. and Giller, K.E., 2010. Resource use efficiency and environmental performance of nine major biofuel crops, processed by first-generation conversion techniques. Biomass and Bioenergy 34, 588-601.

Wahlund, B., Yan, J. and Westermark, M.O., 2004. Increasing biomass utilization in energy systems: A comparative study of $\mathrm{CO} 2$ reduction and cost for different bioenergy processing options. Biomass and Bioenergy 26, 531-544.

Williams, J.R., 1995. The EPIC Model. In V. P. Singh, ed. Computer Models of Watershed Hydrology. Highlands Ranch, Colorado: Water Resources Publications, pp. 909-1000.

van der Zwaan, B. and Gerlagh, R., 2009. Economics of geological CO2 storage and leakage. Climate Change 93, 285-309. 


\title{
Land use, greenhouse gas emissions and fossil fuel substitution of biofuels compared to bioelectricity production for electric cars in Austria
}

\author{
Johannes Schmidt ${ }^{1, *}$, Viktoria Gass ${ }^{1}$, Erwin Schmid ${ }^{1}$ \\ ${ }^{1}$ Institute for Sustainable Economic Development, University of Natural Resources and Life Sciences, Vienna, \\ Austria \\ * Corresponding author. Tel: +43 650 2151579, Fax: +43 1 47654-3692, E-mail: johannes.schmidt@boku.ac.at
}

\begin{abstract}
Bioenergy is one way of achieving the indicative target of $10 \%$ renewable energy outlined in the EU Directive 2009/28/EC. This paper assesses the consequences for land use, greenhouse gas (GHG) emissions and fossil fuel substitution of increasing the use of bioenergy for road transportation. Different technologies, including first and second generation fuels and electric cars fuelled by bio-electricity are assessed in relation to existing bioenergy uses for heat and power production. The paper applies a spatially explicit energy system model that is coupled with a biomass production model to allow estimating impacts of increased biomass utilization for energy production on agriculture and forestry. Uncertainty is explicitly considered with the help of Monte-Carlo simulations of input parameters. Results indicate that second generation fuels perform better with respect to land use than first generation ethanol and that costs are lower. Biodiesel is also a cheap option, although the total potential is limited at a low level due to constraints in feedstock production. Electric vehicle mobility minimizes land use, however, costs are still high and prohibitive. First generation ethanol production is effective in reducing domestic GHG emissions because it does not induce feedstock competition with existing bioenergy uses (i.e. heat and power production). However, land use change is significant.
\end{abstract}

Keywords: biofuels, electric cars, e-mobility, 2020 goals, spatially explicit optimization

\section{Introduction}

Directive 2009/28/EC requires all member states of the EU to guarantee a share of $10 \%$ of renewable fuels in transportation by 2020. The target may be reached by various measures, including an increase in the share of biofuels and an increase in the share of renewably produced electricity in the transportation sector. However, since the large scale introduction of biofuels in the US and Europe an extensive discussion has evolved because the large land requirements were identified as cause for direct and indirect greenhouse gas (GHG) emissions [1], [2] and as the driver for increasing competition between food and fuels [3], [4]. In Austria, bioenergy has played traditionally an important role. It provided around $8 \%$ of the primary energy demand in 2006, mainly for heating purposes [5]. Other uses of bioenergy developed in recent years, include biofuel and power production. Austria has complied with the 5.75\% indicative EU biofuel target since late 2008 and used around 4.00 TWh of biodiesel and 0.60 TWh of ethanol in 2008 [6]. A further increase of the supply of biofuels will be difficult to achieve, particularly if only domestic biomass supply is considered. However, new technologies are emerging that aim to increase biofuel productivity and diversify feedstock supply. Second generation biofuels that may use ligno-cellulosic feedstock for fuel production are regarded as a sustainable alternative to first generation biofuels which are mainly produced from food and feed crops [2], [7]. A technological alternative is electric cars. Technical and economical barriers currently prevent the large scale introduction of electric cars, however, future potentials are considered significant [8], [9]. Electric cars will only contribute to renewable energy targets if the electricity for cars is produced in a renewable manner. Biomass is one possible source for this purpose. An existing study estimates [10] that the 
utilization of biomass resources for electricity generation and subsequent utilization in electric cars is a far more effective way of using limited land resources for transportation than the conversion of food and feed crops to first generation ethanol. However, the assessment relied merely on technical details without considering economics and alternative uses of biomass in the energy sector - e.g. for heating. This paper contributes to research by applying a spatially explicit agricultural-bioenergy-system model to evaluate several technological options for the transportation sector, including first and second generation fuels and electric cars, with respect to land use, GHG emissions and fossil fuel substitution. The techno-economic characteristics of future biofuel production as well as of electric cars are not well known yet. Also, high uncertainty is attached to future price energy scenarios. We therefore apply a MonteCarlo simulation of input parameters to explicitly include uncertainty in the modeling process.

\section{Methodology}

\subsection{Model and Model Boundaries}

A spatially explicit, techno-economic mixed integer program is developed and applied to assess the costs, land use and GHG emissions of different bioenergy conversion routes. The model minimizes the costs of supplying Austria with transportation fuels, heat and electricity from either bioenergy or fossil fuels. It is static and simulates one year of operation. The current model version considers domestic biomass supply and energy demand only and does not allow imports and exports of biomass or bioenergy commodities. The model determines which bioenergy plants of a specific size and specific location shall be built and which demand regions are supplied with bioenergy and/or with fossil fuels. Each plant produces various energy commodities, e.g. the heat produced in a combined heat and power (CHP) may be delivered to district heating networks (Figure 1). By-products of biofuel plants are sold as animal feed. Biomass supply curves endogenously determine the price of feedstock from forestry and agriculture, while prices of fossil fuels and energy demand are defined exogenously. Taxes currently applied to both fossil and bioenergy fuels are not included in the model.

\subsection{Technologies}

We assess several bioenergy technologies which are able to replace fossil fuels in the transportation sector along with technologies that convert biomass to heat and power. First generation biofuels are classified into ethanol produced from fermentation of starchy and sugar crops (e.g. wheat and corn) and biodiesel which is produced from vegetable oil derived

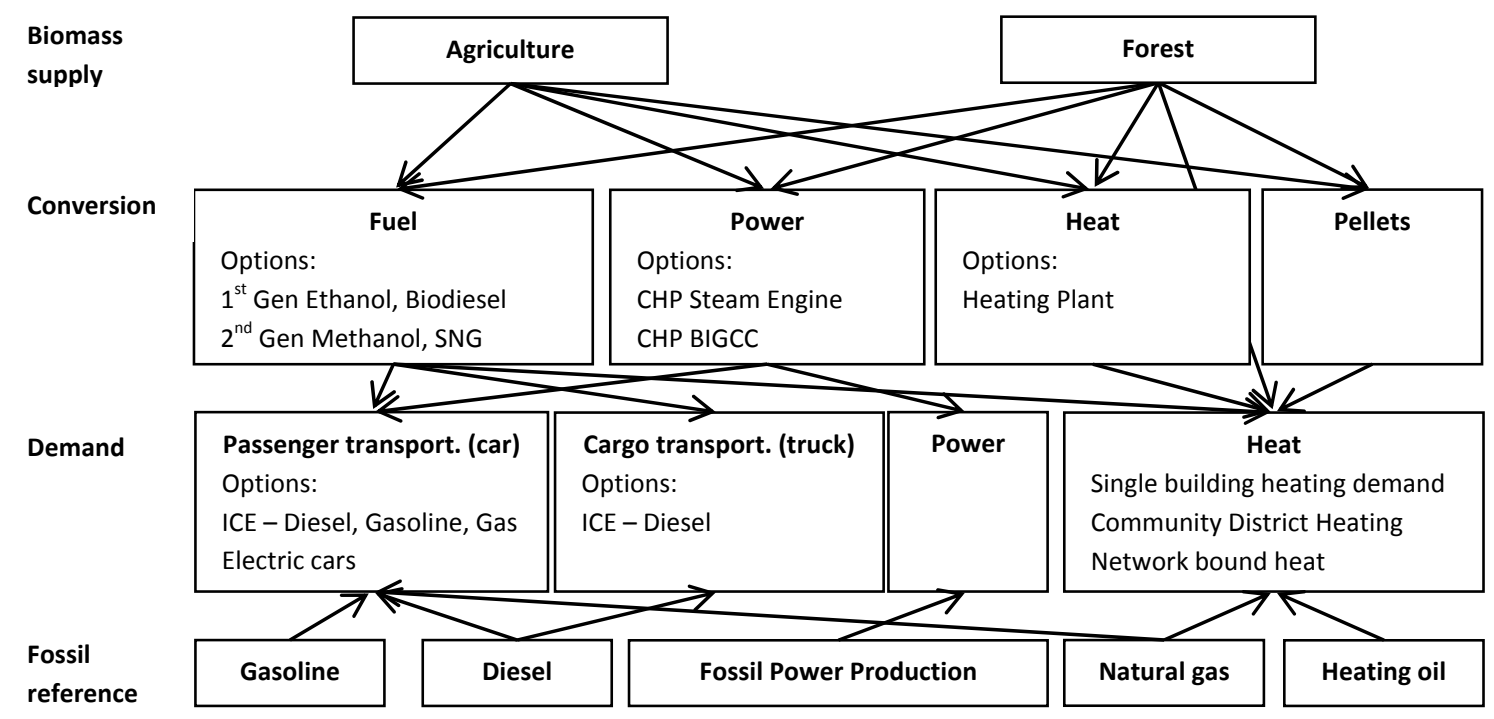

Figure 1: Diagram of the mixed integer programming model. 
from oil crops (e.g. sunflower and rapeseed). Both technologies are commercially available and are currently used for the production of biofuels in Austria. Ethanol is blended with gasoline. A blend of 5\% ethanol and 95\% gasoline is considered safe to be used in all cars, while all cars sold currently on the market are also able to handle a blend of $10 \%$ of ethanol. Similar limitations apply to biodiesel [11]. Second Generation biofuels are able to use cellulosic feedstock and even waste for the production of biofuels. There are two major technological options [7]. The biomass can be gasified and subsequently upgraded to liquid transportation fuels such as methanol or synthetic natural gas (SNG) which can also be used as transportation fuel. The second option is the hydrolysis of cellulose to sugars that are fermented to ethanol afterwards. We assess gasification only as it is estimated to be economically more viable than hydrolysis with fermentation [12], [7]. Second generation production technologies are currently under research and first pre-commercial installations are being built. US legislation requires 572 TWh of yearly cellulosic biofuel production until 2022 [13], therefore a rapid increase in the construction of second generation facilities can be expected. Current cars cannot run solely on methanol and the amount of methanol that may be blended to gasoline is, similar to ethanol, limited. SNG requires significant modifications to the car, including the installation of a gas tank. Electric cars are currently globally under research, however, costs and ranges of batteries are major economic and technical obstacles to full implementation of the technology. Ranges of above $150 \mathrm{~km}$ are currently only achieved at very high costs [9]. Also, electric cars need the large scale deployment of charging stations. Metering of power and billing still has to be developed. The model considers investment costs for electric cars. Costs associated with additional infrastructure necessary for electric cars are not included. With respect to power production, the model allows two technologies: steam engines and biomass integrated gasification combined cycle (BIGCC) plants. While steam engines are well established in Austria and the installed capacity exceeded $300 \mathrm{MW}$ in 2007 [5], BIGCC is a technology that is still under research. It allows higher electrical conversion efficiencies than steam engines but capital costs are also significantly higher. We assume that power can be either used to fuel electric cars or that it is simply sold on the electricity market at a fixed price. Heating technologies modelled include fuel wood furnaces, pellet furnaces and heating plants for district heating networks.

\subsubsection{Total Cost of Ownership - Cars}

We use the concept of total cost of ownership (tco) to assign different costs to different cars in the model. Costs for fuels are endogenously determined by the model and are therefore not included in the calculations of tco. The tco per $\mathrm{km}$ is described by equations (1)-(3):

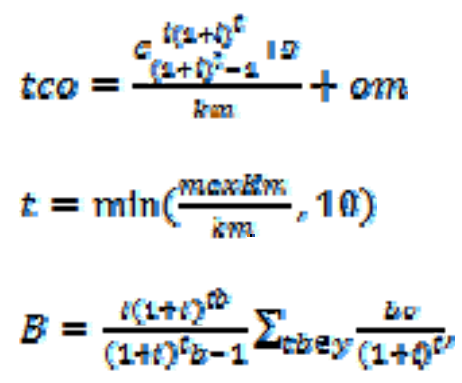

The tco is determined by the annuity of capital costs $C$ of the car, assuming an interest rate $i$ and a lifetime $t$. For electric cars, the battery $\operatorname{cost} B$ is additionally considered as explained below. Total necessary yearly investment costs are divided by the kilometres $\mathrm{km}$ driven annualy. Additionally, operation \& management costs per $\mathrm{km}$ of om are assumed. These costs are assumed to be lower for electric cars because maintenance of the electric motor is less complex than for an internal combustion engine (ICE) [9]. The lifetime of the car is limited to 
ten years, however, if the car is driven a lot (i.e. more than $\operatorname{maxKm}$ ), the lifetime is further reduced as indicated by equation (2). The lifetime of a battery is significantly less than that of the carriage. A change of the battery within the lifetime is therefore probable and is modelled by equation (3): the annuity of battery costs is derived by adding up the discounted battery costs over the whole life time, assuming that one battery costs $b c$. The battery is changed in year $y$ when the driven kilometres since the last change exceed the lifetime of the battery. The tco depends significantly on the kilometres driven each year. A higher amount of kilometres implies lower specific capital costs per $\mathrm{km}$. We therefore estimate ten classes of annual car utilization based on data provided by ÖAMTC. ÖAMTC, the biggest Austrian Automobile Association, checks approximately $10 \%$ of all cars for their technical liability each year. The total driven kilometers and the year of the first registration of the car are collected in the examination of the cars. An approximate estimate of the yearly driven kilometers can be derived from this data. We classified the cars by the annual driven kilometers into ten classes (0 km - 10,000 km, 10,001 km - 20,000 km, ..., 90,000 km - 100,000 km). For each class, the mean of the yearly driven kilometers by car and the mean of the sum of driven kilometers by all cars in the class are determined. The sum of driven kilometers is linearly extrapolated from the ÖAMTC data with data of total Austrian car ownership from Statistik-Austria to allow an estimate for whole Austria as ÖAMTC data only covers around 10\% of all registered cars.

\subsection{Demand}

We estimate current transportation demand from the ÖAMTC data and assume that the demand for transportation remains constant until 2020. We assume a total of 60 billion annual kilometres for personal transportation and total of 24 billion tonne kilometres for cargo transportation by truck. Although transportation fuel consumption has historically seen significant increases in the last years, the increase was significantly caused by "tank tourism" due to lower fuel taxes in Austria. We exclude demand from "tank tourism" from our analysis and also assume that public transportation will take a higher share of the overall transportation supply, thus allowing that road transportation remains constant. While the model allocates biomass resources to various conversion routes depending on energy prices and production costs, the demand for biomass heating is assumed to not fall under 17 TWh in the simulations. This is a possible decline of 5 TWh from current consumption levels. Setting a lower bound for biomass consumption for heating is reasonable because adjustment of individual heating devices to new economic conditions generally takes a lot of time.

\subsection{Uncertainty}

Most of the parameters in the study are of high uncertainty. Uncertainties on the performance and costs of various technologies as well as uncertainty about future energy prices are high. We explicitly address this issue by performing Monte-Carlo simulations of the MIP model and conducting an extensive sensitivity analysis. We first define plausible ranges for the uncertain parameters from a literature research and assume that the parameters are distributed uniformly within that range. For energy and $\mathrm{CO}_{2}$ prices, correlation between the prices of oil, gas, gasoline and $\mathrm{CO}_{2}$ are determined from historical spot prices. The input data for the Monte-Carlo simulation is generated by performing a Latin Hypercube Sampling procedure and combining it with the Iman-Conover method to guarantee correlation of correlated parameters in the procedure [14]. Latin Hypercube Sampling is used to guarantee that the whole parameter range is covered in the Monte-Carlo simulations. Results are given in form of probability distributions and a stepwise regression analysis is performed to examine the sensitivity of results to input parameters. The assumption on the distribution of the most important parameters is reported in Table 1. Further parameters modelled stochastically are biomass costs, conversion efficiencies and investment costs of bioenergy plants. 
Table 1: Main model parameters and uncertainty ranges

\begin{tabular}{lcc}
\hline & Lower Bound & Upper Bound \\
\hline Price of oil $\left(€ \mathrm{MWh}^{-1}\right)$ & 40 & 60 \\
Price of gas $\left(€ \mathrm{MWh}^{-1}\right)$ & 30 & 50 \\
Price of gasoline $\left(€ \mathrm{MWh}^{-1}\right)$ & 42 & 62 \\
Price of electricity $\left(€ \mathrm{MWh}^{-1}\right)$ & 54 & 74 \\
Price of carbon $\left(€ \mathrm{MWh}^{-1} \mathrm{tCO}_{2}^{-1}\right)$ & 21 & 55 \\
Battery costs $(€)$ & 4,000 & 6,500 \\
Replacement distance battery $(\mathrm{km})$ & 70,000 & 90,000 \\
Investment costs electric cars $(\mathrm{w} / \mathrm{o}$ battery) $(€)$ & 14,000 & 16,500 \\
Investment costs gasoline cars $(€)$ & 16,500 & 16,500 \\
Investment costs diesel cars $(€)$ & 17,000 & 17,000 \\
Investment costs gas cars $(€)$ & 17,500 & 17,500 \\
O\&M costs electric car $\left.(€ \mathrm{~km})^{-1}\right)$ & 0.02 & 0.025 \\
Conversion efficiency car $-\mathrm{Gasoline}\left(\mathrm{km} \mathrm{MWh}_{\text {fuel }}{ }^{-1}\right)$ & 2,000 & 2,200 \\
Conversion efficiency car - Diesel $\left(\mathrm{km} \mathrm{MWh}_{\text {fuel }}{ }^{-1}\right)$ & 2,250 & 2,450 \\
Conversion efficiency electric car $\left(\mathrm{km} \mathrm{MWh}_{\text {elec }^{-1}}\right)$ & 5,600 & 7,000 \\
\hline
\end{tabular}

\subsection{Scenarios}

We model one baseline scenario, that assumes no policy intervention at all, and 7 policy scenarios. Three of the scenarios assume that 5\% (S5), 10\% (S10) and 15\% (S15) of the transportation sector are supplied by bioenergy, allowing all technologies to be selected by the model. The other four scenarios examine the impact of a $10 \%$ target of renewable transportation fuels, if only single technologies (i.e. ethanol (eth), methanol (met), sng (sng), electric mobility (emo)) are allowed. Biodiesel is not modelled in these scenarios because domestic feedstock production is too low to supply $10 \%$ of the transportation sector with biofuels.

\section{Results}

\subsection{Technologies and fuel utilization}

The first three scenarios allow free choice of technologies. Biodiesel and methanol supply the biofuels in these scenarios. Biodiesel is however limited at around 0.5 TWh due to restrictions in feedstock supply of oil-crops. Second generation methanol is the supplement to biodiesel to complete the full target. E-Mobility plays a role in the first three scenarios - however, variation is very high and the contribution is significantly lower than that of methanol. Ethanol and SNG are not selected in the first three scenarios. These results indicate that methanol production can be considered superior to ethanol in terms of costs - although the variation of results is generally high, the dominance of methanol over ethanol is stable. Competing bioenergy technologies (i.e. heating and power production) are mainly reduced in S15, met and SNG. This is due to the high demands for woody biomass for biofuel production which increases prices for the feedstock and therefore makes production of power and heat partly unprofitable. The ethanol scenario has less influence on the woody biomass market as ethanol feedstock competes with food and feed crops. Biodiesel is mainly used in the freight sector where it substitutes diesel. Ethanol and methanol are used for personal transportation in driving classes with low annual distances because fixed capital costs contribute more to the total costs of transportation in those classes than the distance dependent fuel costs. Higher classes with higher annual driving distances are more likely to be supplied by electric cars where the influence of the high capital costs of the car and the battery decrease and the fuel costs become more important. 

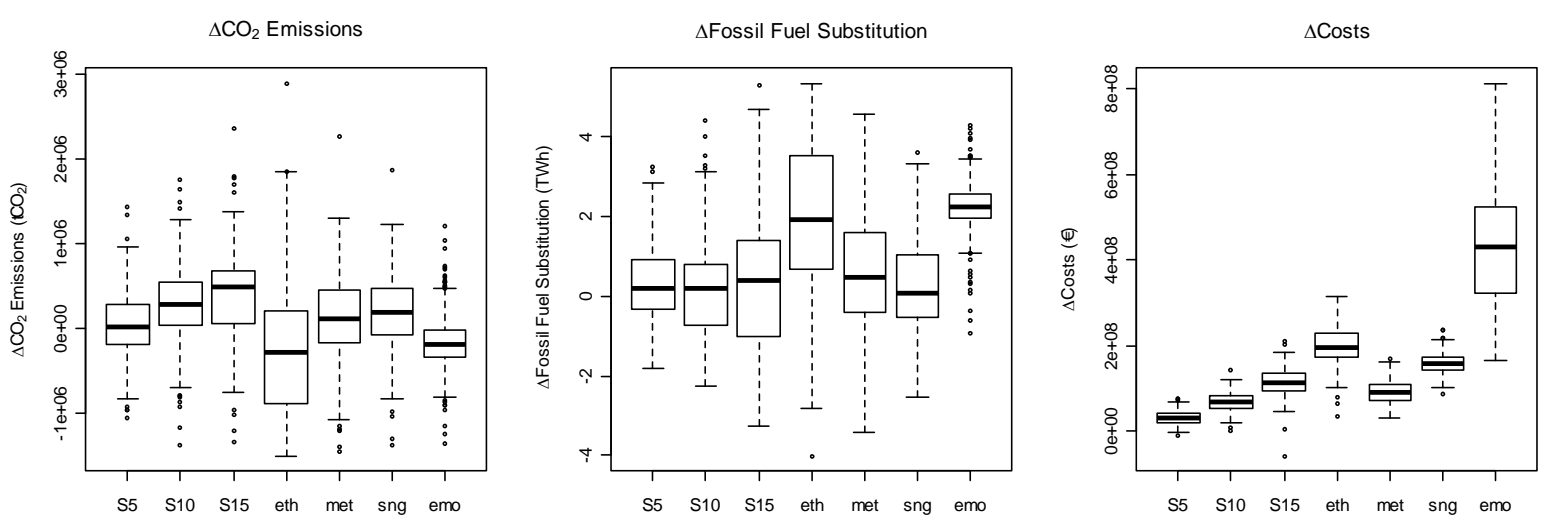

Fig. 2: Differences in $\mathrm{CO}_{2}$-Emissions, Fossil Fuel Substitution and Costs between the baseline and the biofuel scenarios.

\section{2. $\mathrm{CO}_{2}$ Emissions, Fossil Fuel Substitution and Costs}

Figure 2 shows $\mathrm{CO}_{2}$ emissions, fossil fuel substitution and costs calculated as the difference from the baseline scenario. A significant reduction in $\mathrm{CO}_{2}$ emissions and an increase in fossil fuel substitution are achieved by the eth and the emo scenario. These two scenarios also have highest costs. The variance of costs is highest in emo due to the large uncertainties in the development of the costs of electric vehicles. However, the model only considers domestic GHG emissions while effects of indirect land use change on GHG emissions are not modeled.

\subsection{Land use}

While the eth policy substitutes a lot of fossil fuels, the land use effects are also substantial in comparison to the other policy scenarios (See Figure 3). Up to 200,000 ha of agricultural land are converted to energy crop production while all other scenarios stay well below 50,000 ha. This implies that food and feed production is reduced significantly in the eth scenario while all other policies have rather low impacts on the production of other agricultural products. There are two reasons for this: first, productivity is higher for second generation fuels and for electric mobility due to higher total conversion efficiencies (see Figure 3). Second, these technologies rely on lignocellulose resources that may come from additional forest harvesting or that may otherwise be used for power and heat production (see Figure 3, bottom-right). There are also important differences between the S10, met, sng and emo scenarios. Combining biodiesel and methanol for the biofuel goals as in $S 10$ reduces land use change in comparison to the methanol only scenario. Biodiesel therefore plays a small, but important role in the technological portfolio. Figure 3 shows that $S N G$ is more efficient in converting biomass than methanol. Electric mobility has by far the lowest impact on land use change and on additional forest wood utilization.
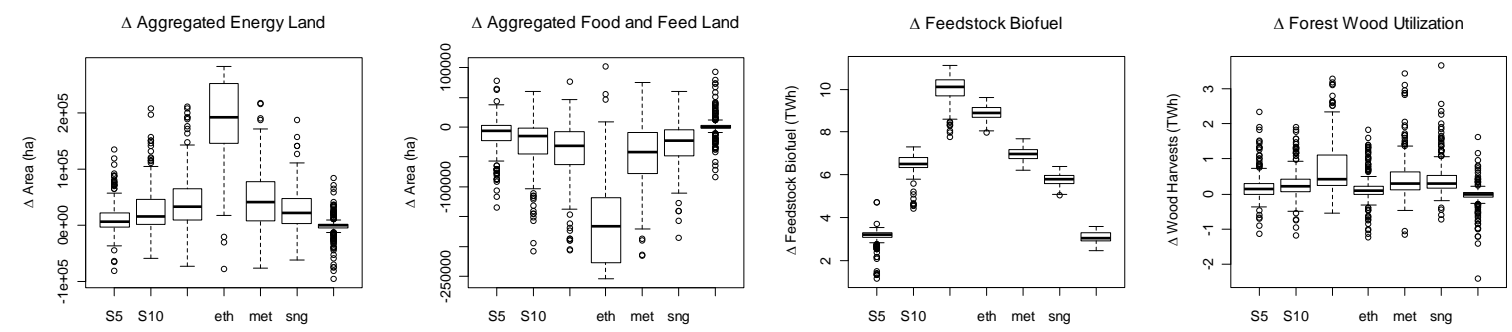

Fig. 3: Differences in Land Use, Feedstock Utilization and Forest Wood utilization between the baseline and policy scenarios. 


\subsection{Sensitivity Analysis}

Table 2 show the results of the sensitivity analysis performed on the results of the S15 scenario. We checked for the influence of parameters on the deployment of electric mobility to show which factors mainly influence the competition between second generation fuels and electric mobility by performing a regression of the input parameters on the output variables (a stepwise regression procedure is used). The regression coefficients are normalized. The most important input parameters regard the cost for the electric car (i.e. battery costs, investment costs, O\&M). The carbon price and the kilometers until replacement of battery also prove to significantly influence the results while the gasoline price does not show significant influence on results.

\section{Discussion}

Results of our study are in line with other studies that estimate lower land use for bio-electriccars than for biofuel production [10]. They are also in line with studies that come to the conclusion that battery replacement costs are currently the biggest economic barrier to the large scale introduction of electric mobility in the transportation sector [8], [9]. However, there are additional barriers to electro-mobility that were not modelled within this study: the change from cars that are refuelled at gas stations in very short time to cars that need hours of recharging and that have a comparably low driving range probably plays a more important role than sole considerations of the tco. The model results indicate that drivers who use their car a lot are more likely to choose electric cars than those with low car utilization because of lower fuel costs. However, technical reasons may impede the utilization of electric cars for those drivers: the low range and the high recharging times may render electric cars impractical for them. With respect to economics, renewable electricity production from wind or small water power plants may produce electricity at much more competitive costs than biomass powered thermal plants. Therefore, electric cars may be more competitive than stated in this study due to lower fuel costs from renewables. The GHG emission effects of biofuel policies have to be considered in conjunction with the land use change that is caused by the expansion of biofuel production. The GHG emissions stated in this paper do not include indirect or leakage effects of the policies. However, it can be clearly stated that fuelling electric cars with electricity produced from biomass induces by far the least change of land use and can therefore be considered to also minimize leakage effects.

Table 2: Results of sensitivity analysis. Confidence levels: *** 0.999, **0.99 and *0.95

\begin{tabular}{lcc}
\hline & Coefficient & \\
\hline Amount of electric mobility $\left(\mathbf{R}^{2} \mathbf{0 . 4 9}\right)$ & & $* * *$ \\
Battery Costs & -0.54 & $* * *$ \\
Investment costs electric car & -0.12 & $*$ \\
O\&M costs electric car & 0.08 & \\
Gasoline price & 0.15 & $* *$ \\
Kilometers until replacement of battery & 0.17 & $* *$ \\
Carbon price & \\
\hline
\end{tabular}

\section{Conclusions}

Second generation biofuels have less impact on land use than first generation ethanol due to two reasons: yields of biofuel per hectare are higher for agricultural land and the feedstock may additionally come from forests. Biodiesel has high yields per hectare, but the total domestic potential is limited at a low level. The lowest land use is implied by the utilization of electric cars, which, at current technological standards, are still very costly in comparison to 
cars fuelled by liquid fuels. With respect to policies for promoting second generation biofuel production, one has to consider that investments in second generation biofuel production will have a long-term effect on the utilization of biomass resources. The results of the study indicate, however, that the gains in efficiency in relation to first generation fuels are relatively low while significant efficiency increases can only be expected when developing a transportation system based on electricity. A large scale introduction of second generation biofuels has to be considered very carefully therefore and in the light of a possible total restructuring of the transportation sector within the next 20 to 30 years.

\section{References}

[1] T. Searchinger et al., "Use of U.S. croplands for Biofuels Increases Greenhouse Gases Through Emissions from Land Use Change,” Science, vol. 319, no. 5867, pp. 12381240, 2008.

[1] P. Havlík et al., "Global land-use implications of first and second generation biofuel targets,” Energy Policy, p. doi:10.1016/j.enpol.2010.03.030, 2010.

[3] B. A. Bryan, D. King, and E. Wang, "Biofuels agriculture: landscape-scale trade-offs between fuel, economics, carbon, energy, food, and fiber,” GCB Bioenergy, vol. 2, no. 6, pp. 330-345, 2010.

[1] P. Dauvergne and K. J. Neville, "Forests, food, and fuel in the tropics: the uneven social and ecological consequences of the emerging political economy of biofuels," Journal of Peasant Studies, vol. 37, no. 4, p. 631, 2010.

[1] L. Kranzl and R. Haas, Strategies for the optimal development of biomass potentials in Austria until the year 2050 aiming at a maximal reduction of green house gas emissions (Strategien zur optimalen Erschließung der Biomassepotenziale in Österreich bis zum Jahr 2050 mit dem Ziel einer maximalen Reduktion an Treibhausgasemissionen). Energy Economics Group, University of Technology Vienna, 2008.

[1] R. Winter, Biokraftstoffe im Verkehrssektor in Österreich 2008 (Biofuels in the transportation sector in Austria 2008). Umweltbundesamt, 2010.

[1] J. Lange, "Lignocellulose conversion: an introduction to chemistry, process and economics,” Biofuels, Bioproducts and Biorefining, vol. 1, no. 1, pp. 39-48, 2007.

[8] C. Sandy Thomas, "Transportation options in a carbon-constrained world: Hybrids, plug-in hybrids, biofuels, fuel cell electric vehicles, and battery electric vehicles," International Journal of Hydrogen Energy, vol. 34, no. 23, pp. 9279-9296, 2009.

[9] C. Thiel, A. Perujo, and A. Mercier, "Cost and CO2 aspects of future vehicle options in Europe under new energy policy scenarios,” Energy Policy, vol. 38, no. 11, 2010.

[10] J. E. Campbell, D. B. Lobell, and C. B. Field, "Greater Transportation Energy and GHG Offsets from Bioelectricity Than Ethanol,” Science, vol. 324, no. 5930, pp. 1055-1057, 2009.

[11] O. van Vliet, M. van den Broek, W. Turkenburg, and A. Faaij, “Combining hybrid cars and synthetic fuels with electricity generation and carbon capture and storage,” Energy Policy, vol. 31, no. 1, 2011.

[12] S. Bram, J. De Ruyck, and D. Lavric, "Using biomass: A system perturbation analysis," Applied Energy, vol. 86, no. 2, pp. 194-201, 2009.

[13] Environmental Protection Agency, Regulation of Fuels and Fuel Additives: Changes to Renewable Fuel Standard Program; Final Rule. 2010.

[14] A. Saltelli and MAT, Sensitivity Analysis. Chichester [u.a.]: Wiley, 2000. 


\title{
How can Austria Increase its Biofuel Production?
}

\author{
Sylvain Leduc ${ }^{\mathrm{a}}$, Johannes Schmidt ${ }^{\mathrm{b}}$, Erik Dotzauer $^{\mathrm{c}}$ \\ a International Institute for Applied Systems Analysis, Schlossplatz 1, A-2361 Laxenburg, Austria \\ ${ }^{b}$ University of Natural Resources and Applied Life Sciences, Peter Jordan Straße 82, A-1190 Vienna, Austria \\ ${ }^{c}$ Mälardalen University, P.O. Box 883, SE-72123 Västerås, Sweden
}

\begin{abstract}
The target set by the European Union for Austria is to reach a share of 34\% of energy from renewable resources by the year 2020. Significant efforts are then required and second generation biofuels may be an option. In order to be competitive to fossil fuel, second generation biofuel would be produced at large scale. Logistics for feedstock and biofuel transportation becomes then an issue, and the location of the production plant is of major importance. By finding out the optimal location of the biofuel production plant, this work analyses the biofuel potential for Austria.

A mixed integer linear programm is used to determine the possible location of biofuel production plants, their capacity, and the technology. The complete forestry market of Austria is considered by the integration into the model of the actual location and wood demand of all the existing forest industries. Depending of the availability and access to the feedstock, second generation methanol or/and ethanol production plant can be set up. A complete road and railway network for Austria is also implemented into the model. The biofuel potential is then studied in regards with the wood availibility, a carbon cost and the price of fossil fuel for transportion. Forestry wood and poplar plantations are considered as feedstcock.

The results show that methanol prodcution plants are selected over ethanol production plants when the availibilty of feedstock becomes scarcer. With today's wood consumption in Austria, and today's fossil fuel price, up to 14.4 PJ of biofuel could be produced. Setting a carbon cost, forces the production of biofuel to a limit of $40 \mathrm{PJ}$ biofuel, and an increase of the wood demand by $25 \%$ would limit the biofuel production to $20 \mathrm{PJ}$ if poplar plantations is added into the system. Two locations are of high interest for the methanol production plants which are in the vicinity of
\end{abstract}


Salzburg and Amstetten, whereas the ethanol production plants are mainly located close to areas of high heat demand.

\section{Introduction}

The European Union has set a target of $34 \%$ for the share of energy from renewable sources in gross final consumption of energy by the year 2020 for Austria. Thisrepresents an increase of 11 percentage points compared to the year 2005 [1]. To meet this target, significant efforts are necessary [2], and the use of forestry wood appears to be an atractive pathway [3]. This study inquires the biofuel production potential in Austria under consideration of the competition of wood from other forest industries. For this analises, a spatially explicit optimization model is used to determine the optimal distribution of wood between the different wood industries, the capacity and location of possible biofuel production plants. This study is a follow up analysis from the work done by [4,5]. [5] assessed the cost-effectiveness of various energy policy instruments with respect to greenhouse gas (GHG) emission reductions and fossil fuel substitution under consideration of new bioenergy technologies for the year 2030 while [4] compared various options of introducing renewable energy into the transportation sector. Both analyses show clearly that second generation biofuel production uses land more efficiently for biofuel production than first generation biofuels. The applied model is however rather coarse with respect to logistics: the road network is not considered, instead Euclidian distances between biomass supply sites and plant sites are assumed. Also, major suppliers of energy wood, such as the sawnwood industry, are not considered in a spatially explicit way. The competition for wood is modeled by a generic wood supply curve that does not allow drawing conclusions for specific competitors of forestry products, such as the pulp \& paper and wood board industry.

This study extends the results from [4] and [5] by improving the logistics of the model: a complete road and railway network and the locations of all the woody biomass based industries in Austria are spatially explicitly integrated in the analysis. The effect of the change in the wood demand from the competing forest industries and the cost of second generation biofuel production are assessed. The aim of this research is to allow insights into optimal siting of second generation biofuel plants and the effect of forestry wood competition on the economically feasible biofuel potential in Austria. 


\section{Methodology}

\subsection{Model improvement}

A mixed integer linear model has been used to detemine the biofuel protential in Austria. The techno-economic, spatially explicit model determines the optimal location and capcity of biofuel production plants. A complete description of the model can be found in [6-8].

The actual version of the model in this study considers the complete wood market in Austria as described in Figure 1. The position and wood demand of the actual wood based industries are considered in the model, such as combined heat and power plants (CHP), pellet plants, pulp and paper mills, district heating plants and private fuel wood consumption. The total cost of the full supply chain of the system (Figure 1) is minimized. As presented in Figure 1, the plants can be supplied by roundwood or residuals from the sawmill industries. The wood demand from the actual woody based industries has to be met, and if the amount of available wood is sufficient, a biofuel production plant is set up in case the biofuel produced is economically interesting in comparison to the fossil fuel price. The model will determine the optimal number of production plants, their capacity and the type of biofuel that can be produced.

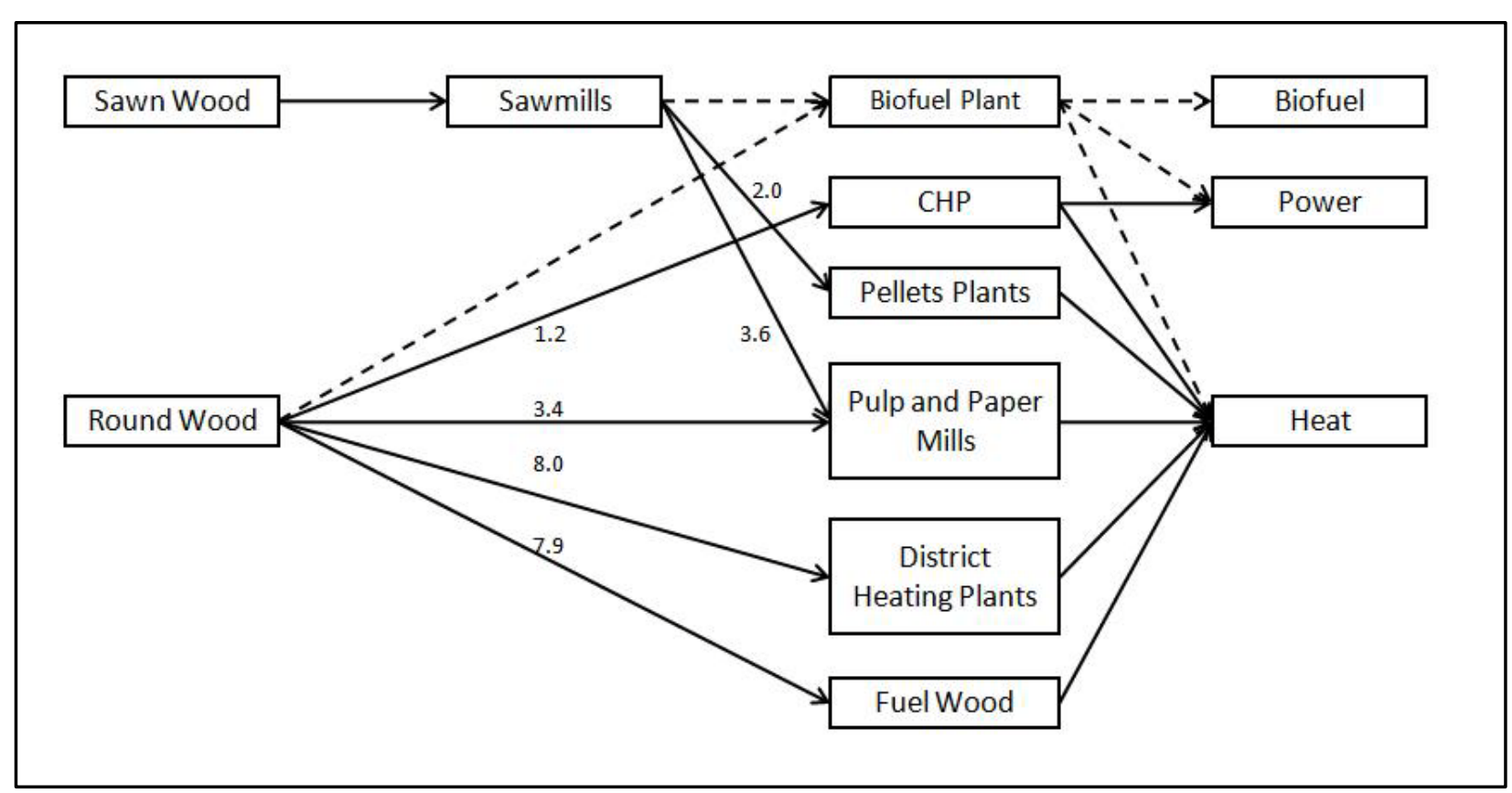

Figure 1: Forest wood conversion route. The dashed lines are potential routes if the amount of biomass is sufficient after meeting the wood demand from the actual woody based industries. The numbers (in million $\mathrm{m}^{3}$ ) represent the amount of wood necessary from each actual woody based industry [9]. 
This version of the model has also been upgraded with a full road and train network map for Austria. From the midle of each grid point, the distance to the closest road is determined. Then the distance from one grid point to any other grid point is determined by the shortest distance that can be travelled with the combination of truck and train. Both the feedstock and the biofuel can be transported either by truck or/and train. For a distance below $200 \mathrm{~km}$, only truck is used, for higher distances, train can be used if the railway network allows it.

\subsection{Input data}

\subsubsection{Feedstock}

The production of forestry wood is calculated from the G4M model [10] on a square kilometer grid. For each grid point, the amount of roundwood and sawnwood is determined as well as the cost for harvesting the wood and transporting it on the side of the closest road. The potential of forest yield is around 32 milion $\mathrm{m}^{3}$ for round wood at an average cost of $50 € / \mathrm{m}^{3}$ [10].

Beside roundwood from forestry and sawmill residuals, agricultural poplar can be used as feedstock for energy purposes. Biomass growth on agricultural land under different management options and crop rotations is simulated with the biophysical process model EPIC (Environmental Policy Integrated Climate) $[11,12]$. The total potential from the poplar plantation provides an additional 2.3 million $\mathrm{m}^{3}$ of energy wood on 156,000 ha of land. An average cost of $25 € / \mathrm{m}^{3}$ is assumed for the poplar plantations. All data is then agregated to a 0.2 degree grid, which gives a total of 310 grid points all over Austria.

\subsubsection{Energy demand}

The biofuel demand is calculated regarding the national transportation fuel consumpation and the number of inhabitants at each grid point. The national consumption in Austria is 183 liters per capita in the year 2007 [13]. It is assumed that power can be produced on site and then sold to the electricity network grid. The heat demand has been calculated from $[14,15]$, and only the locations where the fossil fuel heat can be substituted into bio-heat are taken into consideration. 


\subsubsection{Technology}

This study is a follow up and based on the work from [5]. The same assumptions are therefore made. The same biomass data is used, and the same energy demand grid is used. The feasibility of second generation metanol and ethanol in Austria is analysed. Table 1presents the key factors used in the model for the two technologies studied.

Table 1: Key factors for the production of methanol [16-18] and ethanol [19].

\begin{tabular}{|l|c|c|c|}
\hline Key factors & Unit & $\begin{array}{c}\text { Methanol } \\
\text { (Gasification) }\end{array}$ & $\begin{array}{c}\text { Ethanol } \\
\text { (Hydrolysis and } \\
\text { Fermentation) }\end{array}$ \\
\hline Fuel efficiency & $\mathrm{GJ}_{\text {biofuel }} / \mathrm{GJ}_{\text {biomass }}$ & 0.58 & 0.243 \\
\hline Heat efficiency & $\mathrm{GJ}_{\text {heat }} / \mathrm{GJ}_{\text {biomass }}$ & 0.08 & 0.176 \\
\hline Power efficiency & $\mathrm{GJ}_{\text {electricity }} / \mathrm{GJ}_{\text {biomass }}$ & - & 0.085 \\
\hline Biogas efficiency & $\mathrm{GJ}_{\text {biogas }} / \mathrm{GJ}_{\text {biomass }}$ & - & 0.132 \\
\hline Base plant size & $\mathrm{MW}_{\text {biomass. }}$ & 388 & 100 \\
\hline Investment cost & $\mathrm{M} €$ & 505 & 11.0 \\
\hline Operation cost & $€ / G J_{\text {biofuel }}$ & 6.13 & 100 \\
\hline
\end{tabular}

\subsection{Simulations}

Former studies on a similar topic have extensively analysed the strong effect of the biomass price, heat demand or production characteristics (investment costs, production efficiency) on the biofuel cost and the location of the biofuel production plants [7, 8, 20,21]. For this analysis, those parameters are kept constant, and only the influence of three external factors to the supply chain is analysed: $\mathrm{CO}_{2}$ cost, Fossil fuel price and wood demand. The $\mathrm{CO}_{2}$ cost represents the $\mathrm{CO}_{2}$ emission cost, for example a $\mathrm{CO}_{2}$ tax or tradable emission permits. Fossil fuel represents transportation fossil fuel only. The wood demand represents the wood demand from the already existing woody based industries, the change in wood demand is the same for all of those industries whithout any specific distinction. Table 2 presents the range of the values for those parameters and the increment used for the simulations. 210 simulations were run for all different combinations possible of all values for these three parameters. Runs with and whithout poplar plantations were also computed. 
Table 2: Parameters studied.

\begin{tabular}{|l|c|c|c|c|}
\hline Parameters & Unit & Min & Increment & Max \\
\hline $\mathrm{CO}_{2}$ cost & $€ / \mathrm{t}_{\mathrm{cO} 2}$ & 0 & 25 & 150 \\
\hline Fossil fuel price & $€ / \mathrm{GJ}$ & 15 & 5 & 40 \\
\hline Wood demand* & $\%$ & 0 & 25 & 125 \\
\hline
\end{tabular}

\section{Results and discussion}

\subsection{Fossil fuel price and biofuel production}

The influence of the wood demand from the existing wood industries in Austria on the biofuel (ethanol and methanol) production is presented in Figure 2 for different fossil fuel prices ranging from $15 € / \mathrm{GJ}$ to $40 € / \mathrm{GJ}$. As the demand of wood is increasing the production of biofuel is decreasing, due to a higher feedstock demand. As the fossil fuel price increases, the amount of biofuel produced increases for the same wood demand, letting the biofuel technology beeing more competitive: i.e. at 50\% wood demand, $40 \mathrm{PJ}$ of biofuel can be produced if a $35 € / \mathrm{GJ}$ fossil fuel price is set, whereas $120 \mathrm{PJ}$ of biofuel can be produced if the fossil fuel price increases to 40 $€ /$ GJ. At the present situation (wood demand 100\%, and fossil fuel price between 30 and 35 $€ / G J)$ up to 14.4 PJ biofuel could be produced if only forestry wood was used, whereas 25.5 PJ of biofuel could be produced if both poplar plantations and forestry wood were used.

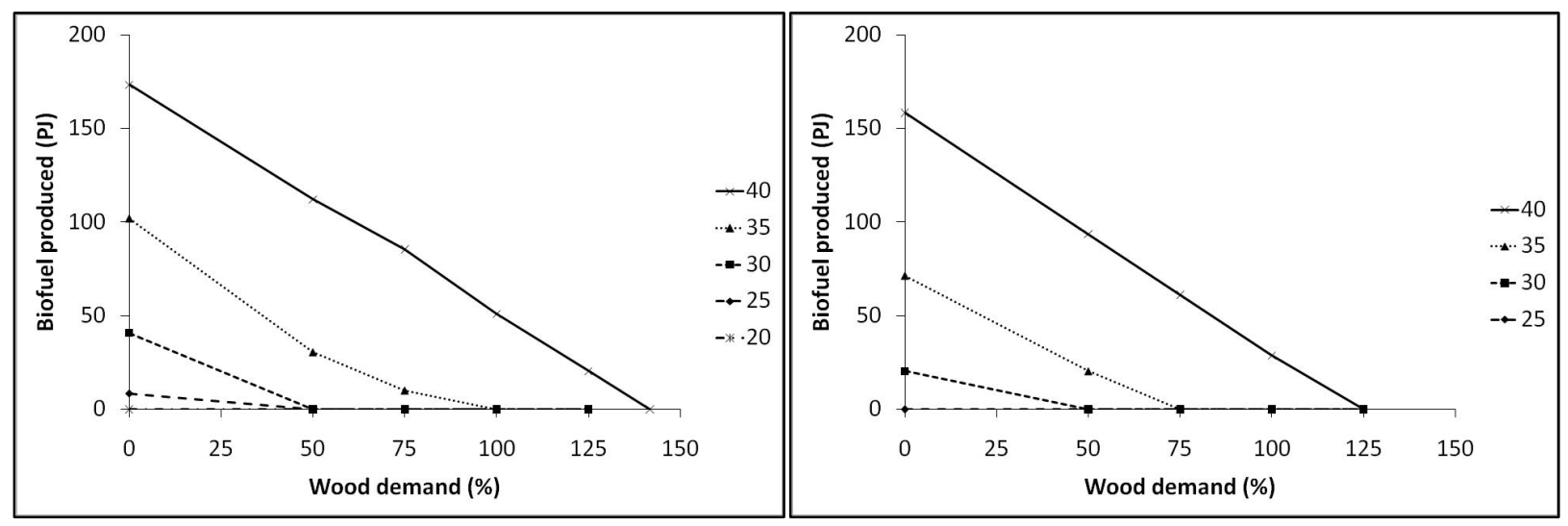


Figure 2: Influence of the wood demand on the biofuel (ethanol and methanol) production for five fossil fuel price $(€ / G J)$ scenarios (carbon cost $0 € / t_{\mathrm{CO} 2}$, with poplar plantations and forestry wood (left), and with forestry wood only (right)).

\section{2. $\mathrm{CO}_{2}$ cost and biofuel production}

The influence of a $\mathrm{CO}_{2}$ cost on the biofuel production is illustrated by Figure 3, left side. The situation at a $\mathrm{CO}_{2}$ cost of $0 € / \mathrm{t}_{\mathrm{CO} 2}$ corresponds to the situation in Figure 2 for a fossil fuel price of $20 € /$ GJ. Setting a $\mathrm{CO}_{2}$ cost over $25 € / t_{\mathrm{CO} 2}$ imposes the production of biofuel. With a $\mathrm{CO}_{2}$ cost applied, the production of biofuel is limited to $40 \mathrm{PJ}$ for a wood demand up to $100 \%$. Over that limit, the biofuel producion decreases. Figure 3, right side, presents the share of methanol produced at a certain wood demand and $\mathrm{CO}_{2}$ cost. Untill a wood demand of $75 \%$, there is as much methanol as ethanol produced. For a wood demand of $100 \%$, the share of methanol produced is between $71-90 \%$ depending of the $\mathrm{CO}_{2}$ tax imposed, and it reaches a share of $100 \%$ for a wood demand of $125 \%$ : as the feestock becomes scarcer, it becomes more interesting to invest in methanol as the overall efficiency is greater than the ethanol efficiency.
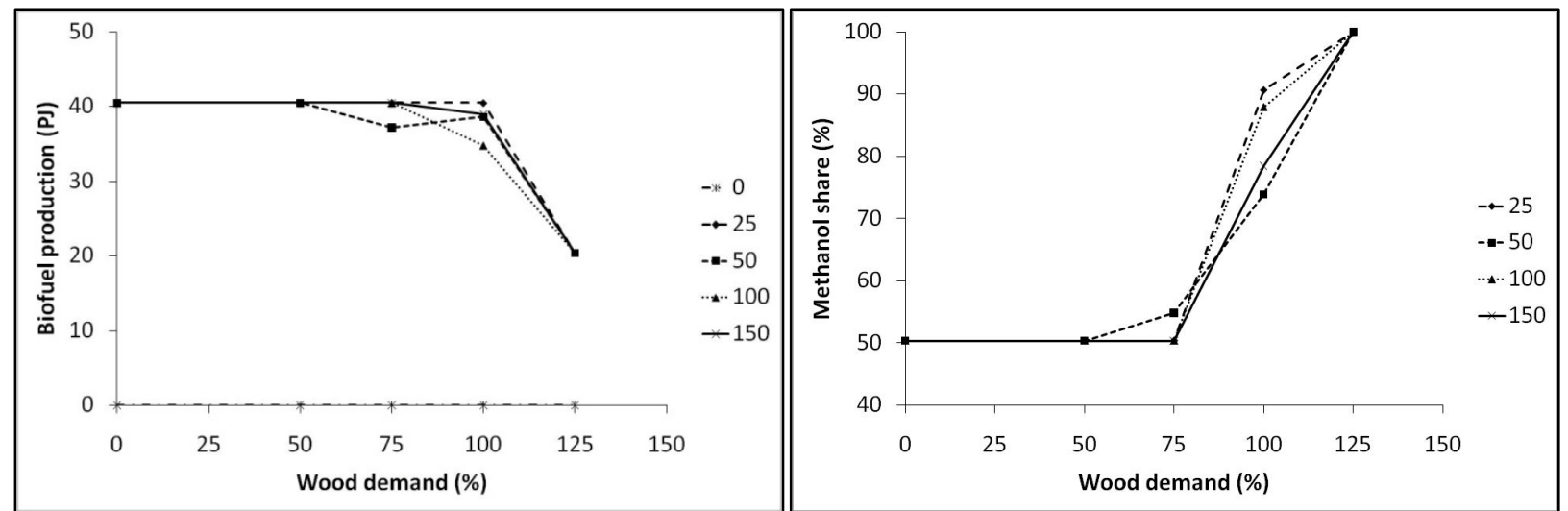

Figure 3: Left: influence of the wood demand on the biofuel production; right: influence of the wood demand on the methanol production, for four carbon cost $\left(€ / t_{\mathrm{CO} 2}\right)$ scenarios. (Fossil fuel price $20 € / G J$, feddstock used: forestry wood and poplar plantations).

The corresponding biofuel costs to Figure 3 are presented in Figure 4 for both methanol (left) and ethanol (right). The biofuel cost corresponds to the sum of the costs from transportation, feedstock, biofuel production, and income from carbon subsidies. As the wood demand increases 
the biofuel cost increases too: the transportation distances for collecting the feedstock increases as the wood demand is increasing. The methanol cost varies whithin a range of $5 € / G J$, whereas the ethanol cost varies within a range of $7 € / G J$. The later is indeed much sensible to income from the by-products, and therefore the location of the plant is of high importance in order to make use of the residual heat. For a wood production of $100 \%$, a methanol cost between 15 and $20 € / \mathrm{GJ}$ can be reached whereas the cost of ethanol can reach $19-28 € / \mathrm{GJ}$.

As the $\mathrm{CO}_{2}$ cost increases, the biofuel cost decreases. This is due to the income from $\mathrm{CO}_{2}$ permits or $\mathrm{CO}_{2}$ tax exemptions. If those incomes were not consired in the cost, the biofuel costs would remain constant whatever the carbon cost applied as the biofuel production does not change for different $\mathrm{CO}_{2}$ cost scenarios (see Figure 3).

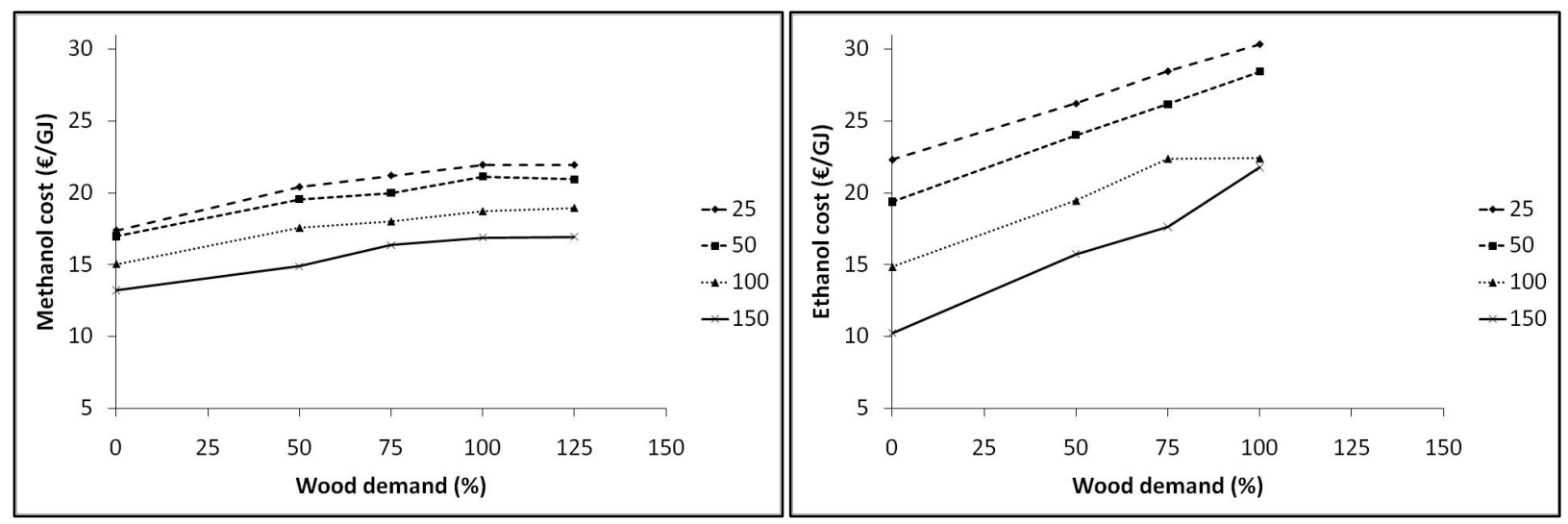

Figure 4: Influence of the wood demand on the methanol cost (left) and ethanol cost (right) for four carbon cost scenarios (fossil fuel price $20 € / G J$, feedstock used: forestry wood and poplar plantations).

\subsection{Production plant locations}

The optimal locations of the biofuel production plants can be determined. The 310 grid points of the grid are potential location for the biofuel production plant. From the 210 scenario runs, Figure 5 presents the optimal locations in respect with their number of appearance for methanol production plants (first row) and ethanol production plants (second row), with the use of forestry wood only (left side) and foresty wood with poplar plantations (right side). Three categories can be defined: the locations that appear for $1-10 \%$ of the runs, $11-25 \%$ of the runs, and the locations that appear for $26-40 \%$ of the runs and constantly $(100 \%)$ for ethanol and methanol production plants respectively. 
For the methanol production plants, two points are of interest (appearance equals to 100\%), one is located in the vicinity of Salzburg, and the other one close to Amstetten. These cities can be supplied by residual heat from the production plants; they are also close to a highway and railway, which facilitates feedstock and biofuel transportation through the country. Adding poplar plantations as an energy feedstock does not influence the results on the locations.

For the ethanol production plants, the main area of interest is around Vienna. The production of residual heat plays a major role in the location of the ethanol production plant. The production of residual heat is higher during the production of ethanol than during the production of methanol; therefore the ethanol production plant should be located closer to higher heating demand areas.
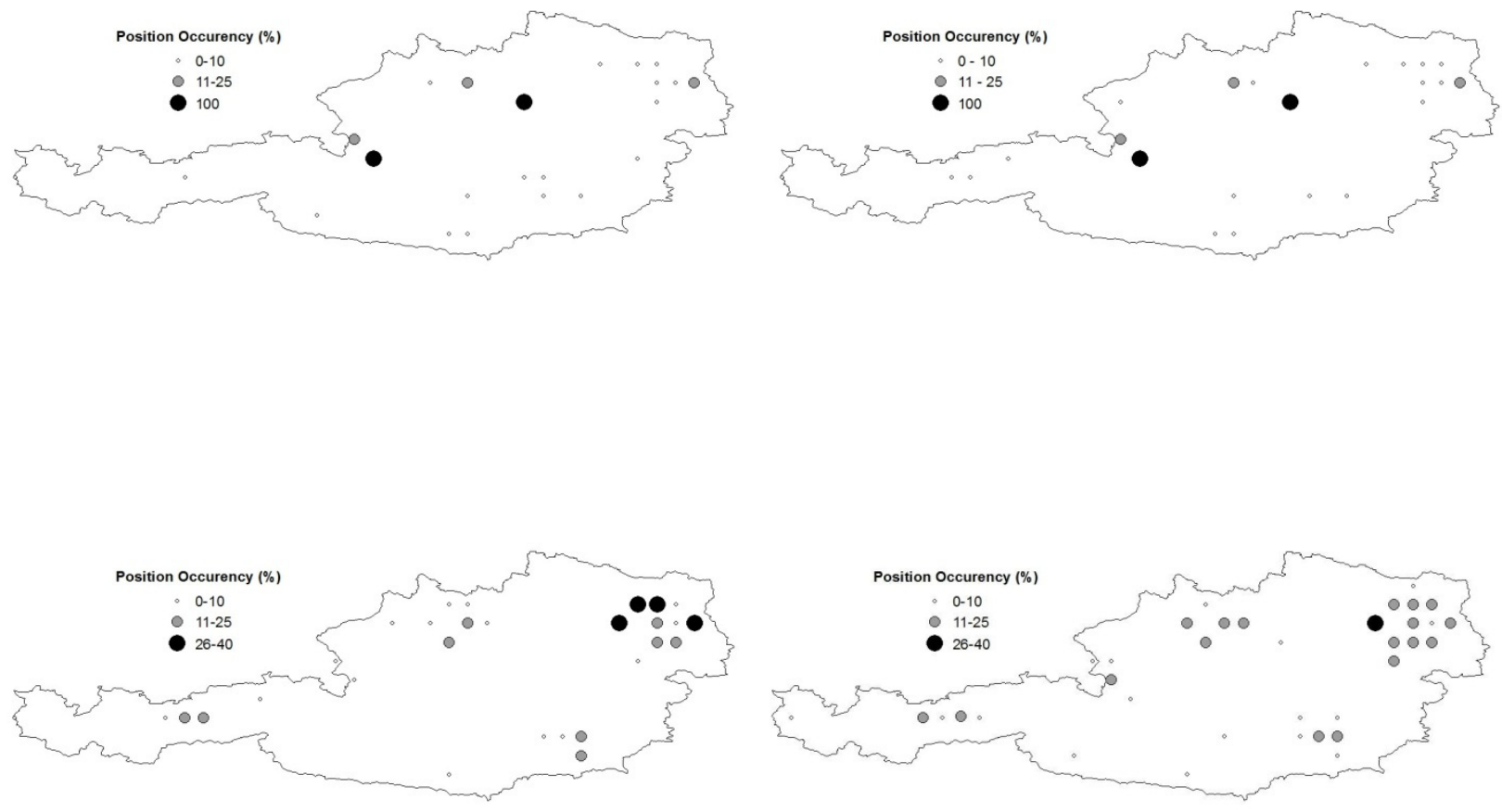

Figure 5: Positions of the production plants selected from the 210 simulations (from top to down, and left to right: 1. methanol with forest only; 2. methanol with forest and poplar plantations; 3 . ethanol with forest only; 4. ethanol with forest and poplar plantations. 


\section{Conclusion}

The present study is a follow up of a work on the potential of bioenergy production in Austria. A geographically explicit model optimisation model has been used to determine the possible location of methanol and ethanol production plants in regards with the wood demand from the already existing forestry industries. The feasibility of the biofuel production plants has been studied considering changes in wood demand, carbon cost and fossil fuel price.

The results show that methanol production plants are selected over ethanol production plants when the availibilty of feedstock becomes scarcer. With today's wood consumption in Austria, and today's fossil fuel price, up to 14.4 PJ of biofuel could be produced. Setting a carbon cost, forces the production of biofuel to a limit of $40 \mathrm{PJ}$ biofuel, and an increase of the wood demand by $25 \%$ would limit the biofuel production to $20 \mathrm{PJ}$ if poplar plantations is added into the system. Two locations are of high interest for the methanol production plants which are in the vicinity of Salzburg and Amsteten, whereas the ethanol production plants are mainly located to higher heat demand areas.

\section{Acknowlegement}

This article has been supported by the Austrian Climate Research Program project "Greenhouse Gas Reduction through Second Generation Biofuels in Austria (GHG-SEBA)”.

\section{References}

[1] Directive 2009/28/EC of the European Parliament and of the Council of 23 April 2009on the promotion of the use of energy from renewable sources and amending and subsequently repealing Directives 2001/77/EC and 2003/30/EC, Official Journal of the European Union (2009).

[2] Nakicenovic, N., Haas, R., Schleicher, S. P., Kletzan, D., Köppl, A., Thenius, G., Assessment of Austrian contribution toward EU 2020 Target Sharing, Vienna, Austrian Institute of Economic Research WIFO, 2008. 
[3] Schadauer, K., Wood and Biomass Study (Holz- und Biomassenstudie), BFW Praxis Information 18, 2009.

[4] Schmidt, J., Gass, V., Schmid, E., Land use, greenhouse gas emissions and fossil fuel substitution of biofuels compared to bioelectricity production for electric cars in Austria, World Renewable Energy Conference, Linköping, Sweden, 2011.

[5] Schmidt, J., Leduc, S., Dotzauer, E., Schmid, E., Cost-effective policy instruments for CO2 emission reduction and fossil fuel substitution through bioenergy production in Austria: evaluating the role of new bioenergy technologies, Energy policy, Submited (2011).

[6] Leduc, S., Development of an Optimization Model for the Loacation of Biofuel Production Plants, Division of Energy Engineering, Luleå, Luleå University of Technology, 2009, p. 72.

[7] Leduc, S., Schwab, D., Dotzauer, E., Schmid, E., Obersteiner, M., Optimal location of wood gasification plants for methanol production with heat recovery, International Journal of Energy Research 32 (2008) 1080-1091.

[8] Leduc, S., Starfelt, F., Dotzauer, E., Kindermann, G., McCallum, I., Obersteiner, M., Lundgren, J., Optimal location of lignocellulosic ethanol refineries with polygeneration in Sweden, Energy 35 (2010) 2709-2716.

[9] Hagauer, D., Lang, B., Nemestothy, K., Woodflow Austria 2005, Vienna, Austrian Energy Agency 2007.

[10] Kindermann, G., McCallum, I., Fritz, S., Obersteiner, M., A global forest growing stock, biomass and carbon map based on FAO statistics, Silva Fennica 42 (2008) 387--396 [2008].

[11] Izaurralde, R. C., Williams, J. R., McGill, W. B., Rosenberg, N. J., Jakas, M. C. Q., Simulating soil $\mathrm{C}$ dynamics with EPIC: Model description and testing against long-term data, Ecological Modelling 192 (2006) 362-384.

[12] Williams, J. R., The EPIC Model, In: Singh V. P., editor, Computer Models of Watershed Hydrology, Highlands Ranch, Colorado, Water Resources Publications, 1995, p. 909-1000. 
[13] Overall Energy Consumption of Households, http://www.statistik.at, [25-01-2011], 2011.

[14] Schmidt, J., Leduc, S., Dotzauer, E., Kindermann, G., Schmid, E., Cost-effective CO2 emission reduction through heat, power and biofuel production from woody biomass: A spatially explicit comparison of conversion technologies, Applied Energy 87 (2010) 2128-2141.

[15] Schmidt, J., Leduc, S., Dotzauer, E., Kindermann, G., Schmid, E., Potential of biomass-fired combined heat and power plants considering the spatial distribution of biomass supply and heat demand, International Journal of Energy Research 34 (2010) 970-985.

[16] Azar, C., Lindgren, K., Andersson, B. A., Global energy scenarios meeting stringent CO2 constraints-cost-effective fuel choices in the transportation sector, Energy Policy 31 (2003) 961976.

[17] Grahn, M., Azar, C., Lindgren, K., Berndes, G., Gielen, D., Biomass for heat or as transportation fuel? A comparison between two model-based studies, Biomass and Bioenergy 31 (2007) 747-758.

[18] Hamelinck, C. N., Faaij, A. P. C., Future prospects for production of methanol and hydrogen from biomass, Journal of Power Sources 111 (2002) 1-22.

[19] Starfelt, F., Thorin, E., Dotzauer, E., Yan, J., Performance evaluation of adding ethanol production into an existing combined heat and power plant, Bioresource Technology 101 (2010) 613-618.

[20] Leduc, S., Lundgren, J., Franklin, O., Dotzauer, E., Location of a biomass based methanol production plant: A dynamic problem in northern Sweden, Applied Energy 87 (2010) 68-75.

[21] Leduc, S., Schmid, E., Obersteiner, M., Riahi, K., Methanol production by gasification using a geographically explicit model, Biomass and Bioenergy 33 (2009) 745-751. 


\section{Biotreibstoffe der 2. Generation - Potentiale}

Biotreibstoffe der 2. Generation können im Gegensatz zu Treibstoffen der 1. Generation aus der gesamten Biomasse einer Pflanze gewonnen werden, während bei Erstgenerationstreibstoffen nur die zucker-, stärke- oder ölhaltigen Pflanzenteile von agrarischen Produkten zur Umwandlung in Treibstoffe zur Verfügung stehen. Als Rohstoffe bieten sich für Zweitgenerationstreibstoffe daher Forstprodukte genauso wie Kurzumtriebsgehölzer aus agrarischer Produktion an. Zurzeit sind weltweit einige Demonstrationsanlagen der 2. Generation in Betrieb, erste kommerzielle Anlagen sind im Bau.

Im Rahmen eines Forschungsprojekts des Austrian Climate Research Programm (ACRP) haben die Universität für Bodenkultur Wien und das International Institute of Applied Systems Analysis Laxenburg untersucht, welche technisch-ökonomischen Potentiale für Zweitgenerationstreibstoffe in Österreich bestehen und wie sie im Vergleich zu anderen Nutzungen von holziger Biomasse abschneiden. Dazu wurde ein räumlich explizites Optimierungsmodell erstellt, das sowohl forstliche als auch agrarische Produkte als Rohstoffe für die Bioenergieproduktion berücksichtigt. Die Konkurrenz zu anderen Bioenergietechnologien zur Wärme- und Stromgewinnung wurde ebenfalls abgebildet. Als konkrete Produktionstechnologien wurden Methanol-, Ethanol- und Fischer-TropschDieselproduktion modelliert. Die Ko-Produktion von Wärme und Strom wurde dabei berücksichtigt.

Die hohen Investitionskosten für Zweitgenerationsanlagen sowie die im Vergleich zur Wärmenutzung bzw. zur Kraft-Wärme-Kopplung geringen Umwandlungseffizienzen machen den Verwertungsweg Treibstoff für holzige Biomasse in Österreich unattraktiv. So können über die Verwertung von Biomasse für Wärme oder gekoppelte Wärme-Stromproduktion (KWK) deutlich mehr fossile Energieträger ersetzt werden als durch die Herstellung von Treibstoffen. Gleichzeitig zeigen die Projektergebnisse, dass im Vergleich zu Treibstoffen der 1. Generation die Effizienzen bei Zweitgenerationstreibstoffen höher und die Kosten geringer sind und dass der Flächenverbrauch zur Erreichung der Biotreibstoffbeimischungsverpflichtungen mit Zweitgenerationstreibstoffen deutlich unter jenem für Erstgenerationstreibstoffe liegt.

Ein interessantes Einsatzfeld würde für die Biotreibstoffproduktion entstehen, falls die $\mathrm{CO}_{2}{ }^{-}$ Abscheidung und -speicherung (CCS) in Europa in großem Maßstab zur Anwendung kommt. Hier bieten Biotreibstofffabriken der 2. Generation eine kostengünstige Möglichkeit. Im Produktionsprozess für Biotreibstoffe fallen relativ reine $\mathrm{CO}_{2}$-Ströme an, die direkt abgeschieden und gespeichert werden können, während in der Stromproduktion eine Abscheidung aufwändig, teuer und energieintensiv ist.

Bei einer Beibehaltung der Verpflichtungen zur Beimischung von Biotreibstoffen ist ein langfristiger Umstieg auf Zweitgenerationstreibstoffe - insbesondere auf die Produktion von Methanol - empfehlenswert, um Kosten zu sparen und den Verbrauch von agrarischem Land zu minimieren. Grundsätzlich ist eine Verwertung holziger Biomasse zur Wärme- und Stromproduktion der Treibstoffproduktion allerdings vorzuziehen. Der vollständige Projektendbericht erscheint Ende Dezember 2010.

Informationen: Univ.-Prof. Dipl.-Ing. Dr. Johannes Schmidt, Institut für nachhaltige Wirtschaftsentwicklung, Universität für Bodenkultur Wien, johannes.schmidt@boku.ac.at

Sylvain Leduc, International Institute for Applied Systems Analysis Laxenburg, leduc@iiasa.ac.at 